Supporting Information

\title{
Electrostatic potential field effects on amine macrocyclizations in yocto-liter spaces: Supramolecular electron withdrawing/donating groups
}

Wei Yao, (D) Kaiyu Wang, Yahya A. Ismaiel, Ruiqing Wang, Xiaoyang Cai(D, Mary Teeler, and Bruce C. Gibb *

\author{
Wei Yao (iD https://orcid.org/0000-0002-4229-0486 \\ Xiaoyang Cai (iD https://orcid.org/0000-0003-4806-1868 \\ Bruce C. Gibb (D) https://orcid.org/0000-0002-4478-4084
}

Department of Chemistry, Tulane University, New Orleans, LA 70118, USA

${ }^{*}$ Corresponding Author bgibb@tulane.edu 


\section{Table of Contents}

1) Materials and Instrumentation S3

2) Synthesis of guest $3 \quad S 4$

$\begin{array}{ll}3) \quad \text { Encapsulation of } \mathbf{3} \text { within hosts } \mathbf{1}_{2} \text { and } \mathbf{2}_{2} & \mathrm{S7}\end{array}$

4) Eyring analysis for the cyclization of $\mathbf{3}$ within $\boldsymbol{1}_{2}$ and $\mathbf{2}_{2} \quad \mathrm{~S} 12$

4.1) Reaction of $\mathbf{3}$ within $\boldsymbol{1}_{2}$ at different temperatures and data fitting $\mathrm{S} 13$

4.2) Reaction of $\mathbf{3}$ within $\mathbf{2}_{2}$ at different temperatures and data fitting S20

5) Cyclization of $\mathbf{3}$ within $\mathbf{1}_{2}$ in the presence of various salts $\quad$ S27

5.1) Anion effect: Summary of data_ S28

5.2) Anion effect: Individual data_ S31

6) Cyclization of $\mathbf{3}$ within $\mathbf{2}_{2}$ in the presence of various salts $\quad S 42$

6.1 Cation effect: Summary of data $\quad$ S43

6.2 Cation effect: Individual data $\quad$ S45

7) Eyring analysis for the cyclization of 3 presence of $10 \mathrm{mM} \mathrm{NaClO}_{4}$ or $\mathrm{CsCl}_{2} \quad \mathrm{~S} 52$

8) References $\quad$ S65 


\section{1) Materials and Instrumentation}

Deep-cavity cavitand 1 (Positand-1) and 2 (octa-acid) were synthesized following the previously reported procedures. ${ }^{1-3}$ All NMR spectra were recorded on a Bruker $500 \mathrm{MHz}$ spectrometer. All spectra were processed with MestReNova (Mestrelab Research). All reagents were purchased from Aldrich Chemical Company and, with the exception of $\mathrm{N}$-bromosuccinamide (recrystallized from boiling water), used without further purification. Guest 3, 14bromotetradecan-1-amine was synthesized and prepared in the form of its ammonium bromide salt. All reactions were performed under a nitrogen atmosphere.

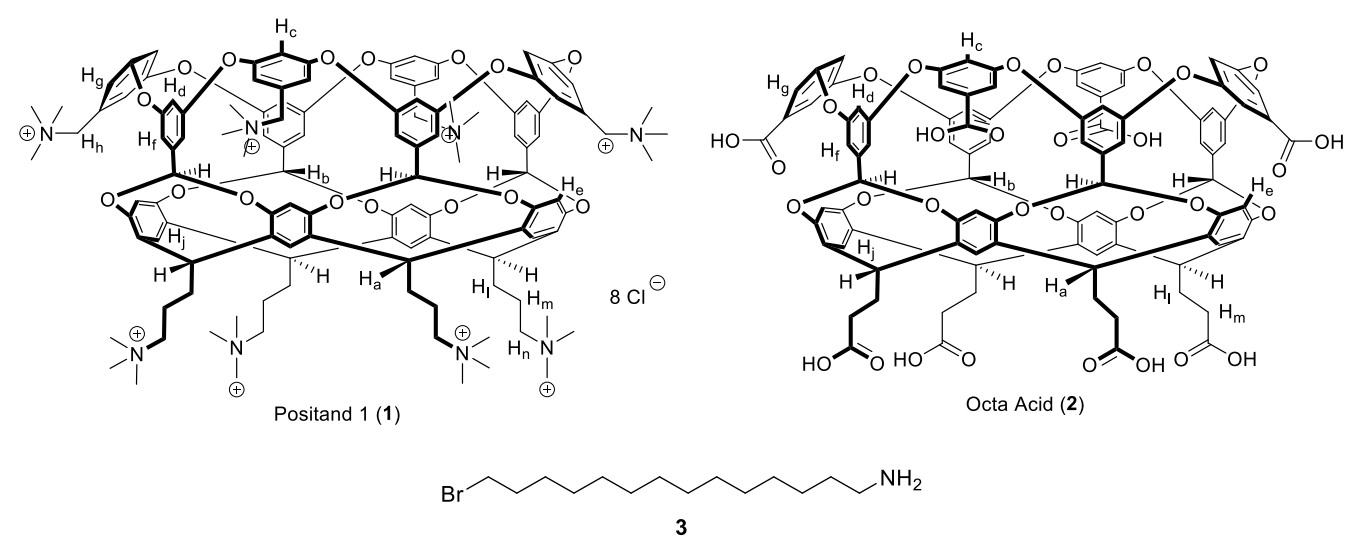

Figure S1: Chemical structures of host 1, 2 and guest 3. 


\section{2) Synthesis of guest 3}

The synthetic route of guest 3 is shown in Scheme S1. The synthesis started from the corresponding commercially available dodecanedioic acid.

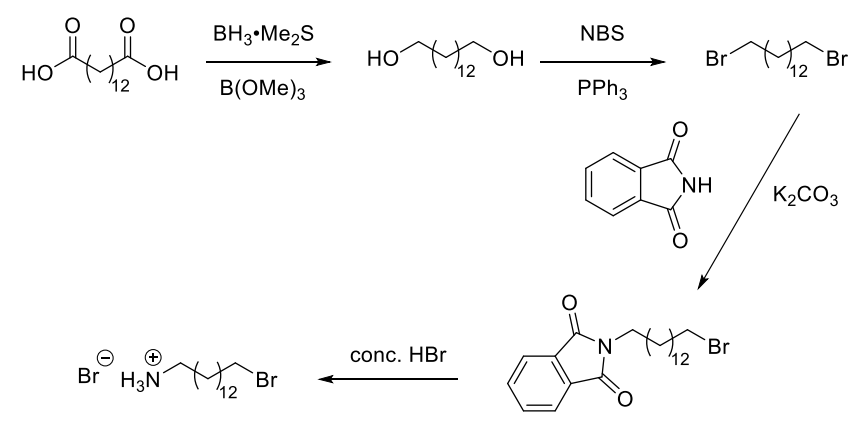

Scheme S1: Synthetic route for guest 3.

\section{Synthesis of 1,14-tetradecanediol}

The reducing agent $\mathrm{BH}_{3}-\mathrm{Me}_{2} \mathrm{~S}(3.6 \mathrm{~mL}, 36.87 \mathrm{mmol})$ and $\mathrm{B}(\mathrm{OMe})_{3}(8 \mathrm{~mL}, 72 \mathrm{mmol})$ were dissolved in $40 \mathrm{~mL}$ anhydrous tetrahydrofuran (THF) at $0^{\circ} \mathrm{C}$. Subsequently, a solution of tetradecanedioic acid $(4.0 \mathrm{~g}, 15.50 \mathrm{mmol})$ in $80 \mathrm{~mL}$ THF was added over a $30 \mathrm{~min}$. period. After this addition, the reaction mixture was heated to reflux for 24 hours. At the end of the reaction the flask and its contents were cooled to rt and quenched by the slow addition of $50 \mathrm{~mL}$ methanol. The crude solution was then stirred for 30 minutes. The combined solvent was then removed under reduced pressure to give an off-white powder as crude diol product (3.34 g, yield 94\%). The ${ }^{1} \mathrm{H}$ NMR spectrum matched that previously reported, ${ }^{4}$ and the crude product used without further purification.

\section{Synthesis of 1,14-dibromotetradecane}

Solutions of triphenylphosphine $(3.14 \mathrm{~g}, 12 \mathrm{mmol})$ and freshly recrystallized $\mathrm{N}$ bromosuccinimide (NBS, $2.14 \mathrm{~g}, 12 \mathrm{mmol}$ ) were made by dissolving each in $50 \mathrm{~mL}$ anhydrous THF at $0^{\circ} \mathrm{C}$. Subsequently, the triphenylphosphine solution was added slowly into the vigorously stirred NBS solution. After this addition, a solution of 1,14-tetradecanediol $(0.8 \mathrm{~g}, 3.47 \mathrm{mmol})$ in $25 \mathrm{~mL}$ THF was slowly added to this mixture. The reaction mixture was subsequently heated at $50^{\circ} \mathrm{C}$ for $4 \mathrm{~h}$. Upon cooling to rt, the solvent was removed under reduced pressure to give the crude product as an off-white powder. This was then recrystallized in ethanol to obtain $1.1 \mathrm{~g}$ of the pure product as a white powder $(0.9 \mathrm{~g}, 74 \%$ yield $)$. The ${ }^{1} \mathrm{H}$ NMR spectrum of the product matched that previously reported. ${ }^{5}$ The product used without further purification.

\section{Synthesis of N-(14-bromotetradecyl) phthalimide}

1,14-dibromotetradecane (1 g, $2.8 \mathrm{mmol}$ ) was dissolved in $50 \mathrm{~mL}$ of acetone, before phthalimide $(520 \mathrm{mg}, 2.8 \mathrm{mmol}$ ) was added to the stirring solution. Once full dissolution had occurred, potassium carbonate powder $(1.38 \mathrm{~g}, 10 \mathrm{mmol})$ was also added, and the reaction 
mixture heated to $60^{\circ} \mathrm{C}$ overnight. After cooling to rt, the solvent was removed under reduced pressure and the product purified by normal-phase silica-gel column chromatography (mobile phase: $100 \%$ hexane to $80 \%$ hexane $/ 20 \%$ acetone $)$ and $\left(R_{f}=0.6\right)$. The fractions containing the product were then combined, and the solvent removed under reduced pressure. Drying under high vacuum overnight yielded the product as a white solid (720 mg, yield $31 \%)$. The ${ }^{1} \mathrm{H}$ NMR spectrum of the product matched that previously reported. ${ }^{6}$

\section{Synthesis of 14-bromotetradecane-1-amine 3}

$\mathrm{N}$-(14-bromotetradecyl) phthalimide $(700 \mathrm{mg}, 166 \mathrm{mmol})$ was added to $20 \mathrm{~mL}$ of glacial acetic acid to form a suspension, before $10 \mathrm{~mL}$ of concentration hydrobromic acid was subsequently added. The mixture was then heated at $100^{\circ} \mathrm{C}$ for $48 \mathrm{~h}$. During the first $2 \mathrm{~h}$, the solution became a clear, light orange solution. After $48 \mathrm{~h}$ the reaction was cooled to $\mathrm{rt}$ and the solvent removed under reduced pressure until dryness to give an orange ppt. Subsequently, 30 $\mathrm{mL}$ of acetone was added to the crude product and the mixture sonicated for $1 \mathrm{~min}$. The resulting suspension was then filtered to give the pure bromide salt as a white powder (418 $\mathrm{mg}, 65 \%)$. The ${ }^{1} \mathrm{H}-,{ }^{13} \mathrm{C}-N M R$ and HRMS spectra are shown in Figures S2-S4. ${ }^{1} \mathrm{H}$ NMR $\left(500 \mathrm{MHz}, d_{6}\right.$-DMSO, ppm) $\delta 7.62(\mathrm{~s}, 1 \mathrm{H}), 3.53(\mathrm{t}, J=6.7 \mathrm{~Hz}, 2 \mathrm{H}), 2.91-2.60(\mathrm{~m}, 2 \mathrm{H}), 1.79(\mathrm{dq}, J=8.6,6.8 \mathrm{~Hz}, 2 \mathrm{H})$, $1.52(\mathrm{t}, J=7.4 \mathrm{~Hz}, 2 \mathrm{H}), 1.37(\mathrm{q}, J=6.9 \mathrm{~Hz}, 2 \mathrm{H}), 1.26(\mathrm{~m}, 18 \mathrm{H}) .{ }^{13} \mathrm{C}-\mathrm{NMR}\left(126 \mathrm{MHz}, d_{6}\right.$-DMSO, ppm) $\delta 35.72,32.69,29.47,29.38,28.97,28.56,27.96,27.44,26.23$. HRMS, Calculated for $\mathrm{C}_{14} \mathrm{H}_{30} \mathrm{BrN}: \mathrm{m} / \mathrm{z},[\mathrm{M}+\mathrm{H}]^{+}, 292.1634$; Found: 292.1628.

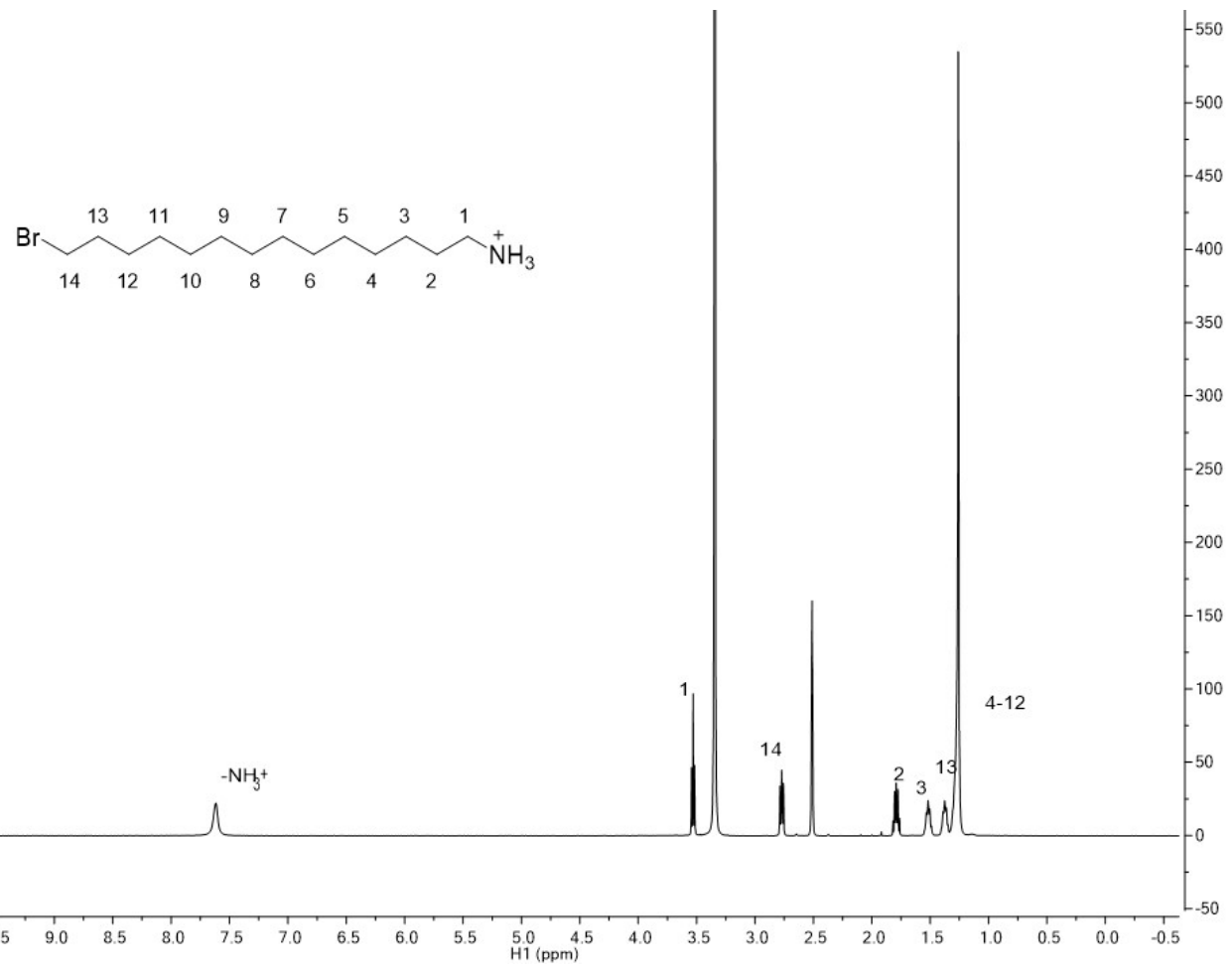

Figure S2: ${ }^{1} \mathrm{H}$ NMR spectrum of 14-bromo-1-tetradecanethiol 3 in $\mathrm{d}_{6}$-DMSO (500 MHz). 


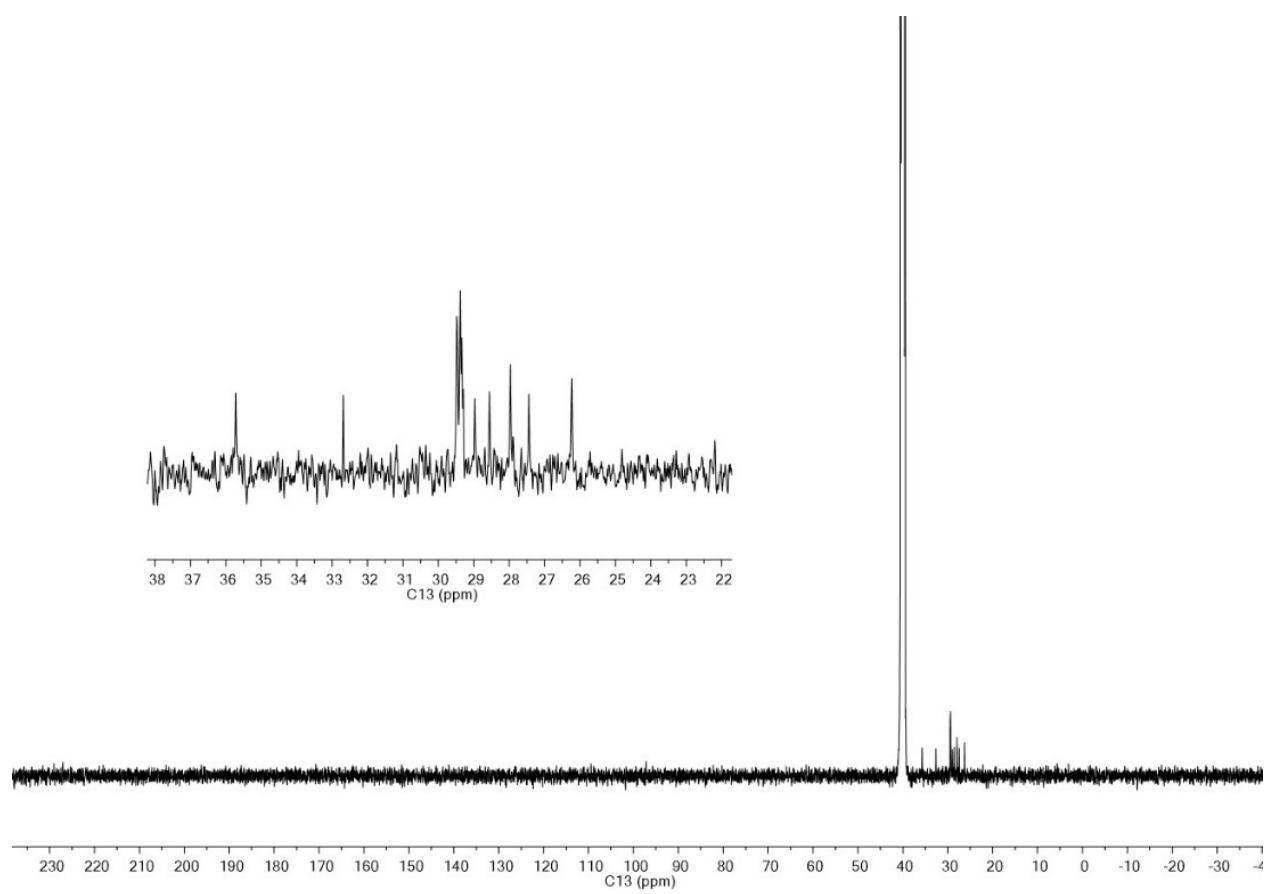

Figure S3: ${ }^{13} \mathrm{C}$ NMR spectrum of 14-bromo-1-tetradecanethiol 3 in $\mathrm{d}_{6}$-DMSO (126 MHz). Inset shows key signals in more detail.

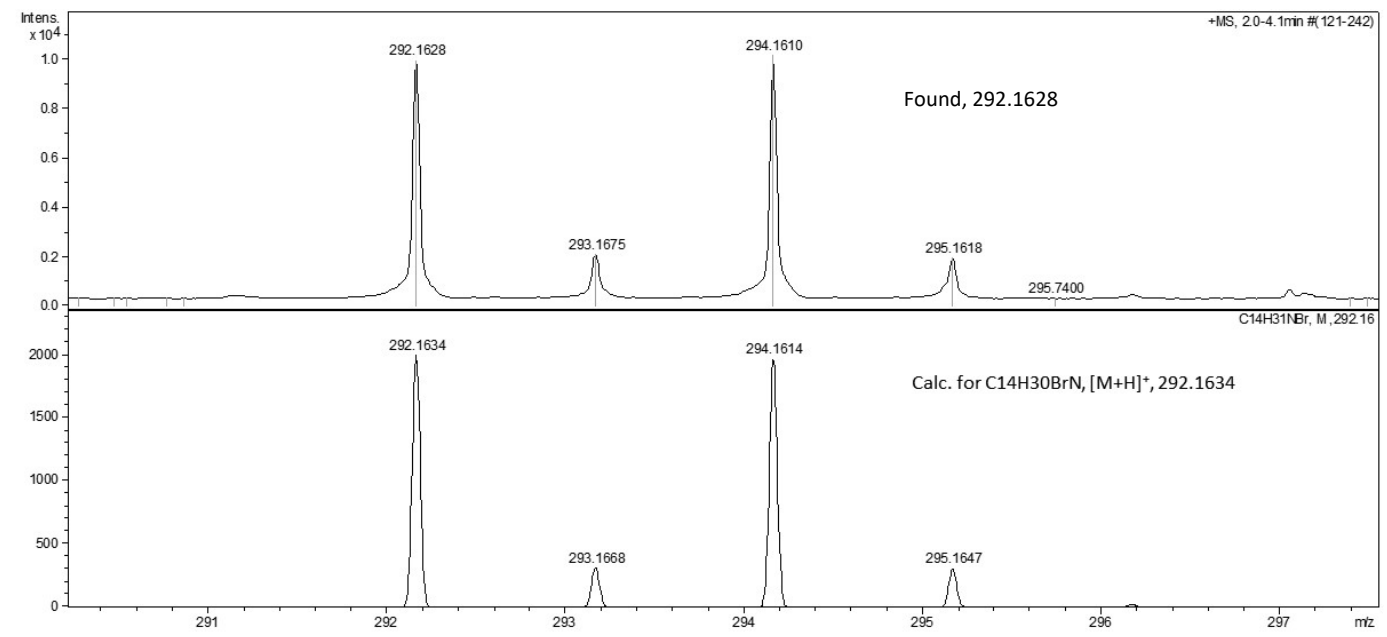

Figure S4: HRMS (ESI) of 14-bromo-1-tetradecanethiol 3. 


\section{3) Encapsulation of 3 within hosts $1_{2}$ and $2_{2}$}

$1 \mathrm{mM} \mathrm{D}_{2} \mathrm{O}$ solutions of hosts 1 and 2 were prepared in the presence of 10 equivalents of $\mathrm{NaOD}$. Subsequently, the bromide salt of guest 3 (14-bromotetradecan-1-ammonium bromide, 3. Br) was added and the complex formed by vortexing for 10 minutes at $25{ }^{\circ} \mathrm{C}$. Figure S5-S12 show the ${ }^{1} \mathrm{H}$ NMR, DOSY NMR, and COSY NMR spectra, as well as the calculated $\Delta \delta$ values for each set of protons of the guest, for both the complex with host $\mathbf{1}$ and $\mathbf{2}$. This data confirmed that both complexes possessed a 2:1 stoichiometry. 

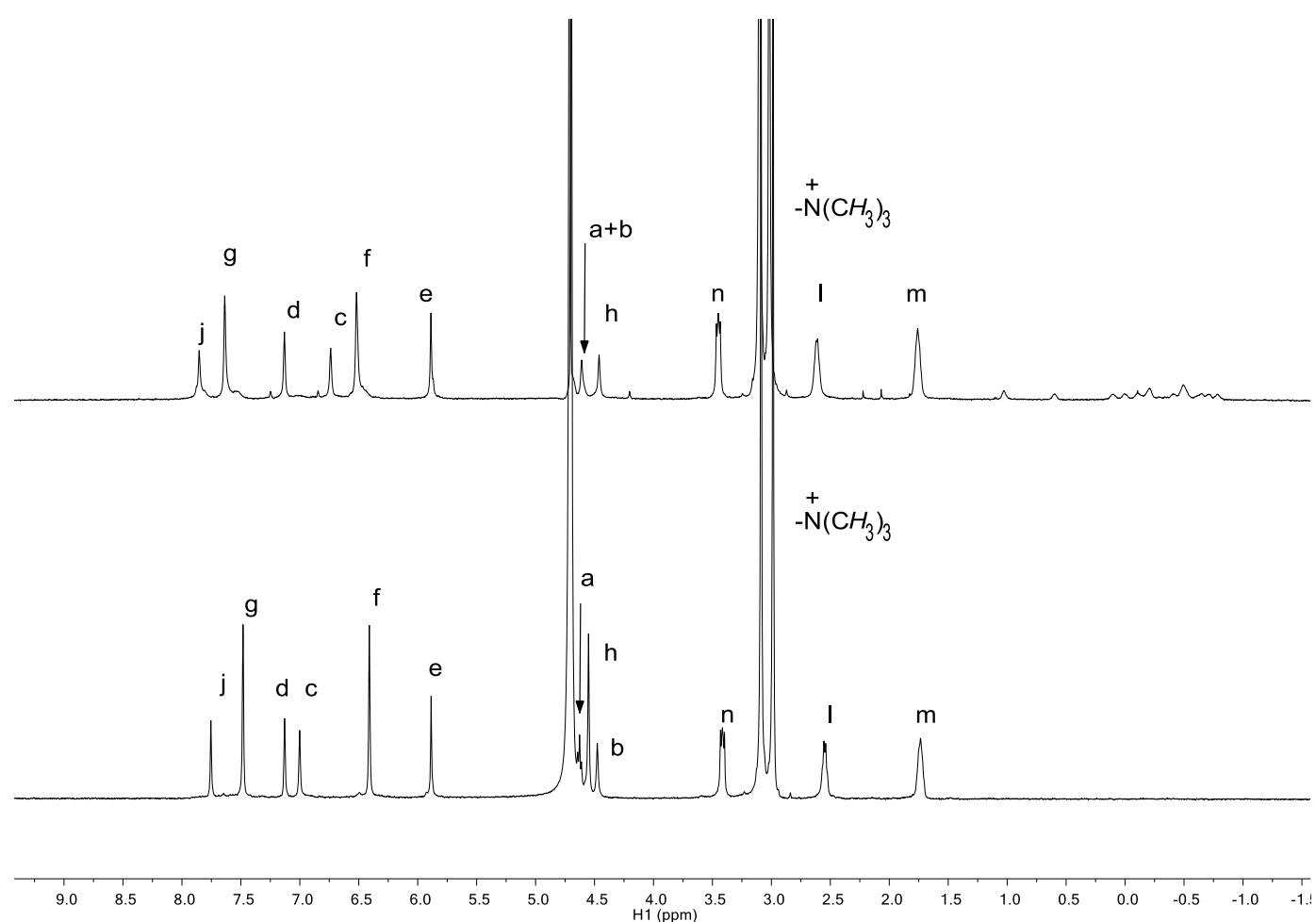

Figure S5: Stack ${ }^{1} \mathrm{H}$ NMR of free host 1(bottom) and the host-guest complex $\mathbf{3} @ 1_{2}$ (top).

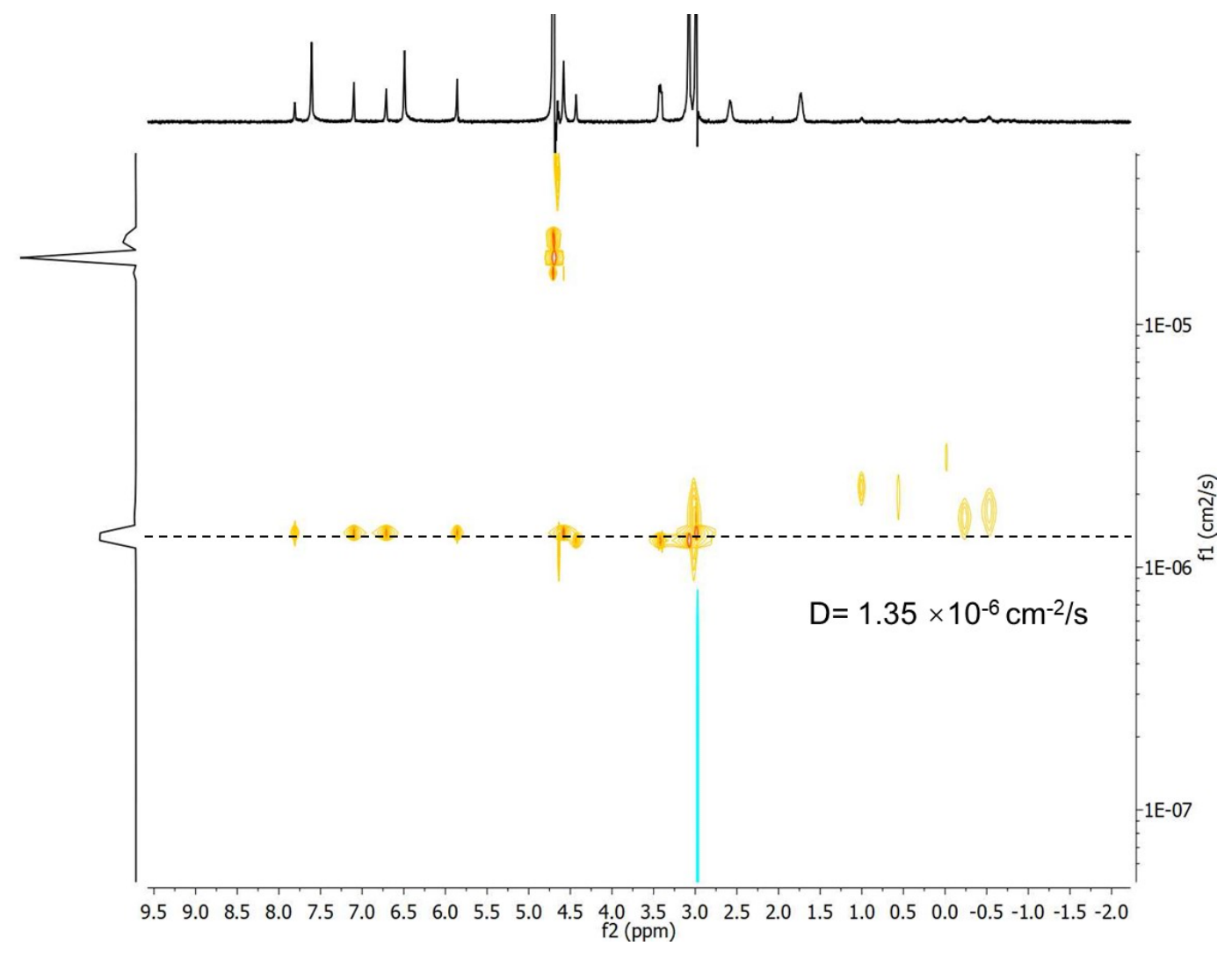

Figure S6: DOSY NMR spectrum of complex 3@12. 


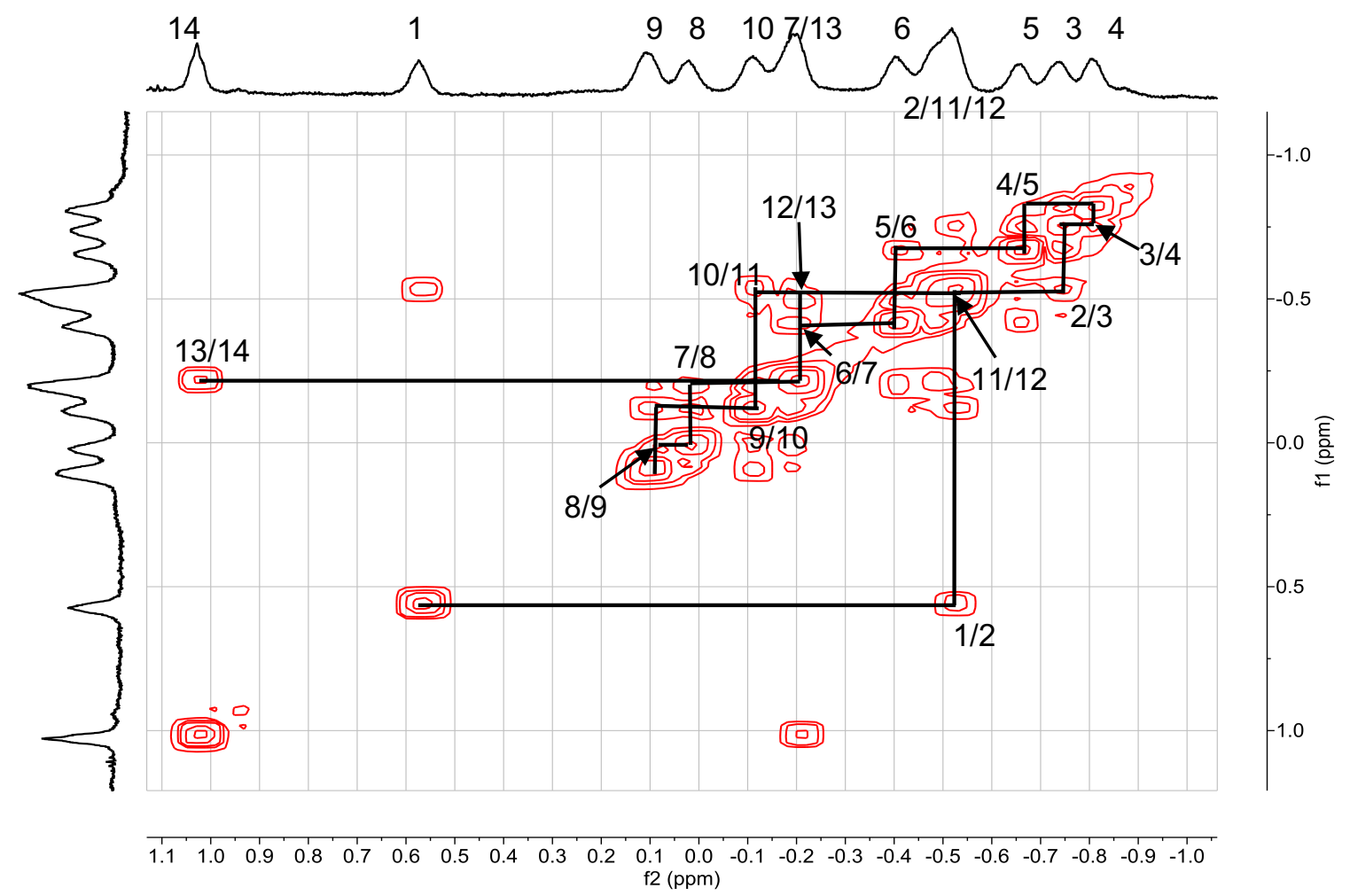

Figure S7: ${ }^{1} \mathrm{H}-{ }^{1} \mathrm{H}$ COSY NMR spectrum of the bound guest region and peak assignment of complex $\mathbf{3} @ \mathbf{1}_{\mathbf{2}}$.

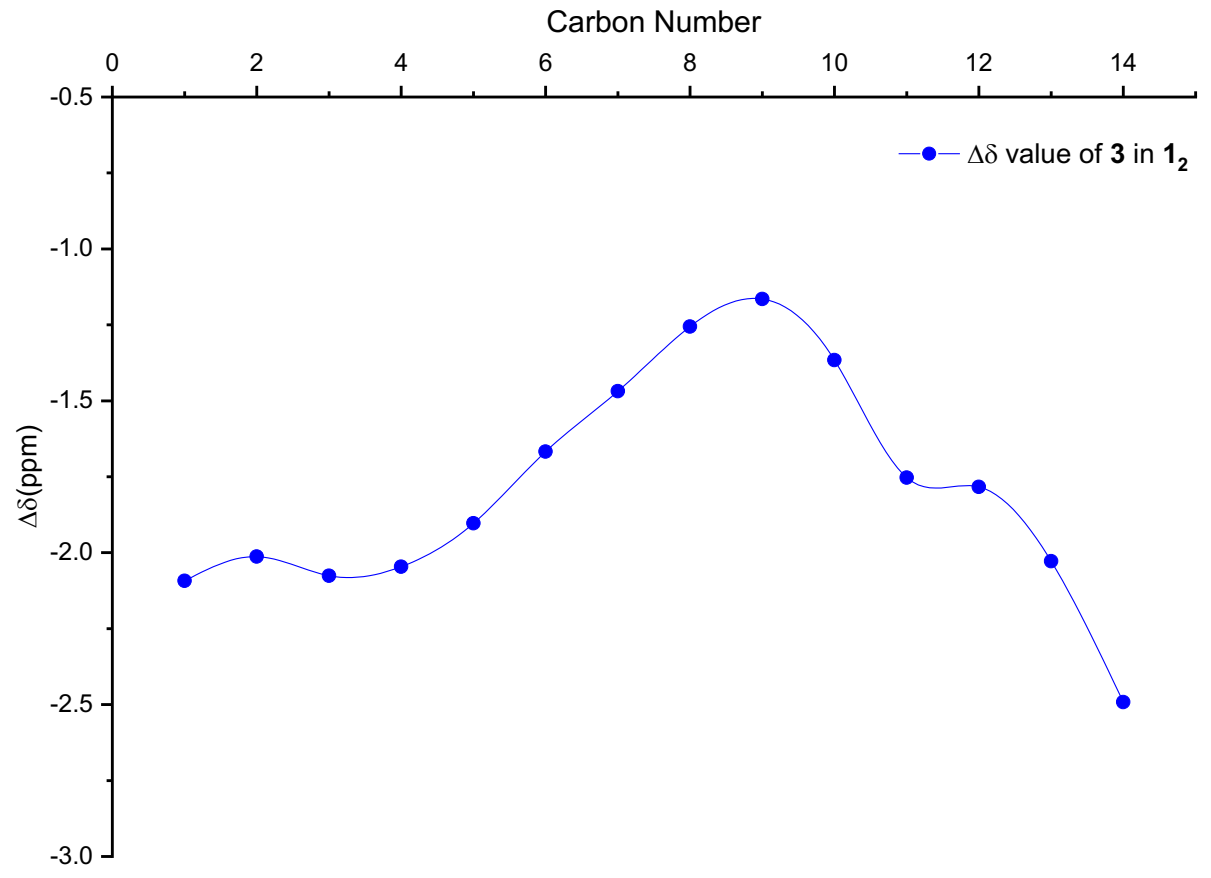

Figure S8 Plot of ${ }^{1} \mathrm{H}$ NMR $\Delta \delta$ values of complex $\mathbf{3} @ \mathbf{1}_{2}$. 


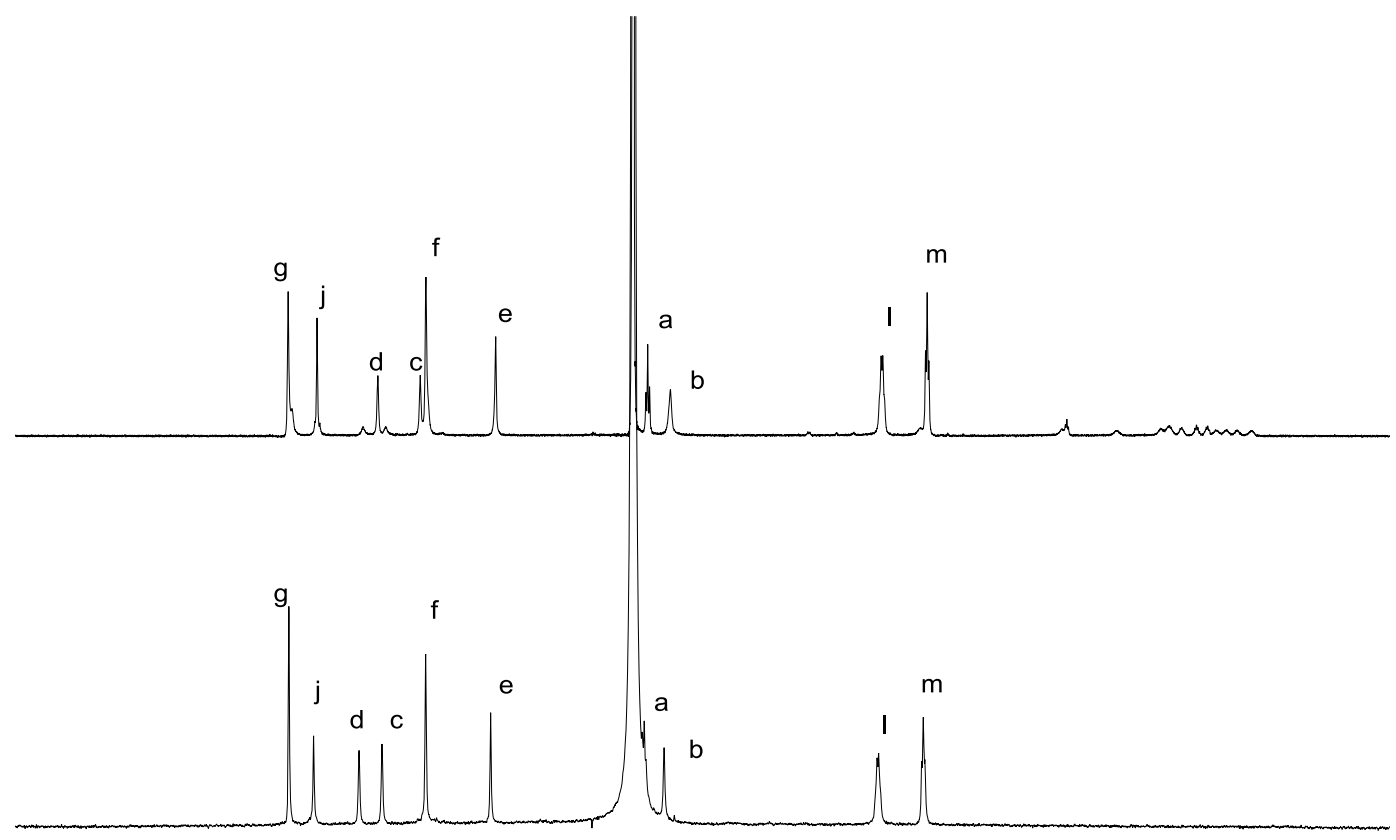

\begin{tabular}{lllllllllllllllllllllllll}
\hline 10.0 & 9.5 & 9.0 & 8.5 & 8.0 & 7.5 & 7.0 & 6.5 & 6.0 & 5.5 & 5.0 & 4.5 & 4.0 & 3.5 & 3.0 & 2.5 & 2.0 & 1.5 & 1.0 & 0.5 & 0.0 & -0.5 & -1.0 & -1.5
\end{tabular}

Figure S9: Stack ${ }^{1} \mathrm{H}$ NMR of free host 2(bottom) and the host-guest complex $\mathbf{3} @ \mathbf{2} \mathbf{2}_{\mathbf{2}}$ (top).

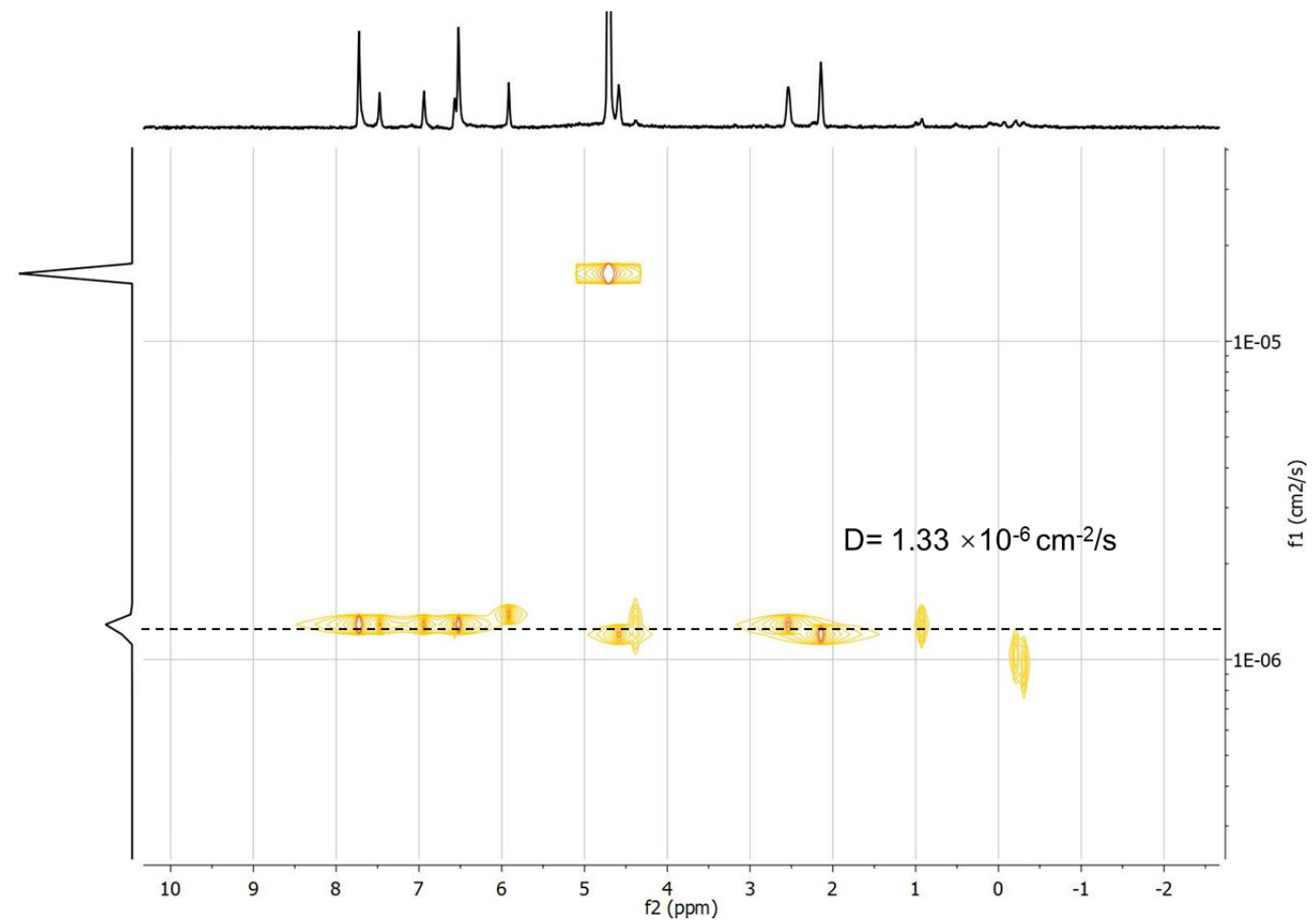

Figure S10 DOSY NMR spectrum of complex 3@22. 


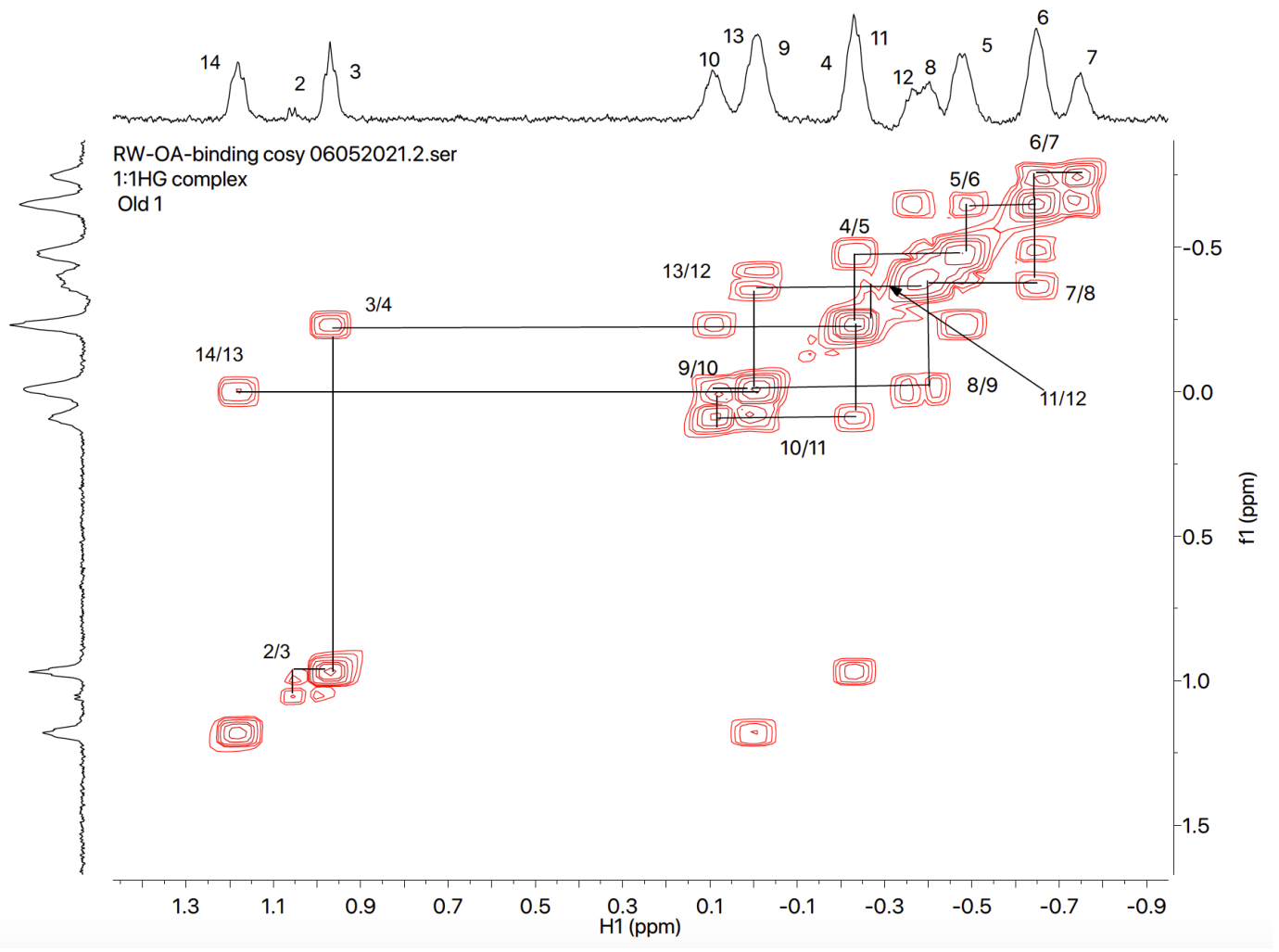

Figure S11: ${ }^{1} \mathrm{H}-{ }^{1} \mathrm{H}$ COSY NMR spectrum of the bound guest region and peak assignment of complex $\mathbf{3} @ \mathbf{2} 2$.

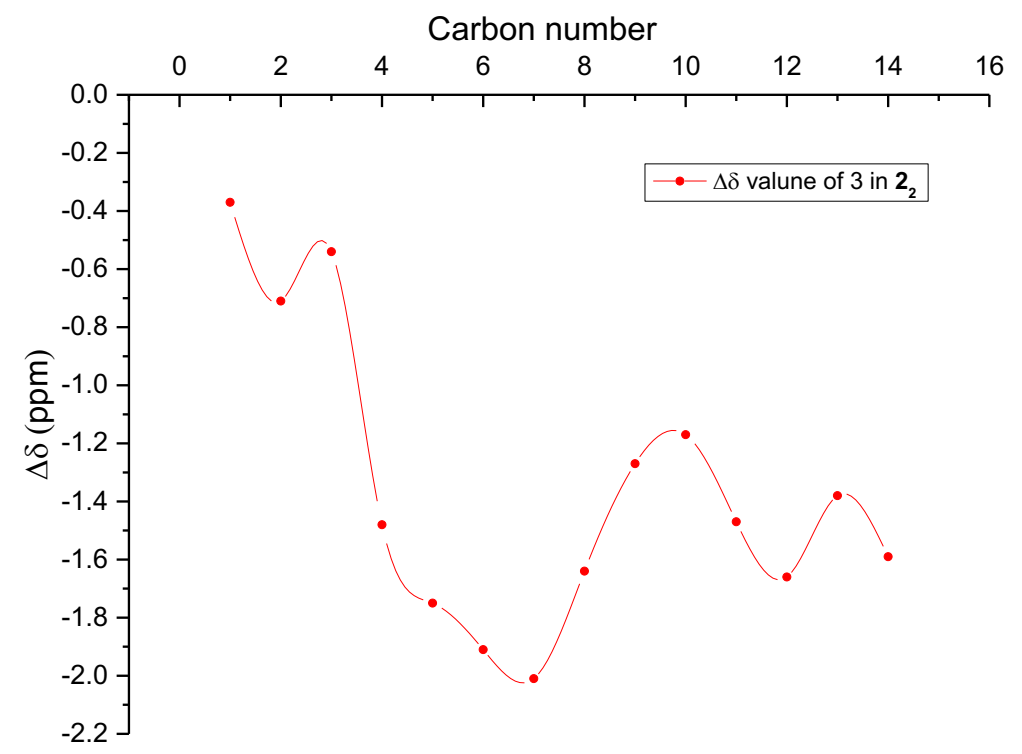

Figure S12: Plot of ${ }^{1} \mathrm{H}$ NMR $\Delta \delta$ values of complex 3@22. 


\section{4) Eyring analysis for the cyclization of 3 within $1_{2}$ and $2_{2}$}

In order to compare the kinetics of macrocyclization inside hosts 1 and 2, i.e., we determined the logarithm of the reaction rate constant $(I n k)$ as a function of temperature. The Eyring equation (Eq. 1) relates $\ln (k / T)$ to the reciprocal of the temperature $(1 / T)$ :

$$
\ln \frac{k}{T}=\frac{-\Delta H^{\ddagger}}{R} \cdot \frac{1}{T}+\ln \frac{k \mathrm{~B}}{h}+\frac{\Delta S^{\ddagger}}{R}
$$

Where $k$ is the reaction rate constant at temperature $T$ (Kelvin), $R$ is the gas constant $\left(8.314 \mathrm{~J} \cdot \mathrm{K}^{-}\right.$ $\left.{ }^{1} \cdot \mathrm{mol}^{-1}\right), \Delta \mathrm{H}^{\ddagger}$ is the activation enthalpy $\left(\mathrm{kJ} . \mathrm{mol}^{-1}\right)$ and $\Delta \mathrm{S}^{\ddagger}$ is the activation entropy $\left(\mathrm{J}^{\mathrm{mol}}{ }^{-1} \cdot \mathrm{K}^{-1}\right)$, $\mathrm{K}_{\mathrm{B}}$ is the Boltzmann constant $\left(1.380649 \times 10^{-23} \mathrm{~J} \cdot \mathrm{K}^{-1}\right)$ and $\mathrm{h}$ is the Planck constant $\left(6.63 \times 10^{-34} \mathrm{~J} \cdot \mathrm{s}\right)$. The experiments were performed between $339 \mathrm{~K}$ and $351 \mathrm{~K}$ for host 1 , and between $325 \mathrm{~K}$ to 338 $\mathrm{K}$ for host 2.

The individual rate constants at each temperature were themselves determined using a first order kinetic model (Eq. S2):

$$
y=A_{1} e^{\left(\frac{-x}{t_{1}}\right)}+y_{0}
$$

Where $y=$ the percentage conversion of the reactants, $A_{1}=$ amplitude fitting constant, $t_{1}=$ lifetime, $x=$ time, $y_{0}=y$-offset at $t=0$ ), and the first-order rate constant $k$ is the inverse of the determined lifetime $t_{1}$. Thus, monitoring the appearance of the new ${ }^{1} \mathrm{H}$ NMR signal from the $\mathrm{H}_{\mathrm{d}}$ proton (Figure $\mathrm{S} 1$ ) in the spectrum of both hosts gave the extent of reaction as a function of time. Individual rate constants were determined at least in duplicate, with an obtained error of $<10 \%$. Figures S13 S24 show: 1) the stacked ${ }^{1} \mathrm{H}$ NMR spectroscopy of each reaction as a function of time at different temperatures; 2 ) the change in integration of the $\mathrm{H}_{\mathrm{d}}$ signal and the fit of this data using Eq. $\mathbf{S 2}$ (all experiments were duplicated or triplicated, with the average or standard deviation shown as error bars), and 3) the Eyring plots for the cyclization processes within $\mathbf{1}_{2}$ and $\mathbf{2}_{2}$. Table $\mathbf{1}$ shows the obtained Eyring data for cyclization. The error in the gradient was calculated (Excel, LINEST function) to be $5 \%$.

\begin{tabular}{|c|c|c|}
\hline & 3 in 12 & 3 in 22 \\
\hline$k\left(\mathrm{~s}^{-1,}, 338 \mathrm{~K}\right)$ & $3.47 \times 10^{-5}$ & $6.25 \times 10^{-5}$ \\
\hline$k\left(\mathrm{~s}^{-1,} 298.15 \mathrm{~K}\right)$ & $1.77 \times 10^{-6}$ & $1.58 \times 10^{-6}$ \\
\hline Half-life $(\mathrm{s}, 338 \mathrm{~K})^{\mathrm{a}}$ & $2.00 \times 10^{4}$ & $1.10 \times 10^{4}$ \\
\hline Half-life $(\mathrm{s}, 298.15 \mathrm{~K})^{\mathrm{a}}$ & $3.90 \times 10^{5}$ & $4.38 \times 10^{5}$ \\
\hline$\Delta G^{\ddagger}\left(\mathrm{kJ} \mathrm{mol}^{-1}\right)$ & 105.8 & 106.2 \\
\hline$\Delta H^{\ddagger}\left(\mathrm{kJ} \mathrm{mol}^{-1}\right)$ & 59.8 & 74.5 \\
\hline$-\mathrm{T} \Delta S^{\ddagger}\left(\mathrm{kJ} \mathrm{mol}{ }^{-1}\right)$ & 45.9 & 31.7 \\
\hline
\end{tabular}

Table 1. Eyring data for the cyclization of guest 3 within the capsules $1_{2}$ and $\mathbf{2}_{2}$. 
4.1) Reaction of $\mathbf{3}$ within $\mathbf{1}_{2}$ at different temperatures and data fitting.

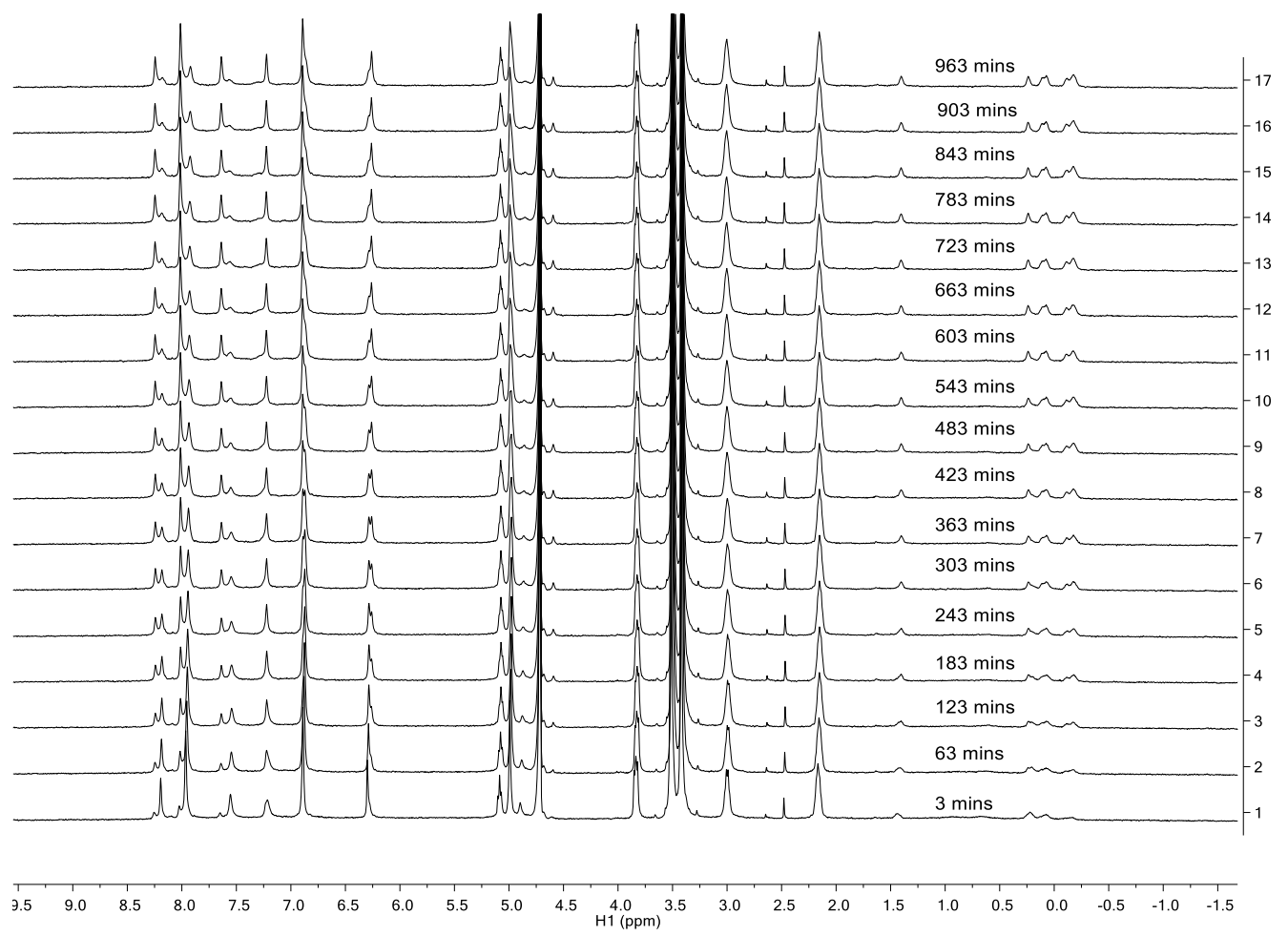

Figure S13: Stack of ${ }^{1} \mathrm{H}$ NMR spectra showing reaction of encapsulated guest $\mathbf{3}$ inside of $\mathbf{1}_{2}$ as a function of time. $\left(\mathrm{D}_{2} \mathrm{O}, 339 \mathrm{~K},[\right.$ Host 1] $=1 \mathrm{mM}$, [Guest 3] = $0.5 \mathrm{mM},[\mathrm{NaOD}]=10 \mathrm{mM})$.

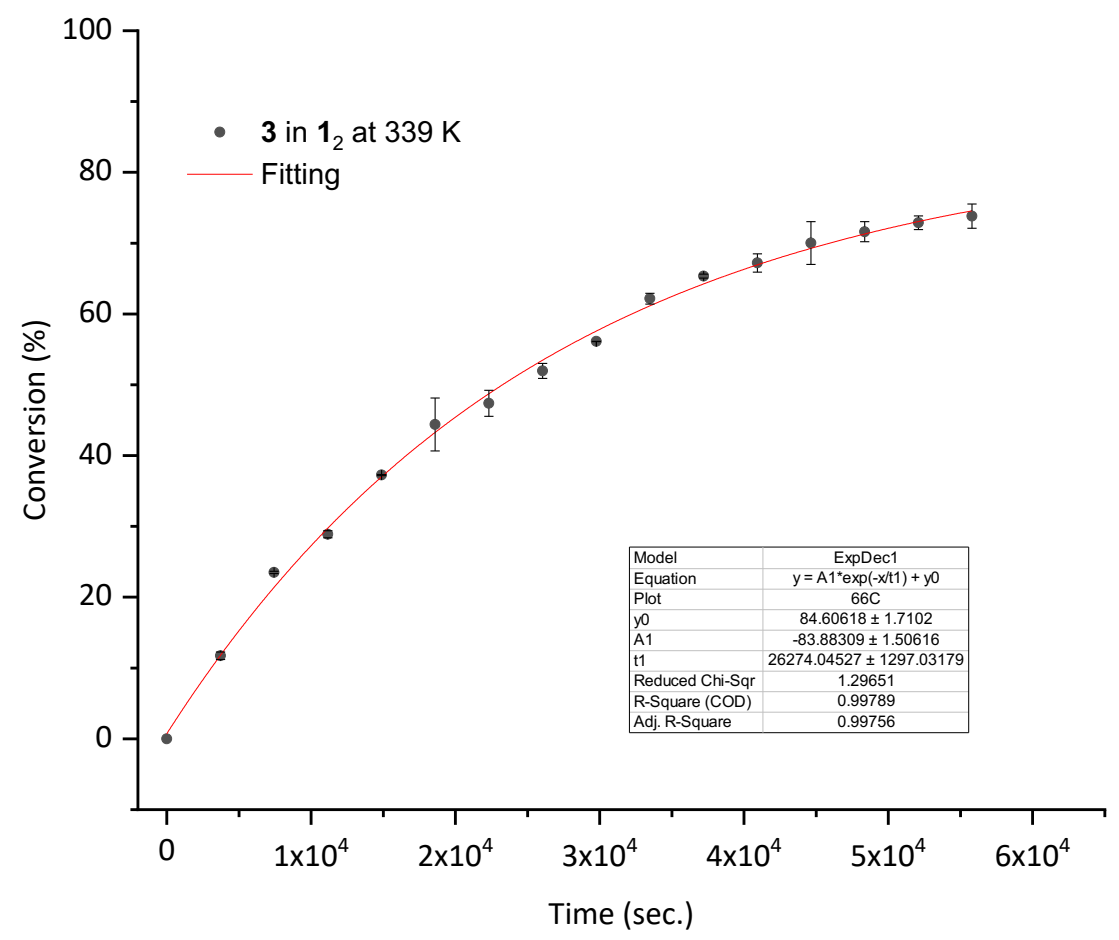

Figure S14: Conversion as a function of time plot for the reaction of guest 3 inside of host $1_{2}$ at $339 \mathrm{~K}$. 


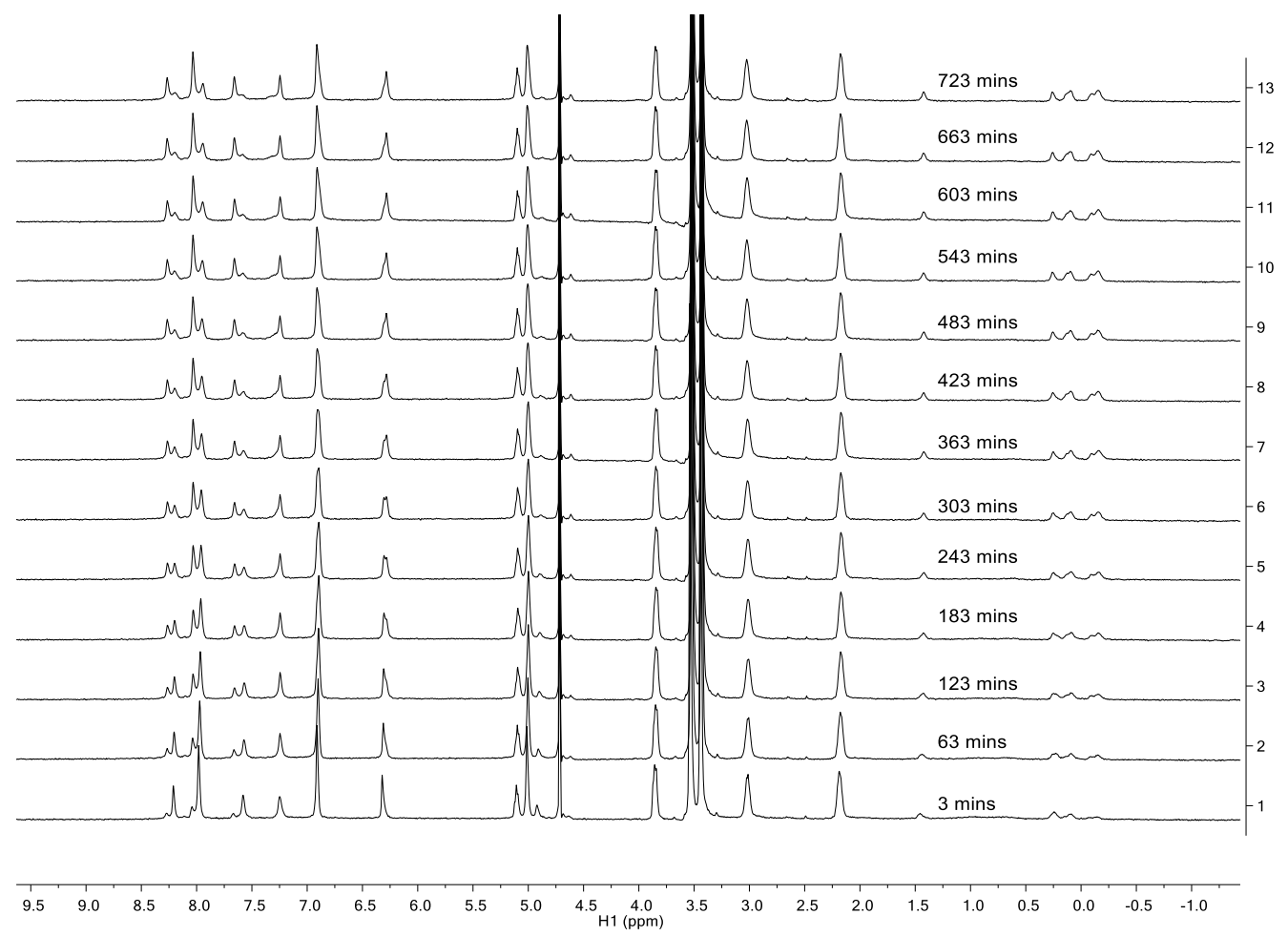

Figure S15: Stack of ${ }^{1} \mathrm{H}$ NMR spectra showing reaction of encapsulated guest 3 inside of $1_{2}$ as a function of time. $\left(\mathrm{D}_{2} \mathrm{O}, 342 \mathrm{~K},[\right.$ Host 1$]=1 \mathrm{mM}$, [Guest 3] $\left.=0.5 \mathrm{mM},[\mathrm{NaOD}]=10 \mathrm{mM}\right)$.

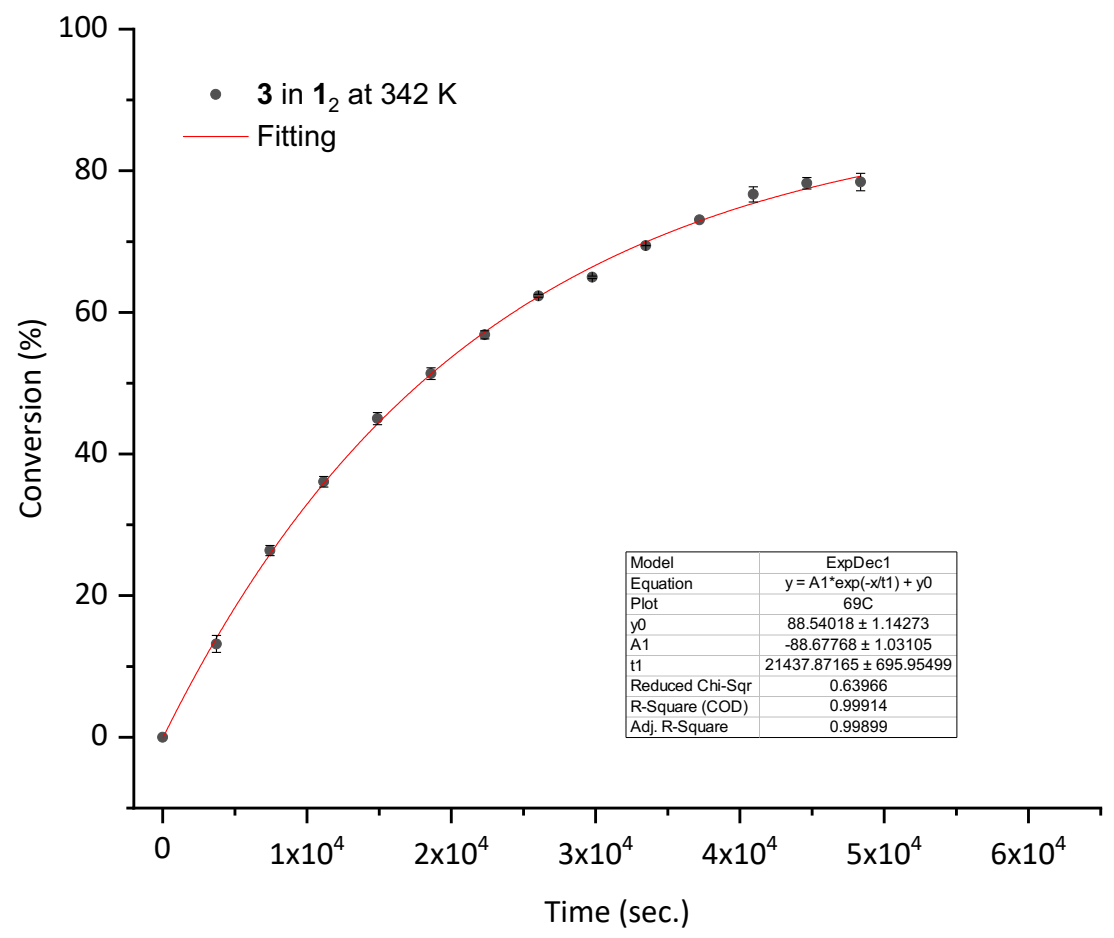

Figure S16: Conversion as a function of time plot for the reaction of guest 3 inside of host $1_{2}$ at $342 \mathrm{~K}$. 


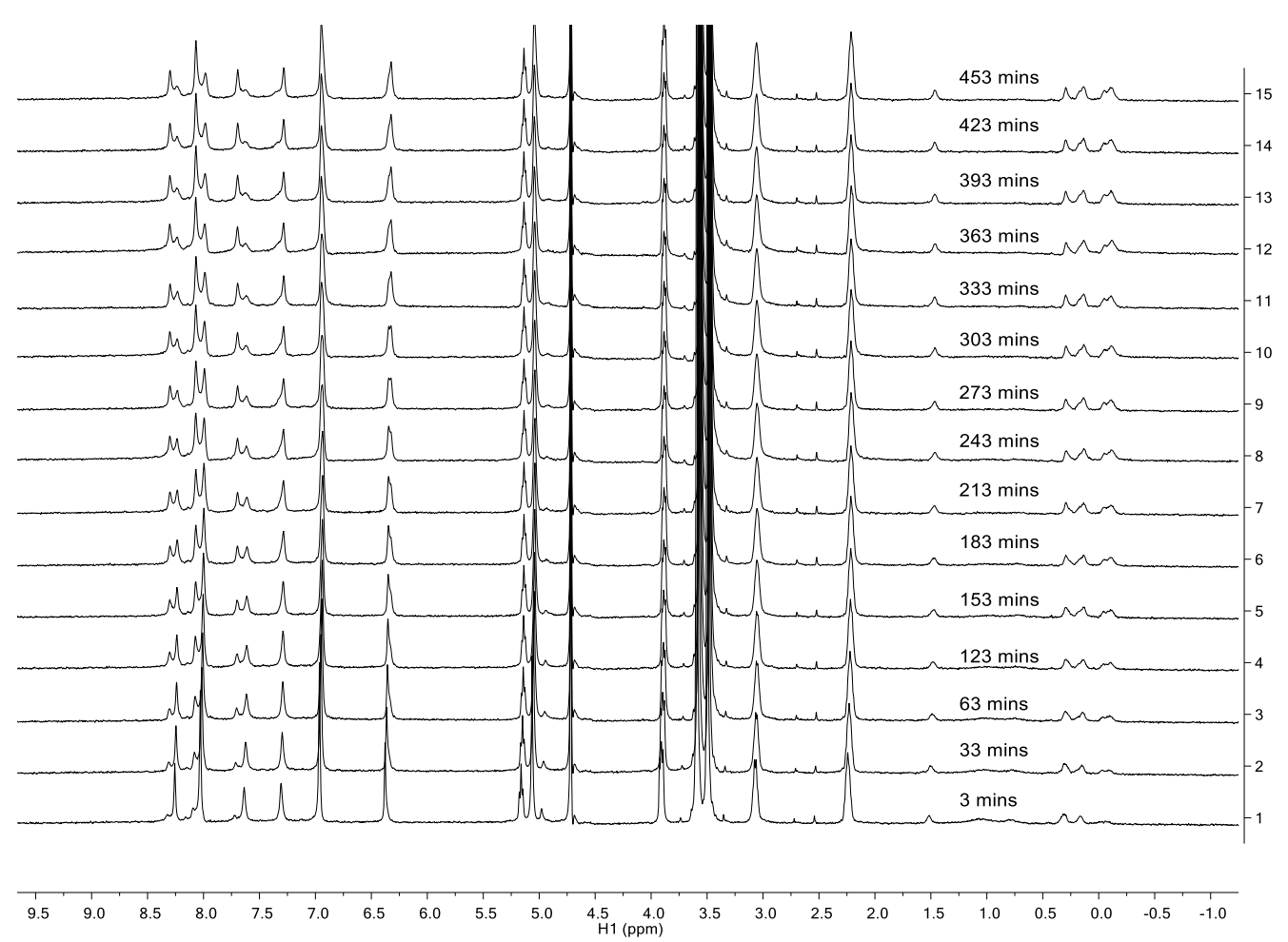

Figure S17: Stack of ${ }^{1} \mathrm{H}$ NMR spectra showing reaction of encapsulated guest $\mathbf{3}$ inside of $\mathbf{1}_{2}$ as a function of time. $\left(\mathrm{D}_{2} \mathrm{O}, 345 \mathrm{~K},[\right.$ Host 1$]=1 \mathrm{mM},[$ Guest 3$\left.]=0.5 \mathrm{mM},[\mathrm{NaOD}]=10 \mathrm{mM}\right)$.

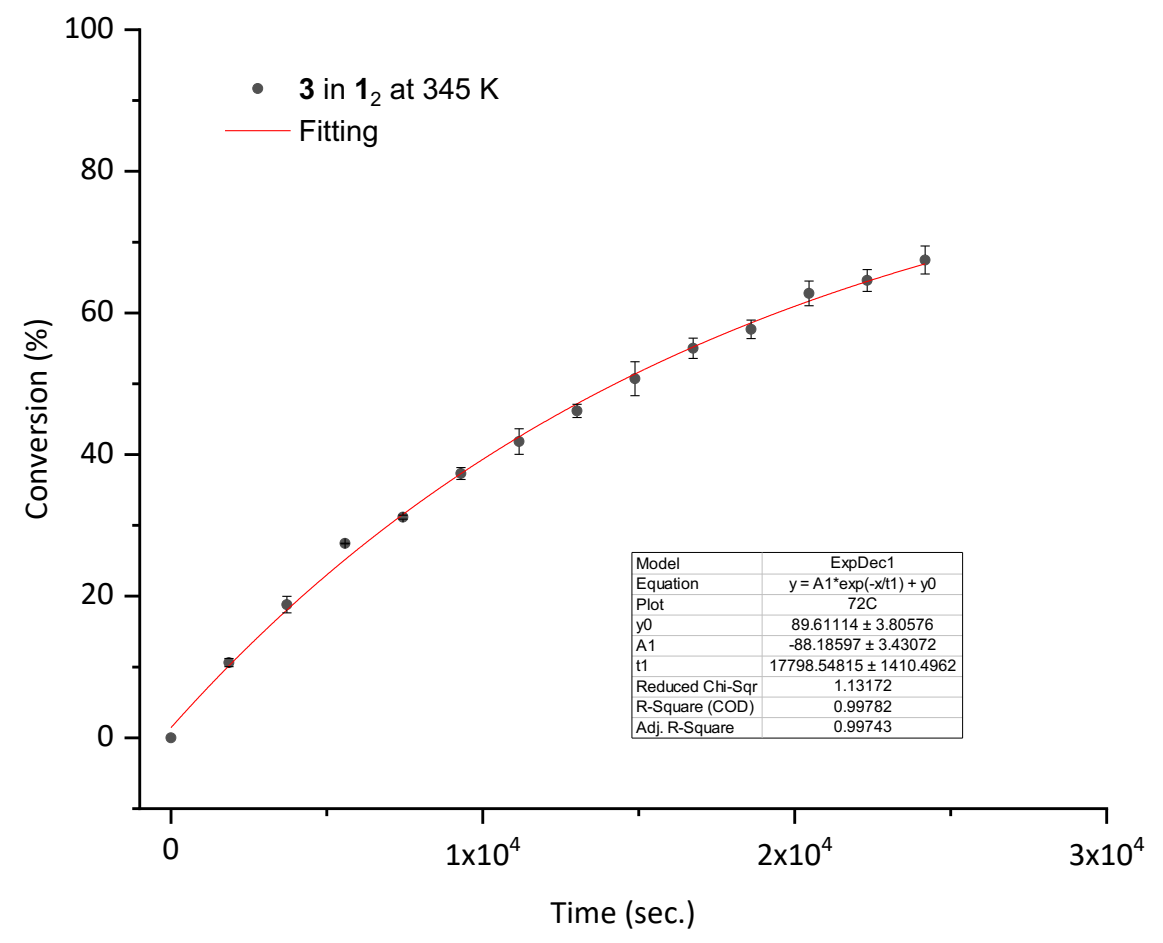

Figure S18: Conversion as a function of time plot for the reaction of guest 3 inside of host $1_{2}$ at $345 \mathrm{~K}$. 


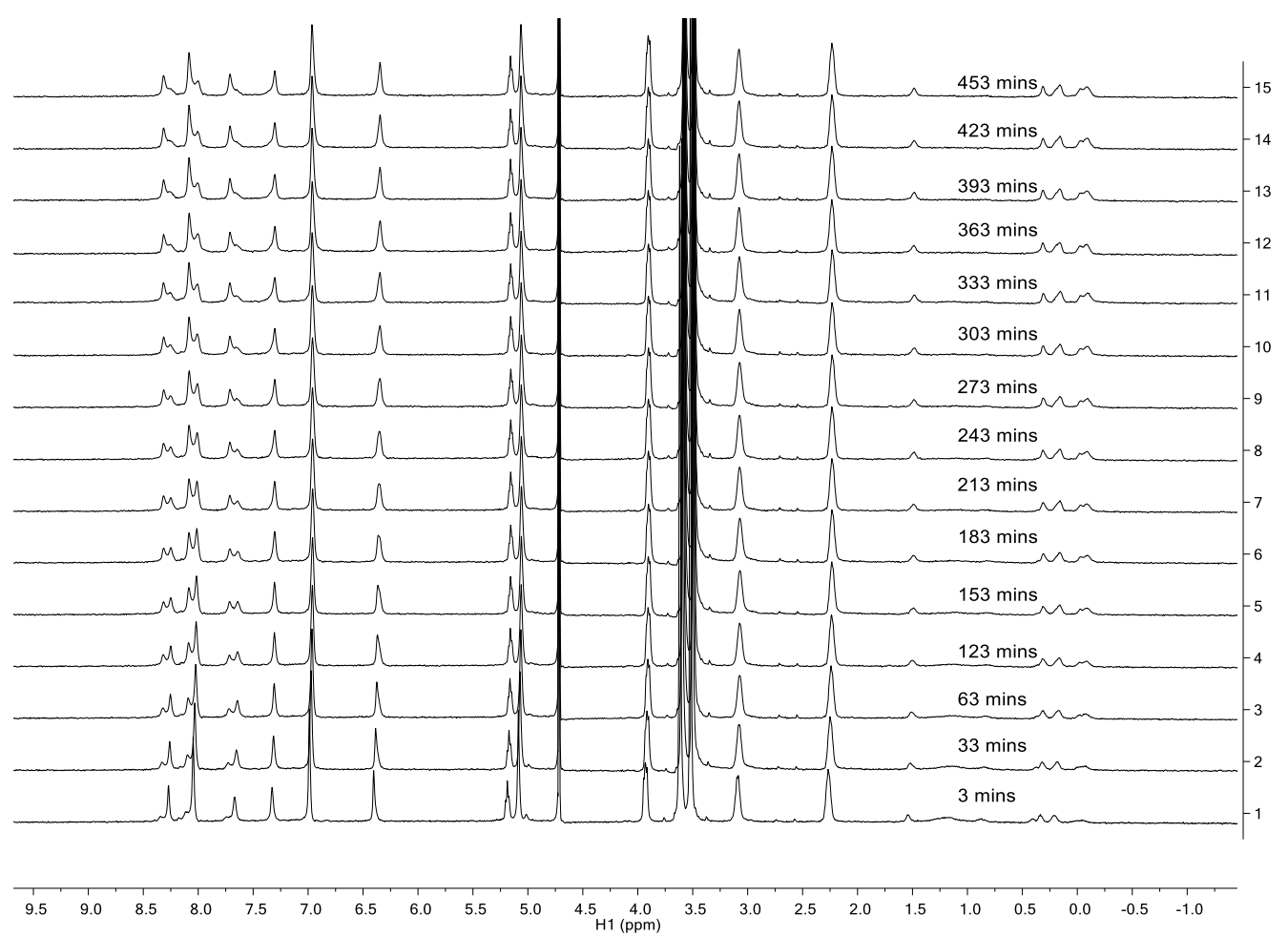

Figure S19: Stack of ${ }^{1} \mathrm{H}$ NMR spectra showing reaction of encapsulated guest $\mathbf{3}$ inside of $\mathbf{1}_{2}$ as a function of time. $\left(\mathrm{D}_{2} \mathrm{O}, 348 \mathrm{~K},[\right.$ Host 1$]=1 \mathrm{mM},[$ Guest 3$\left.]=0.5 \mathrm{mM},[\mathrm{NaOD}]=10 \mathrm{mM}\right)$.

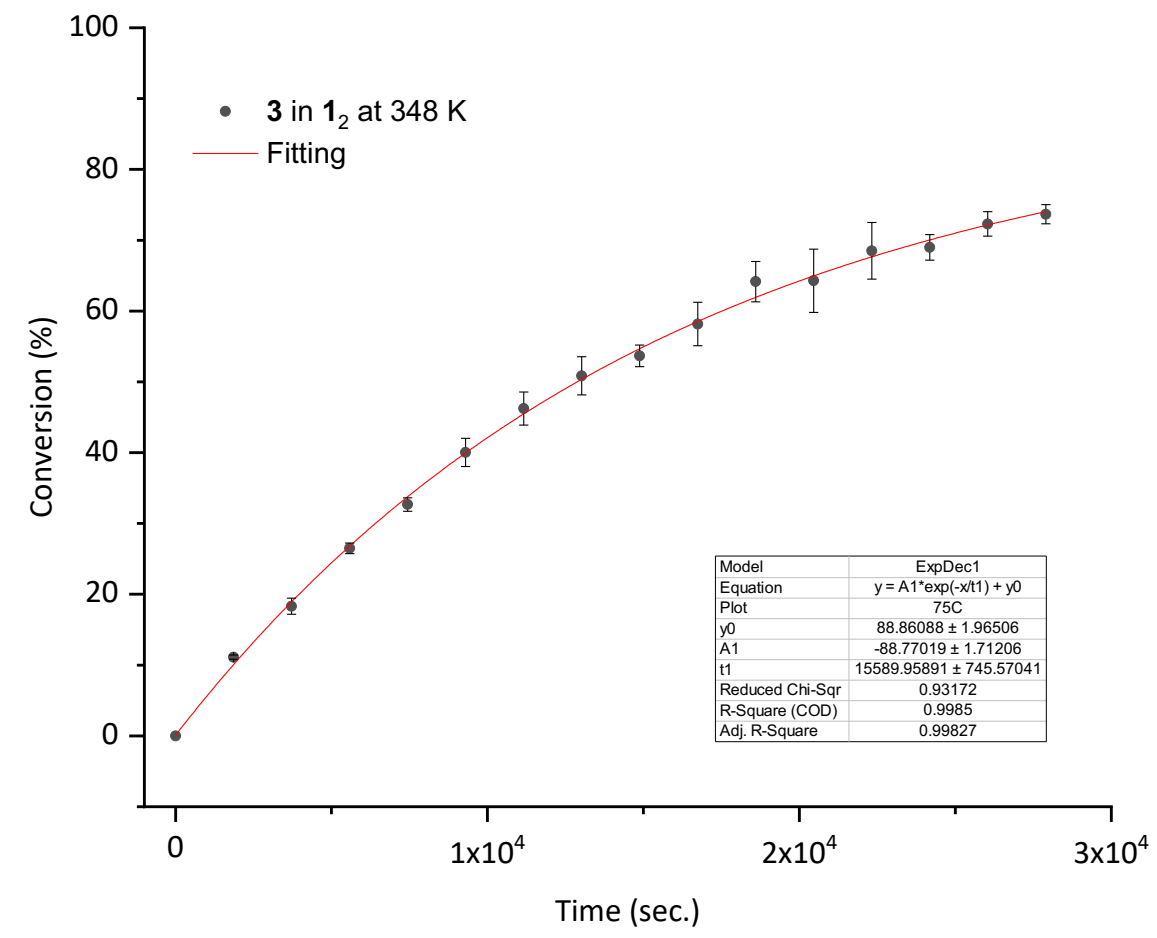

Figure S20: Conversion as a function of time plot for the reaction of guest 3 inside of host $\mathbf{1}_{2}$ at $348 \mathrm{~K}$. 


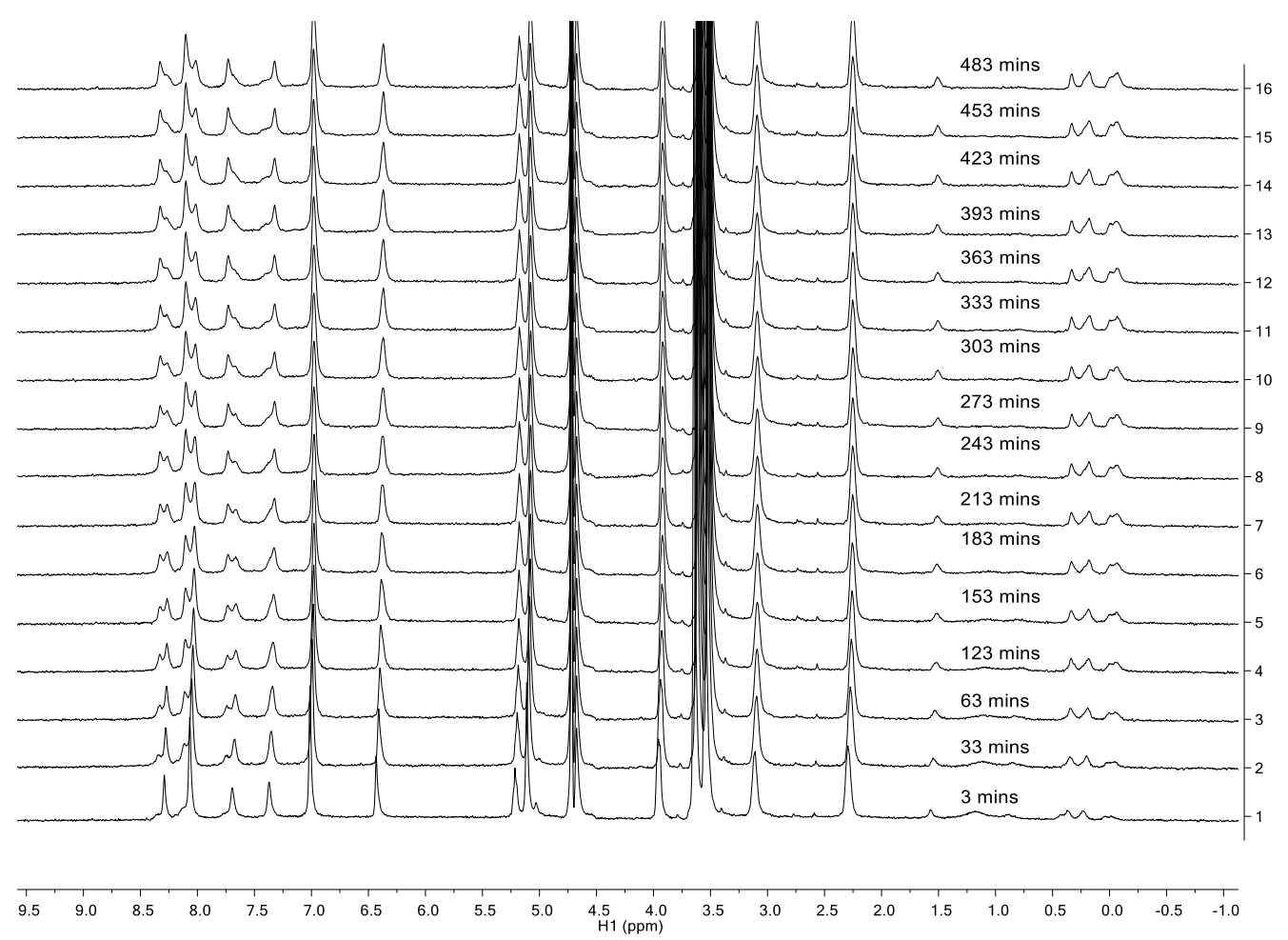

Figure S21: Stack of ${ }^{1} \mathrm{H}$ NMR spectra showing reaction of encapsulated guest $\mathbf{3}$ inside of $\mathbf{1}_{2}$ as a function of time. $\left(\mathrm{D}_{2} \mathrm{O}, 351 \mathrm{~K},[\right.$ Host 1$]=1 \mathrm{mM},[$ Guest 3$\left.]=0.5 \mathrm{mM},[\mathrm{NaOD}]=10 \mathrm{mM}\right)$.

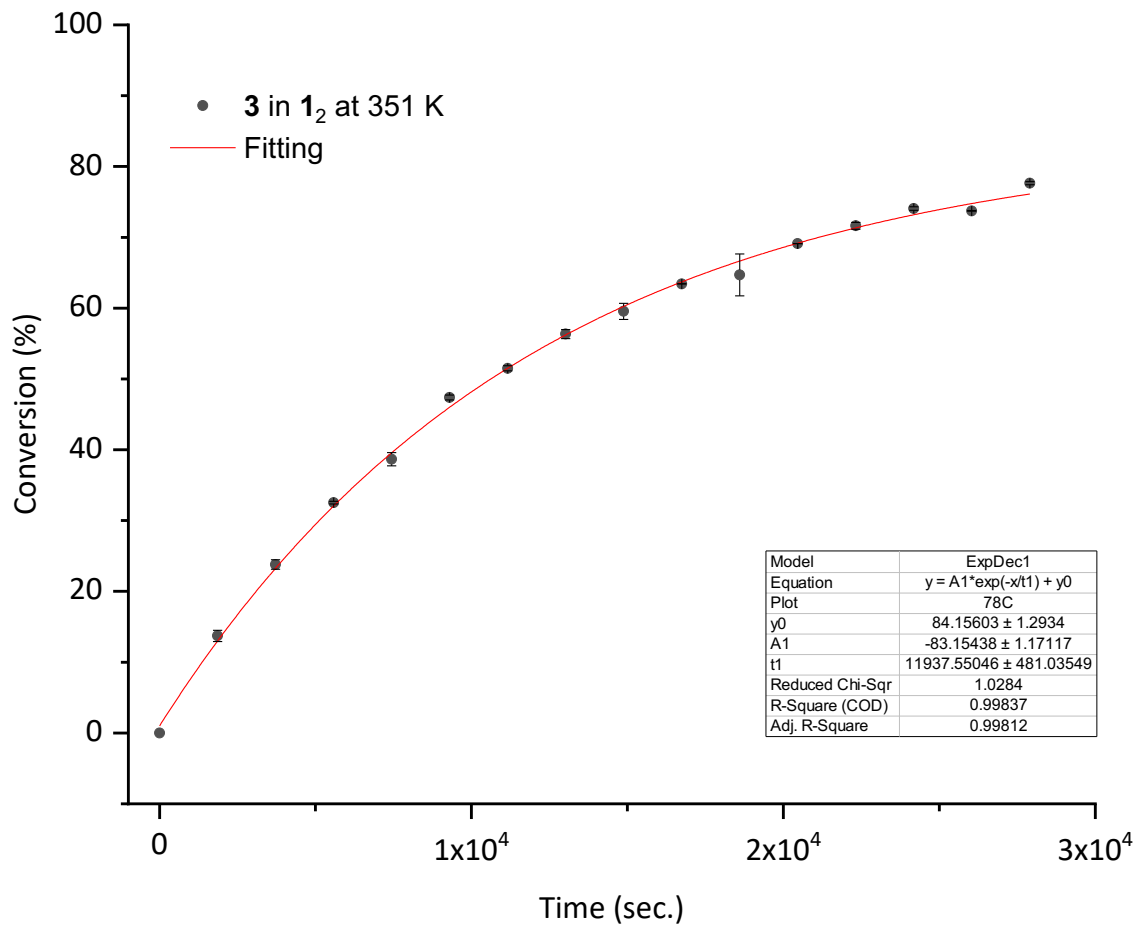

Figure S22: Conversion as a function of time plot for the reaction of guest 3 inside of host $\mathbf{1}_{2}$ at $351 \mathrm{~K}$. 


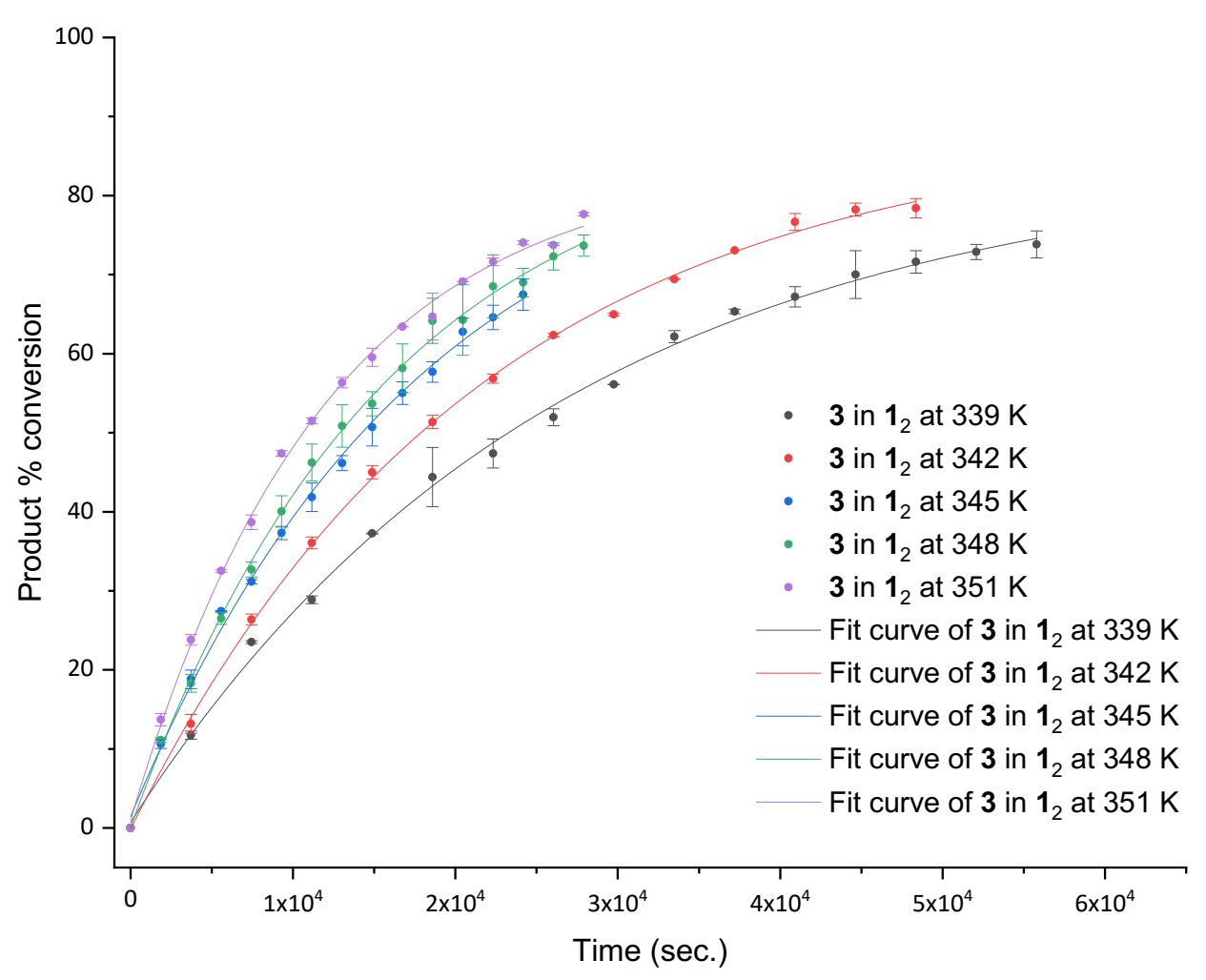

\begin{tabular}{|c|c|c|c|c|c|}
\hline Model & \multicolumn{5}{|c|}{ ExpDec1 } \\
\hline Equation & \multicolumn{5}{|c|}{$y=A 1^{*} \exp (-x / t 1)+y 0$} \\
\hline Plot & $66 C$ & $69 C$ & $72 \mathrm{C}$ & $75 \mathrm{C}$ & $78 \mathrm{C}$ \\
\hline y0 & $84.61 \pm 1.71$ & $88.54 \pm 1.14$ & $89.61 \pm 3.81$ & $88.86 \pm 1.97$ & $84.16 \pm 1.29$ \\
\hline A1 & $-83.88 \pm 1.51$ & $-88.68 \pm 1.03$ & $-88.19 \pm 3.43$ & $-88.77 \pm 1.71$ & $-83.15 \pm 1.17$ \\
\hline t1 & $2.63 E+04 \pm 1.30 E+$ & $2.14 \mathrm{E}+04 \pm 6.96 \mathrm{E}$ & $1.78 \mathrm{E}+04 \pm 1.41 \mathrm{E}+$ & $1.56 \mathrm{E}+04 \pm 7.46 \mathrm{E}$ & $1.19 \mathrm{E}+04 \pm 4.81 \mathrm{E}$ \\
\hline Reduced Ch & 1.30 & 0.64 & 1.13 & 0.93 & 1.03 \\
\hline R-Square (C & 1.00 & 1.00 & 1.00 & 1.00 & 1.00 \\
\hline Adj. R-Squar & 1.00 & 1.00 & 1.00 & 1.00 & 1.00 \\
\hline
\end{tabular}

Figure S23: Overall conversions as a function of time for the reaction of guest $\mathbf{3}$ inside of $\mathbf{1}_{\mathbf{2}}$ at five different temperatures (top), and summary of kinetic data fitting to Eq.2 (bottom). 


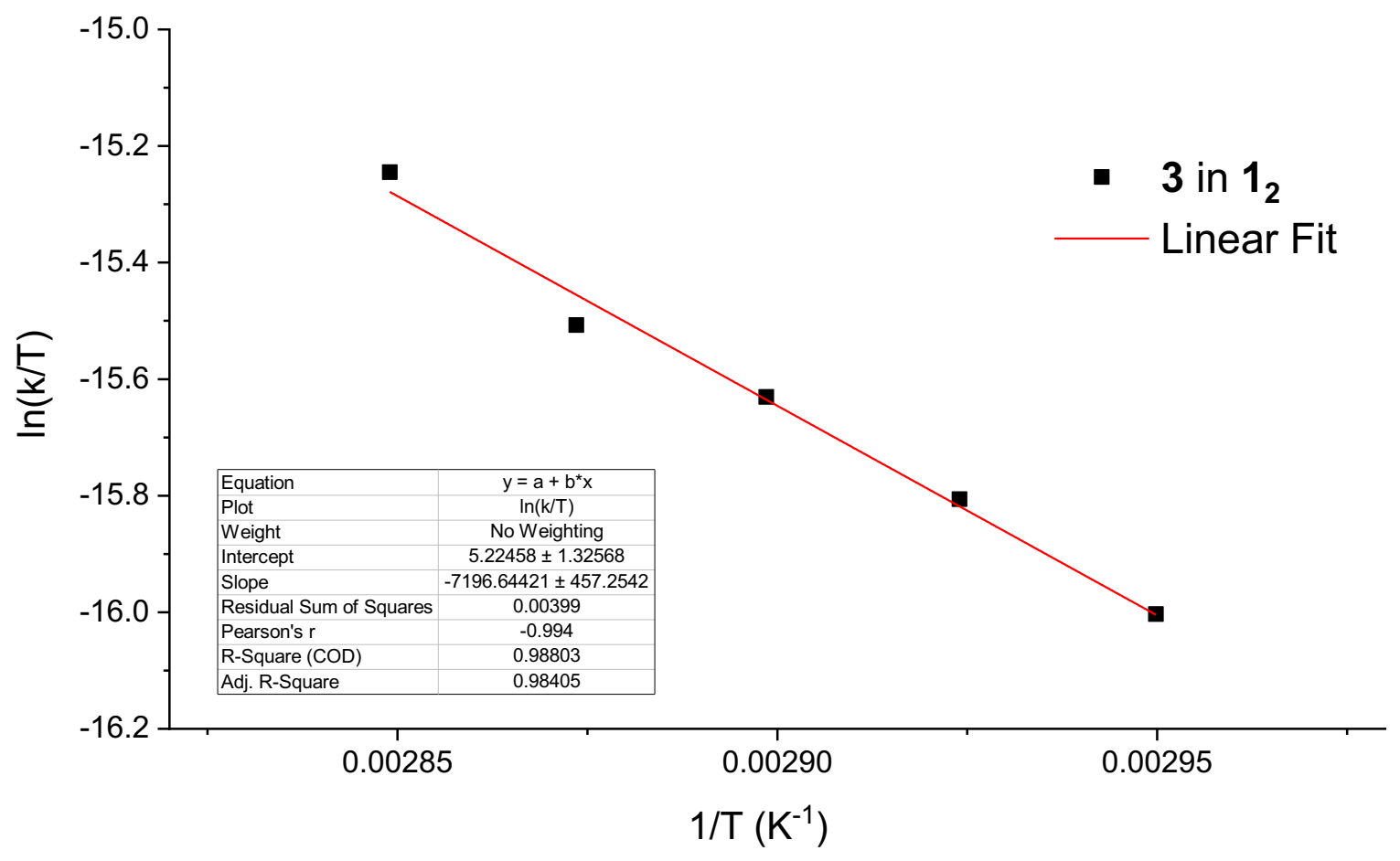

Figure S24: Eyring plot (Eq. 1) for the reaction of guest $\mathbf{3}$ in $\mathbf{1}_{\mathbf{2}}$ at five different temperatures. 
4.2) Reaction of $\mathbf{3}$ within $\mathbf{2}_{2}$ at different temperature and data fitting.

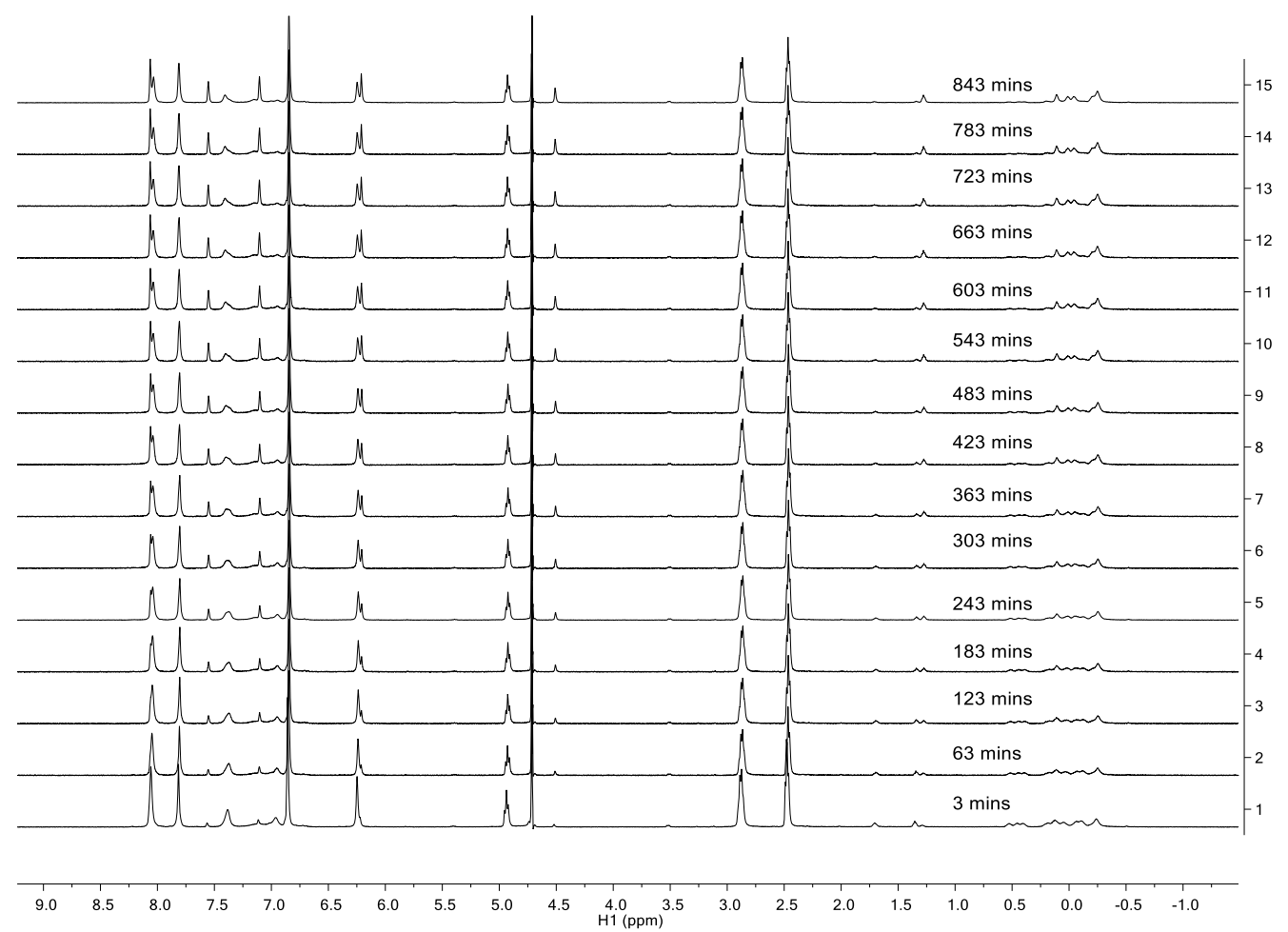

Figure S25: Stack of ${ }^{1} \mathrm{H}$ NMR spectra showing reaction of encapsulated guest $\mathbf{3}$ inside of $\mathbf{2}_{2}$ as a function of time. $\left(\mathrm{D}_{2} \mathrm{O}, 325 \mathrm{~K}\right.$, [Host 2] = $1 \mathrm{mM}$, [Guest 3] $\left.=0.5 \mathrm{mM},[\mathrm{NaOD}]=10 \mathrm{mM}\right)$.

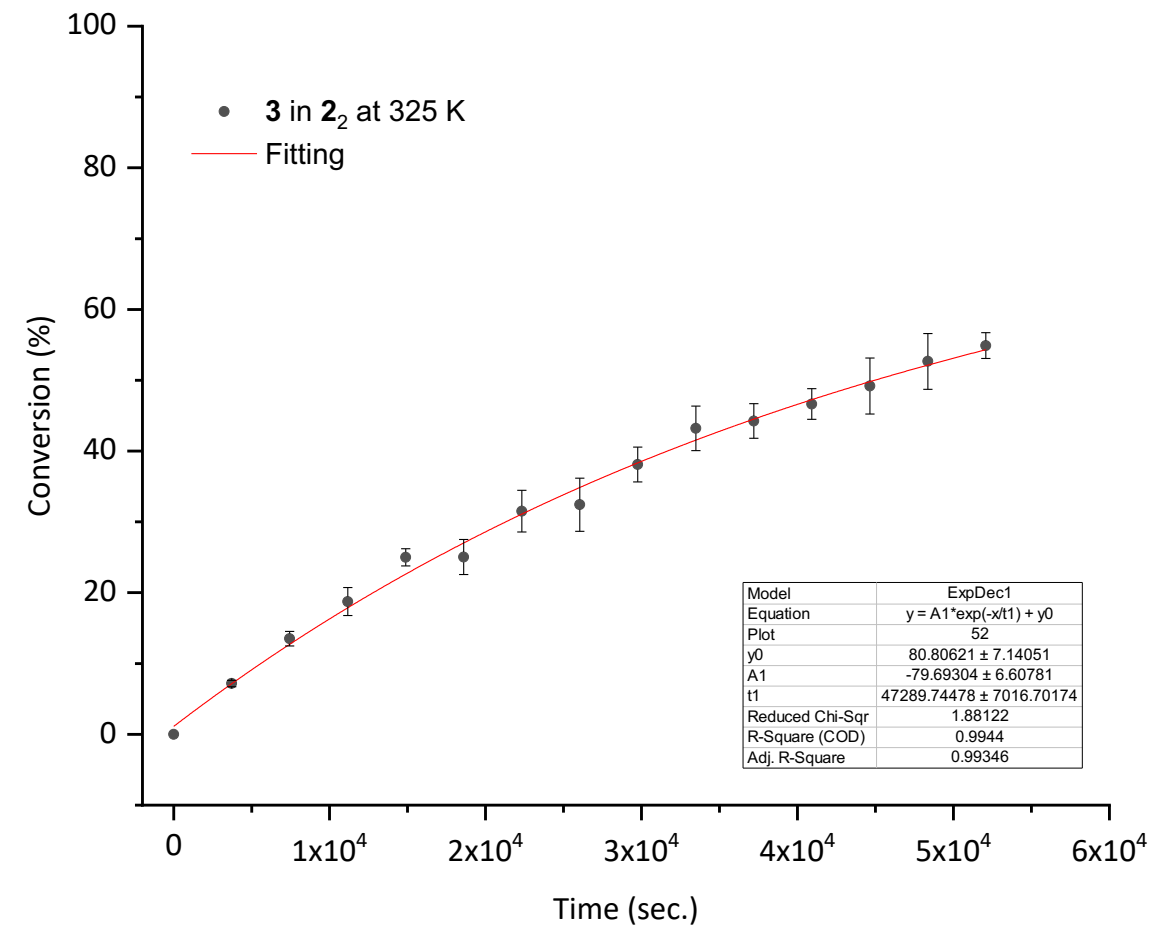

Figure S26: Conversion as a function of time plot for the reaction of guest $\mathbf{3}$ inside of host $\mathbf{2}_{2}$ at $325 \mathrm{~K}$. 


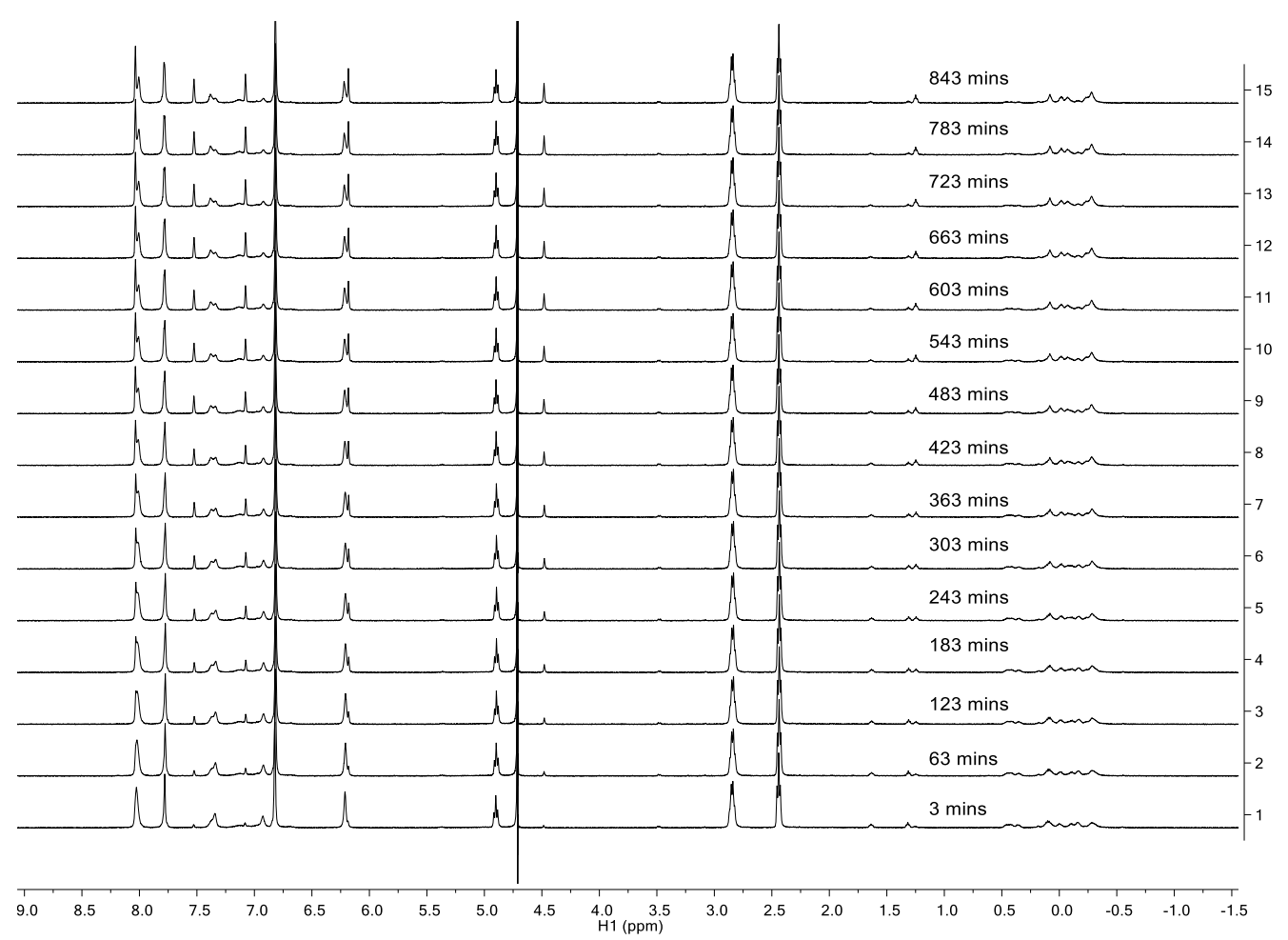

Figure S27: Stack of ${ }^{1} \mathrm{H}$ NMR spectra showing reaction of encapsulated guest $\mathbf{3}$ inside of $\mathbf{2}_{2}$ as a function of time. $\left(\mathrm{D}_{2} \mathrm{O}, 328 \mathrm{~K}\right.$, [Host 2] $=1 \mathrm{mM}$, [Guest 3] $\left.=0.5 \mathrm{mM},[\mathrm{NaOD}]=10 \mathrm{mM}\right)$.

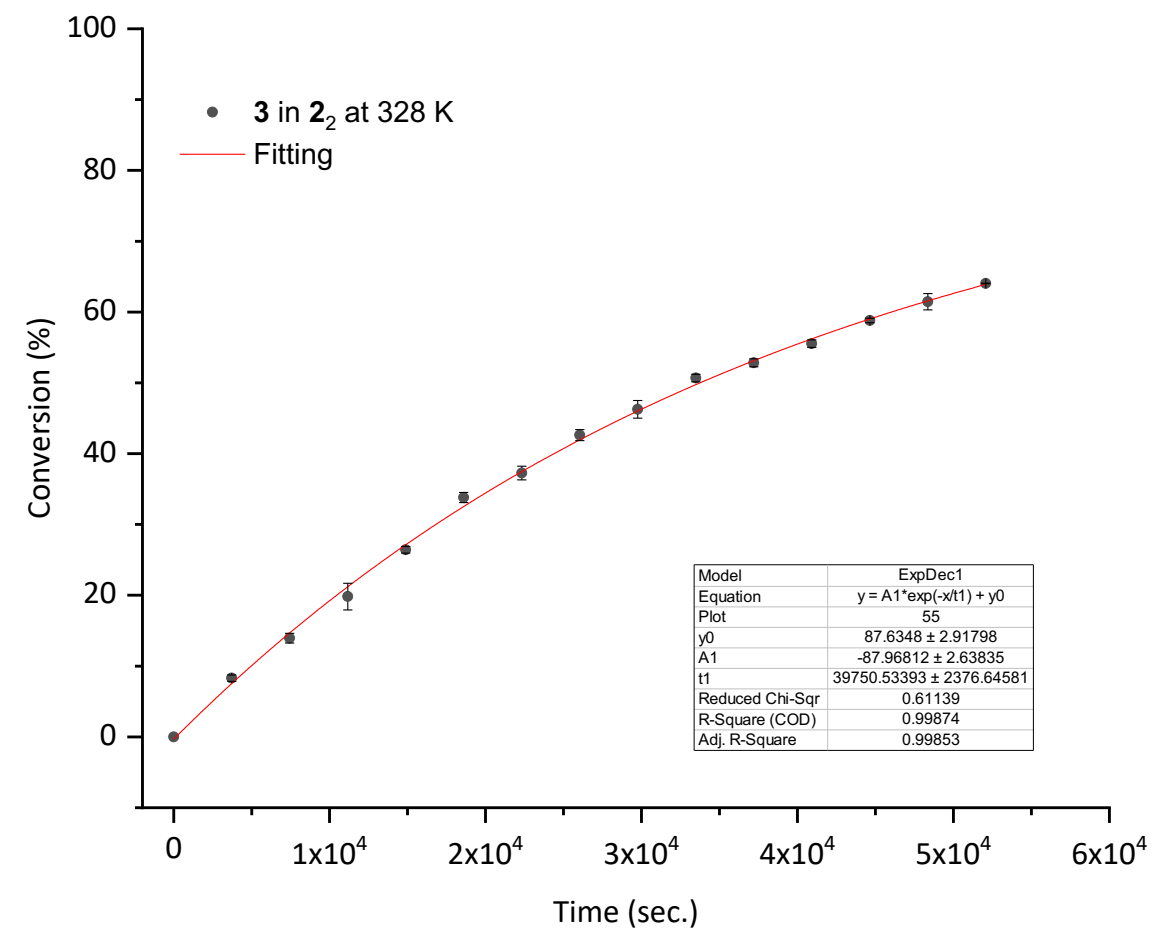

Figure S28: Conversion as a function of time plot for the reaction of guest 3 inside of host $2_{2}$ at $328 \mathrm{~K}$. 


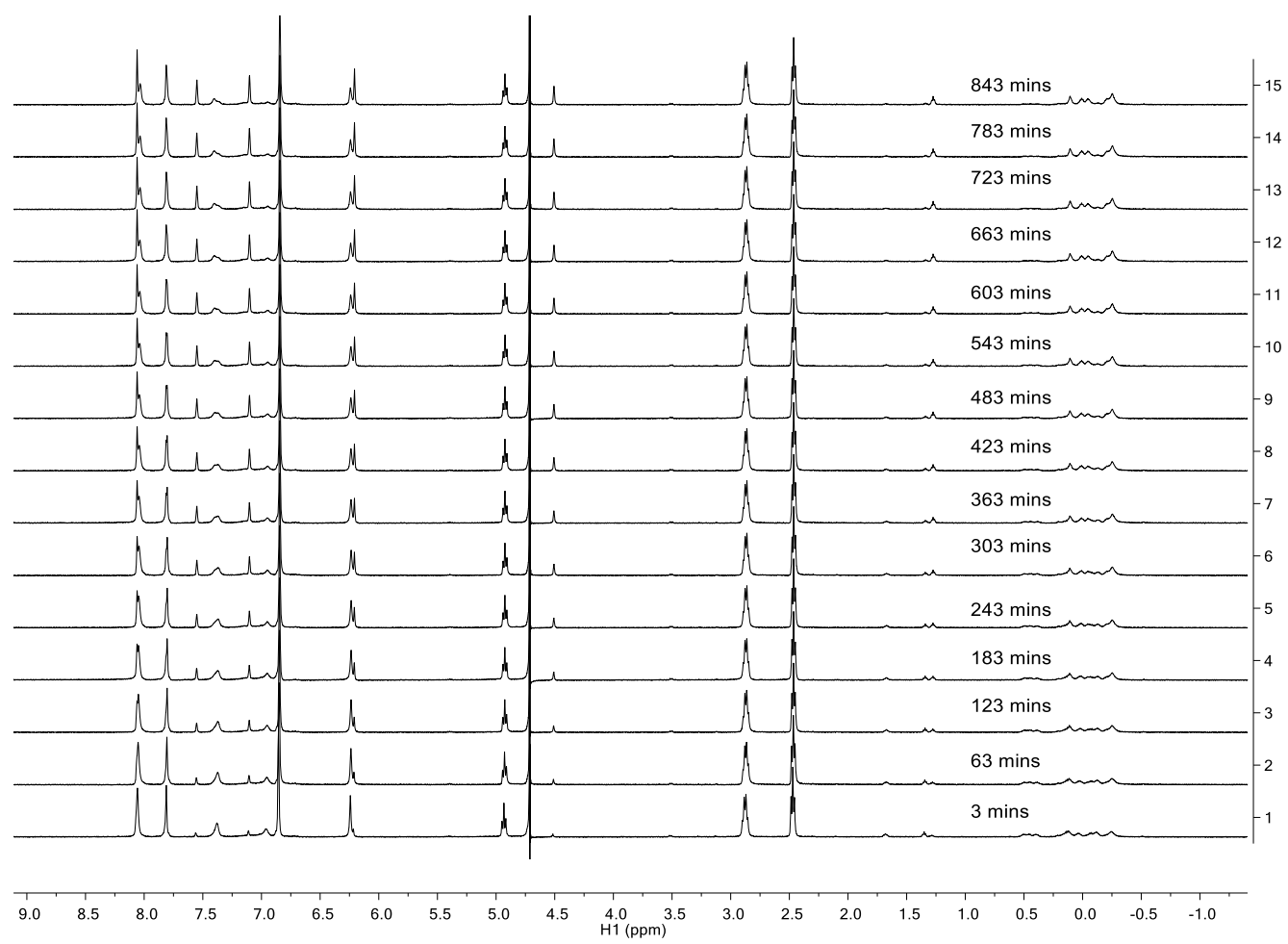

Figure S29: Stack of ${ }^{1} \mathrm{H}$ NMR spectra showing reaction of encapsulated guest $\mathbf{3}$ inside of $\mathbf{2}_{2}$ as a function of time. $\left(\mathrm{D}_{2} \mathrm{O}, 331 \mathrm{~K}\right.$, [Host 2] $=1 \mathrm{mM}$, [Guest 3] $\left.=0.5 \mathrm{mM},[\mathrm{NaOD}]=10 \mathrm{mM}\right)$.

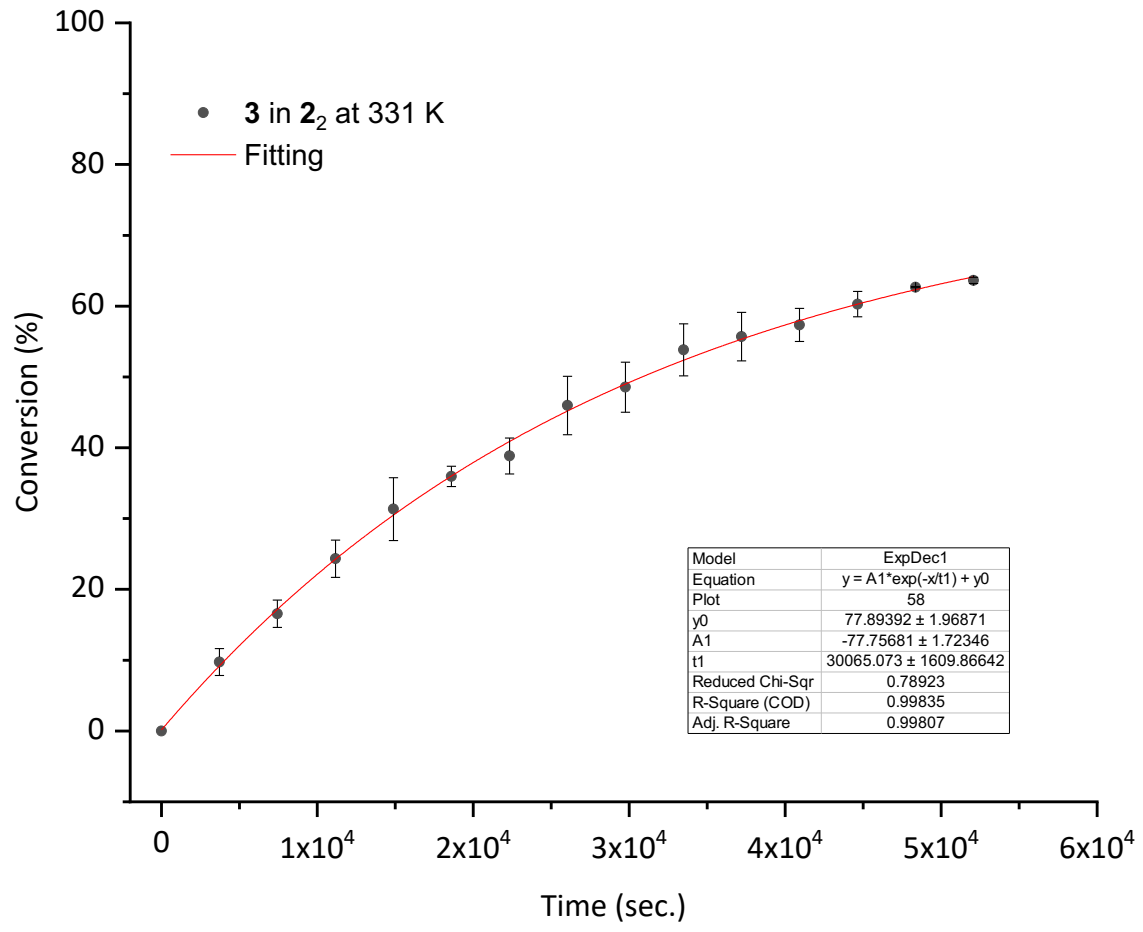

Figure S30: Conversion as a function of time plot for the reaction of guest $\mathbf{3}$ inside of host $\mathbf{2}_{2}$ at $331 \mathrm{~K}$. 


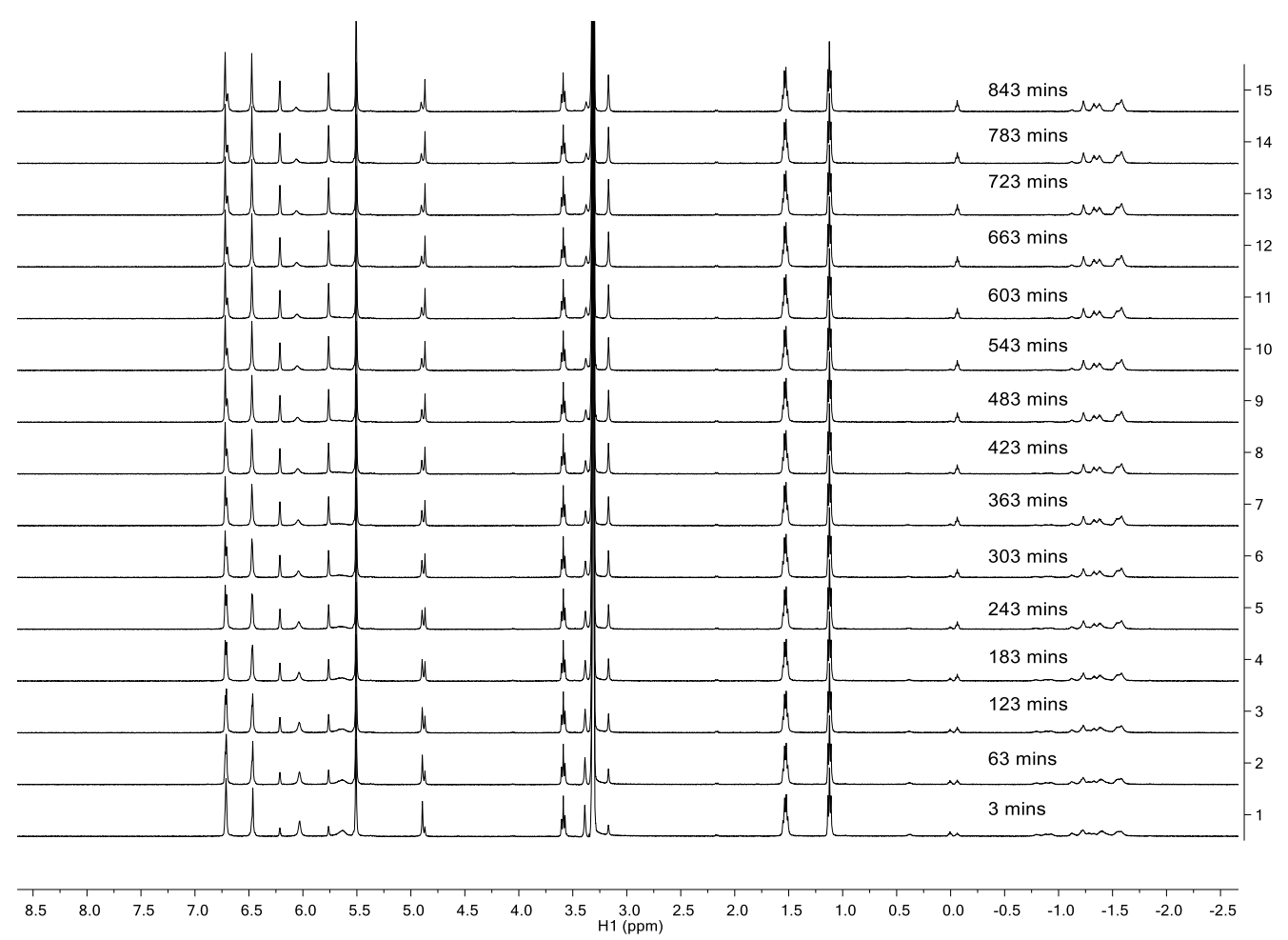

Figure S31: Stack of ${ }^{1} \mathrm{H}$ NMR spectra showing reaction of encapsulated guest $\mathbf{3}$ inside of $\mathbf{2}_{2}$ as a function of time. $\left(\mathrm{D}_{2} \mathrm{O}, 335 \mathrm{~K},[\right.$ Host 2$]=1 \mathrm{mM},[$ Guest 3] $=0.5 \mathrm{mM},[\mathrm{NaOD}]=10 \mathrm{mM})$.

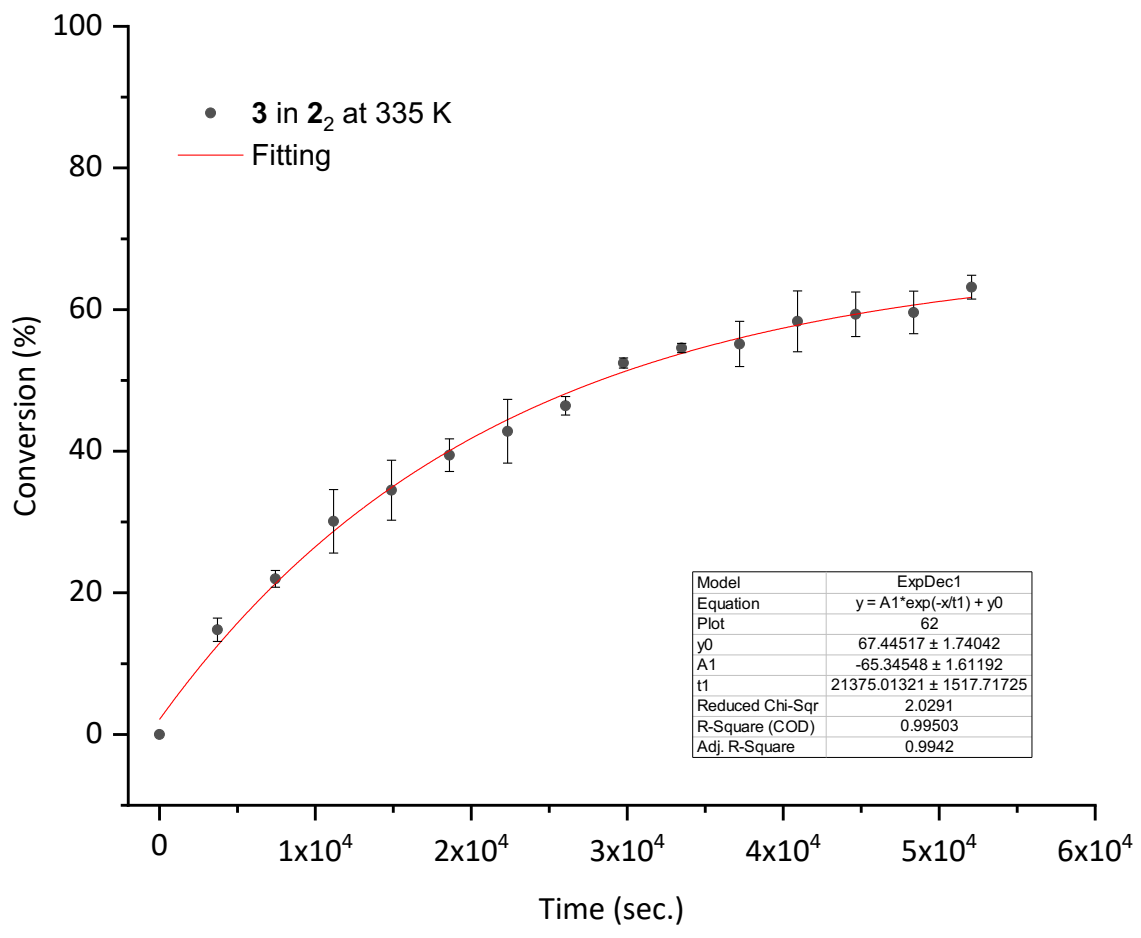

Figure S32: Conversion as a function of time plot for the reaction of guest 3 inside of host $2_{2}$ at $335 \mathrm{~K}$. 


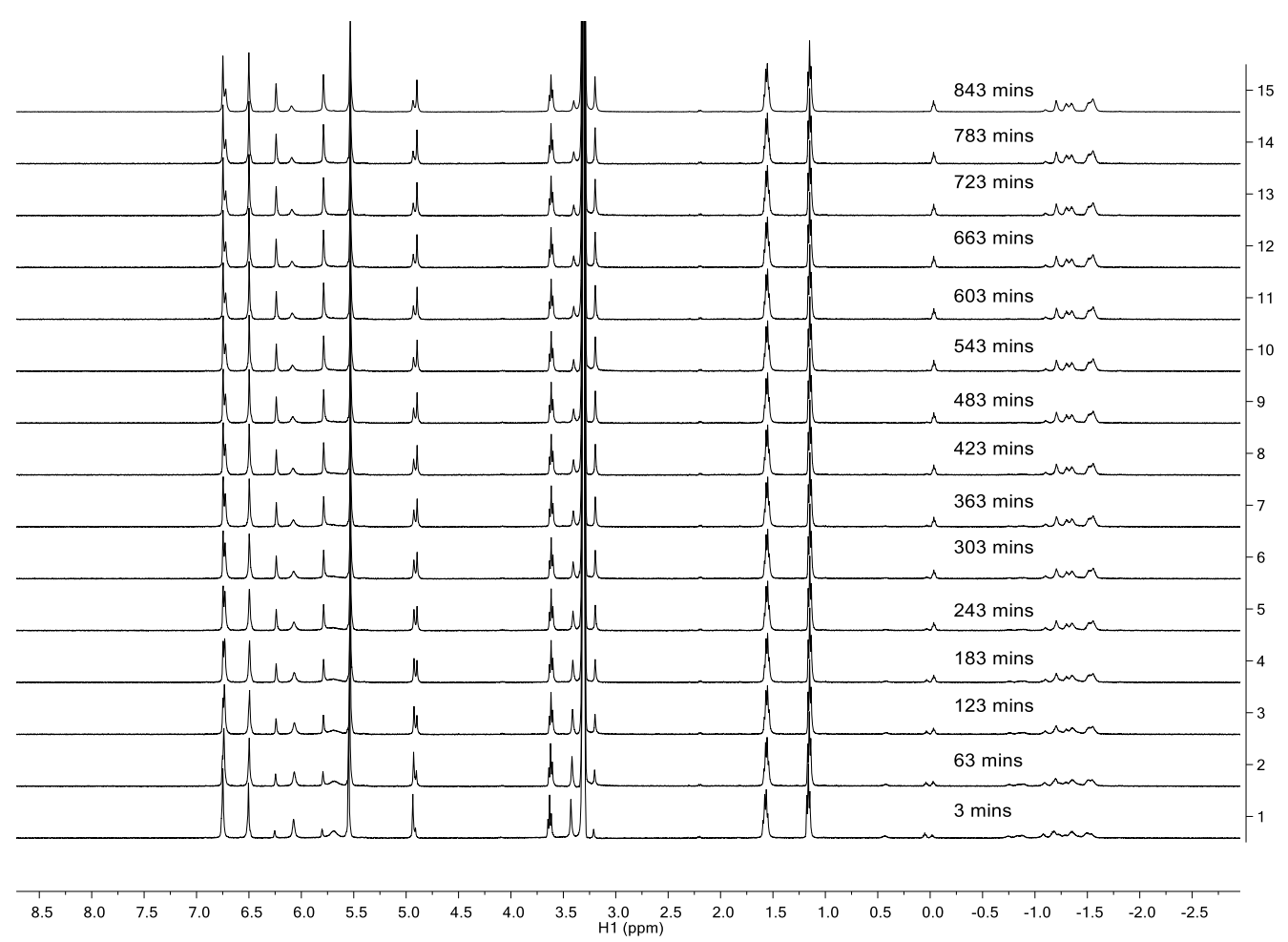

Figure S33: Stack of ${ }^{1} \mathrm{H}$ NMR spectra showing reaction of encapsulated guest $\mathbf{3}$ inside of $\mathbf{2}_{2}$ as a function of time. $\left(\mathrm{D}_{2} \mathrm{O}, 338 \mathrm{~K}\right.$, [Host 2] = $1 \mathrm{mM}$, [Guest 3] = $\left.0.5 \mathrm{mM},[\mathrm{NaOD}]=10 \mathrm{mM}\right)$.

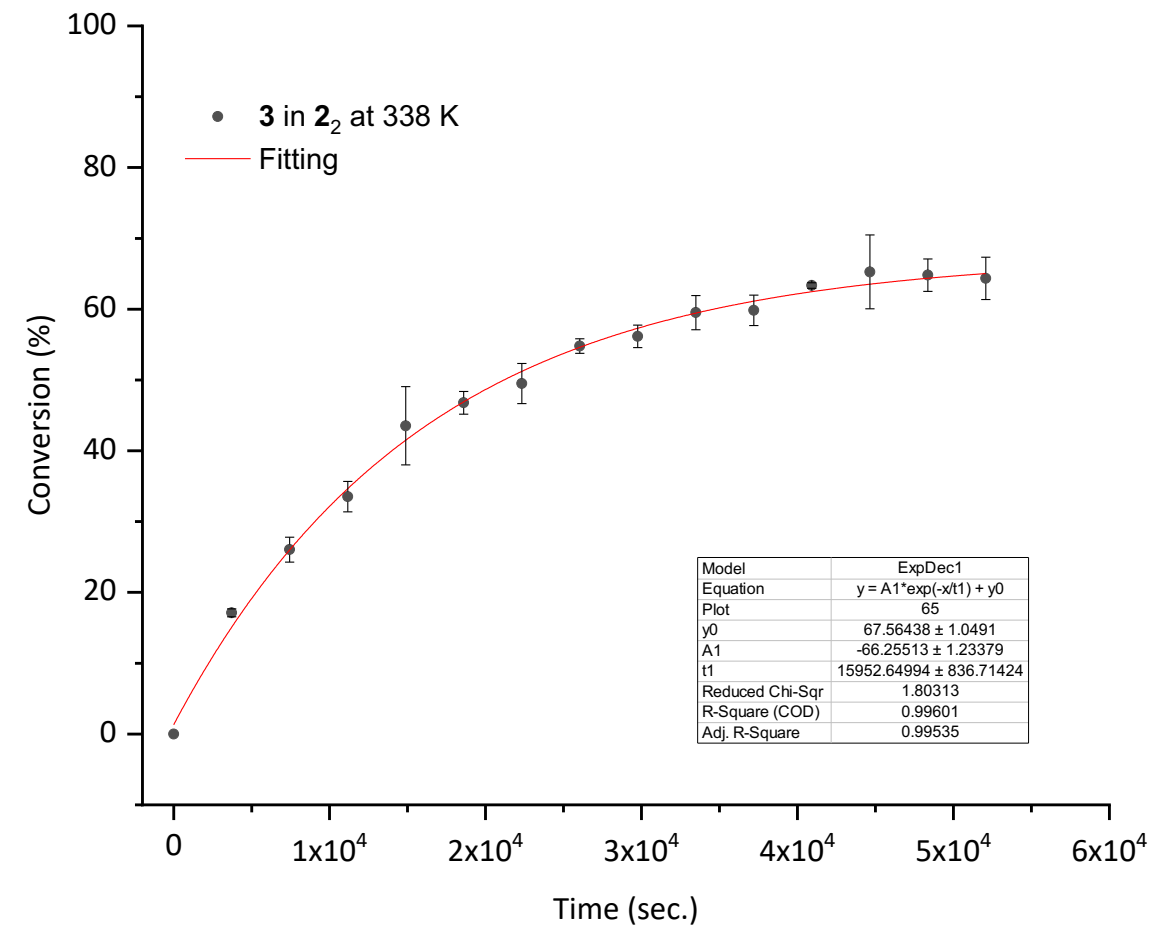

Figure S34: Conversion as a function of time plot for the reaction of guest $\mathbf{3}$ inside of host $\mathbf{2}_{2}$ at $338 \mathrm{~K}$. 


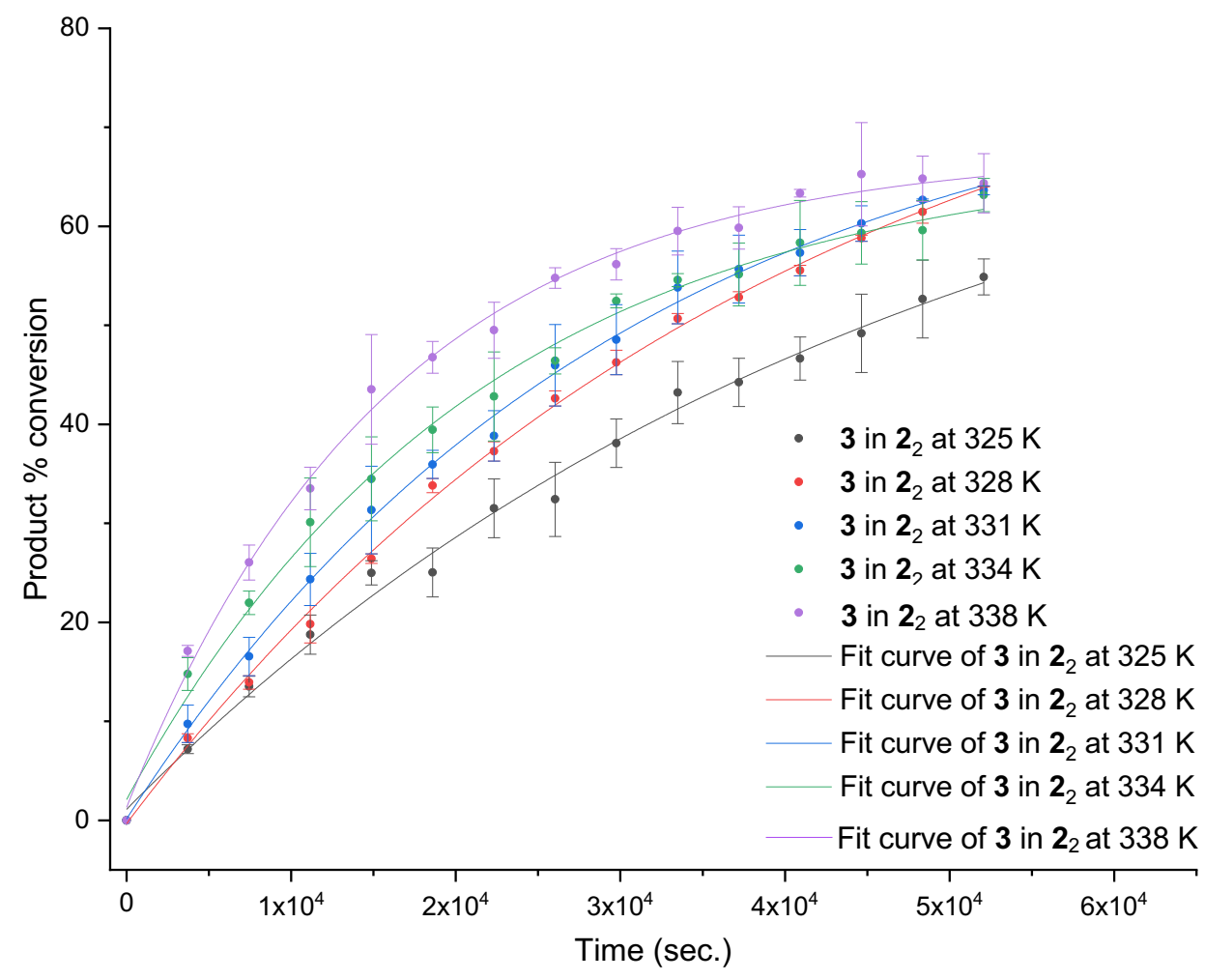

\begin{tabular}{|c|c|c|c|c|c|}
\hline Model & \multicolumn{5}{|c|}{ ExpDec1 } \\
\hline Equation & \multicolumn{5}{|c|}{$y=A 1^{*} \exp (-x / t 1)+y 0$} \\
\hline Plot & 52 & 55 & 58 & 62 & 65 \\
\hline y0 & $80.80621 \pm 7.14051$ & $87.6348 \pm 2.91798$ & $77.89392 \pm 1.968$ & $67.44517 \pm 1.74042$ & $67.56438 \pm 1.0491$ \\
\hline A1 & $-79.69304 \pm 6.6078$ & $-87.96812 \pm 2.6383$ & $-77.75681 \pm 1.723$ & $-65.34548 \pm 1.6119$ & $-66.25513 \pm 1.233$ \\
\hline t1 & $4.73 \mathrm{E}+04 \pm 7.02 \mathrm{E}+$ & $3.98 \mathrm{E}+04 \pm 2.38 \mathrm{E}+$ & $3.01 \mathrm{E}+04 \pm 1.61 \mathrm{E}$ & $2.14 \mathrm{E}+04 \pm 1.52 \mathrm{E}+$ & $1.60 \mathrm{E}+04 \pm 8.37 \mathrm{E}$ \\
\hline Reduced Ch & 1.88122 & 0.61139 & 0.78923 & 2.0291 & 1.80313 \\
\hline R-Square (C & 0.9944 & 0.99874 & 0.99835 & 0.99503 & 0.99601 \\
\hline Adj. R-Squar & 0.99346 & 0.99853 & 0.99807 & 0.9942 & 0.99535 \\
\hline
\end{tabular}

Figure S35: Overall conversions as a function of time for the reaction of guest $\mathbf{3}$ inside of $\mathbf{2}_{\mathbf{2}}$ at five different temperatures (top), and summary of kinetic data fitting to Eq. 2 (bottom). 


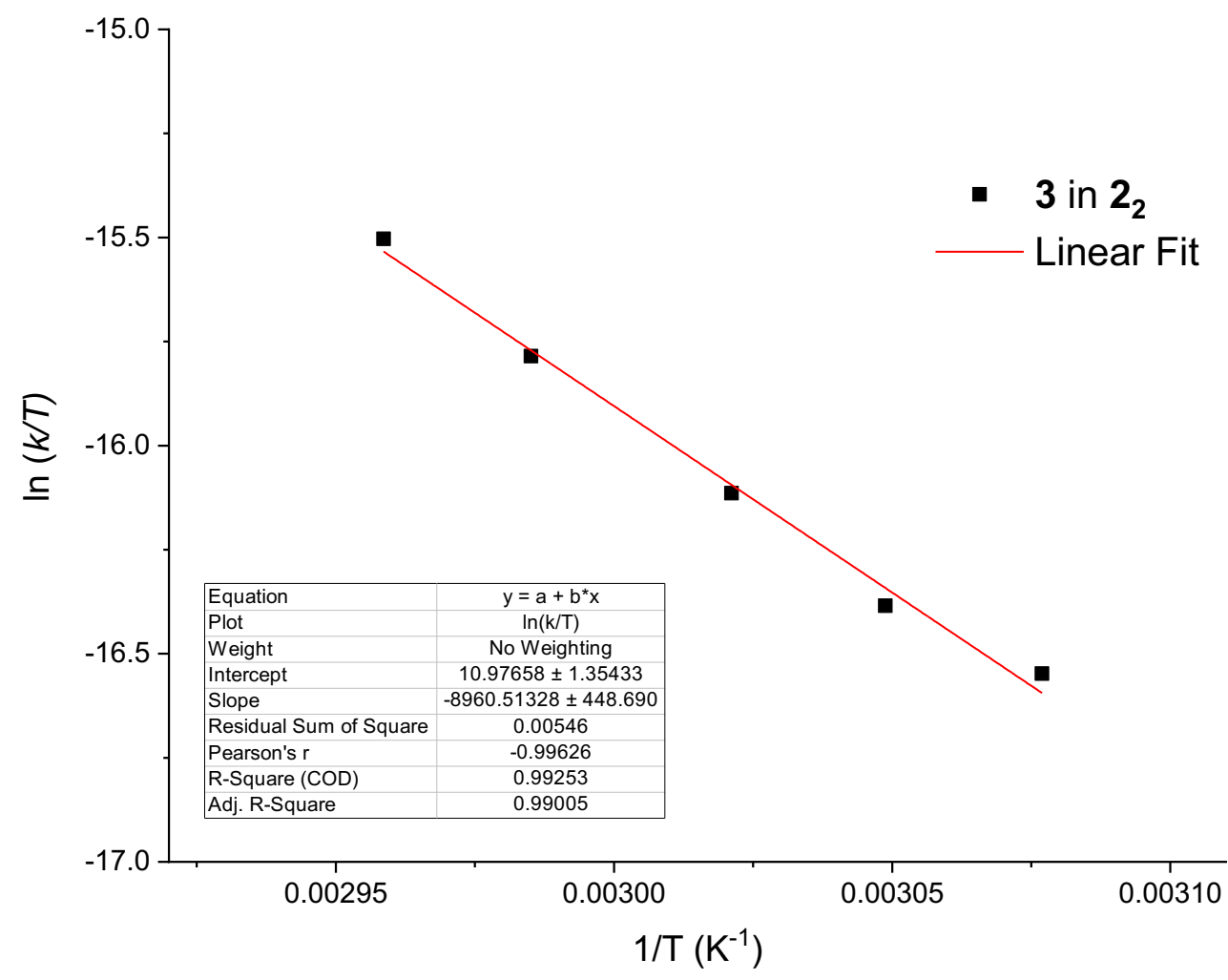

Figure S36: Eyring plot (Eq. 1) for the reaction of guest $\mathbf{3}$ in $\mathbf{2}_{\mathbf{2}}$ at five different temperatures. 


\section{5) Cyclization of 3 within $1_{2}$ in the presence of various salts}

Previous studies have shown that anions can bind to both the pendent groups or feet of host 1 , and the non-polar pocket. ${ }^{7}$ Additionally, studies showed that the electrostatic potential field (EPF) of either host had a significant effect on reactions carried out in the inner-space of the capsule, and that this EPF was modulated by counter-ion binding to the outside of the host. We therefore investigated the cyclization rate of 3 in the presence of anions known to bind to 1. To study this, the effect of nine different anions was investigated: $\mathrm{F}^{-}, \mathrm{Cl}^{-}, \mathrm{Br}^{-}, \mathrm{I}^{-}, \mathrm{ClO}_{4}^{-}, \mathrm{CF}_{3} \mathrm{SO}_{3}^{-}$, $\mathrm{SCN}^{-}, \mathrm{NO}_{3}{ }^{-}$, and $\mathrm{Cl}_{2} \mathrm{CHCO}_{2}^{-}\left(\mathrm{DCA}^{-}\right)$.

Figures S37 - S59 show the corresponding data for reactions carried out with the same protocol but in the presence of $10 \mathrm{mM}$ of the anions (as their sodium salts). The experiments were performed with $0.5 \mathrm{~mL}$ samples of $1.0 \mathrm{mM}$ host 1 in $\mathrm{D}_{2} \mathrm{O}$ at $339 \mathrm{~K}$. In each case, a small volume of $400 \mathrm{mM}$ salt solution was added to make a $10 \mathrm{mM}$ salt solution of the complex. 


\section{1) Anion effect: Summary of data}

Figures S37 and S38 show the ${ }^{1} \mathrm{H}$ NMR spectra of the complex with $\mathbf{1}_{2}$ in the presence of $10 \mathrm{mM}$ salt.

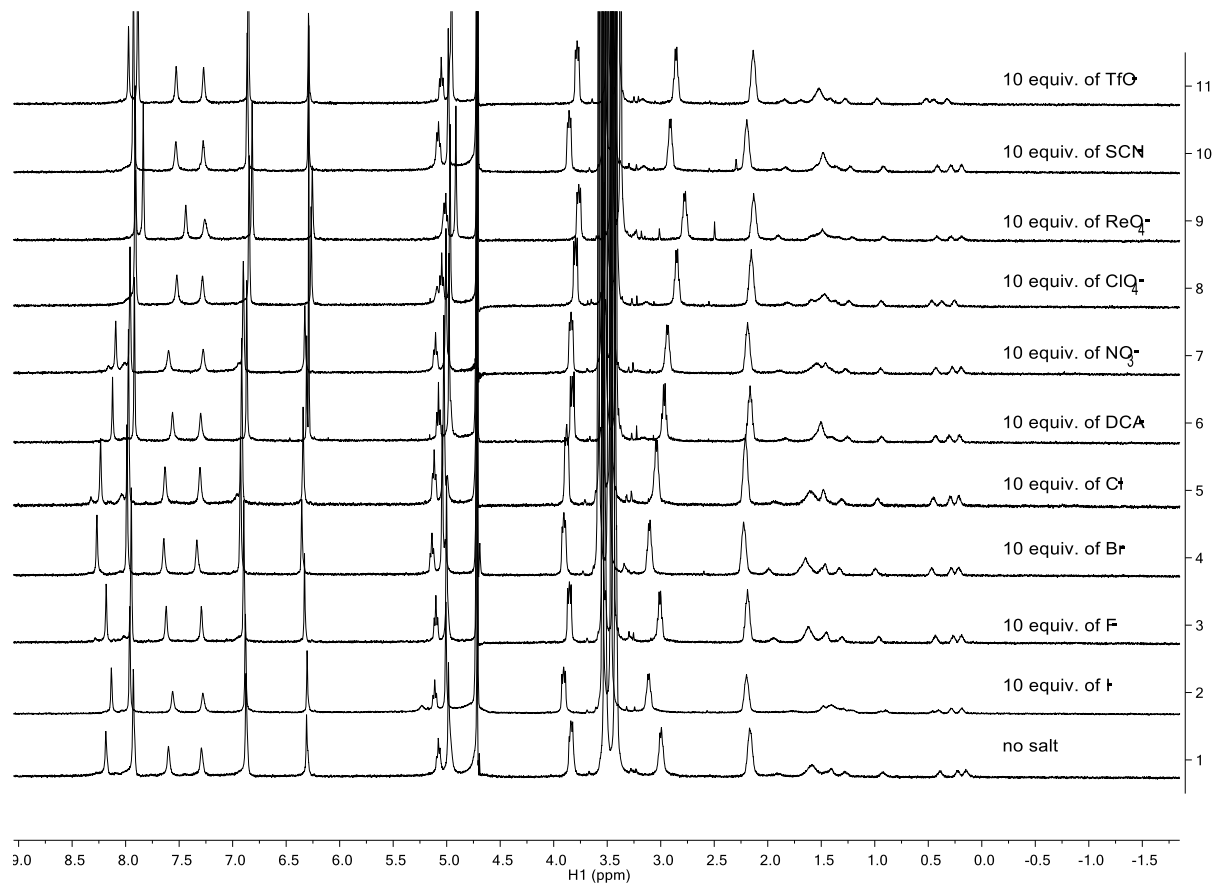

Figure S37: Stack of ${ }^{1} \mathrm{H}$ NMR spectra of $\mathbf{3}$ in $\mathbf{1}_{2}$ in the presence of various of anion at $339 \mathrm{~K}$.

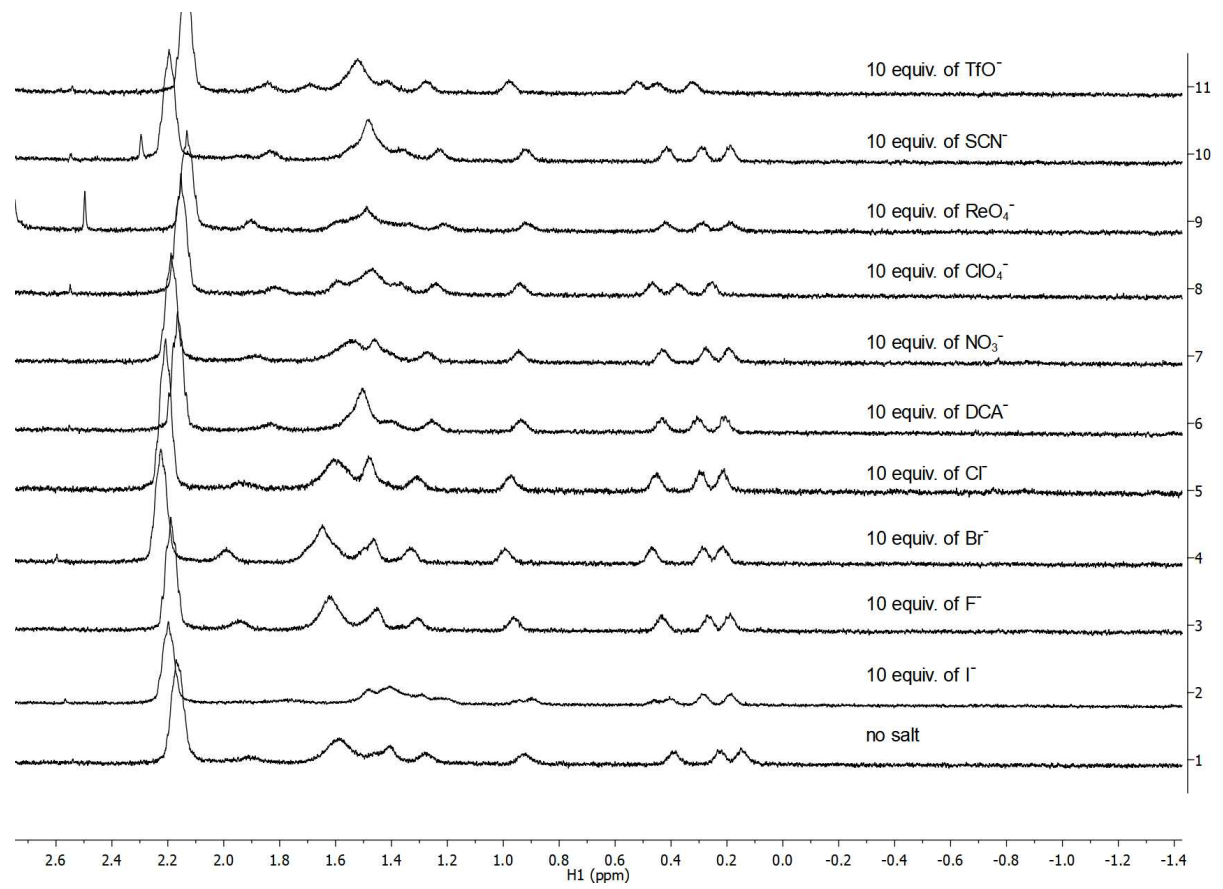

Figure S38: Stack of ${ }^{1} \mathrm{H}$ NMR spectra of $\mathbf{3}$ in $\mathbf{1}_{2}$ in guest region in the presence of various of 10 equivalents of the indicated sodium salt at $339 \mathrm{~K}$. 
The extent of reaction of each experiment was determined by tracking and integrating the ${ }^{1} \mathrm{H}$ NMR signal from the $\mathrm{H}_{\mathrm{d}}$ proton (Mnova) and fitting this data as a function of time to give the rate constant data (Origin Pro 2018. Figure S39 shows the cumulative data for all the salts. Each experiment was carried out in duplicate (error bars shown), with the average calculated used to give the rate constant (Table 2). Errors were $<10 \%$.

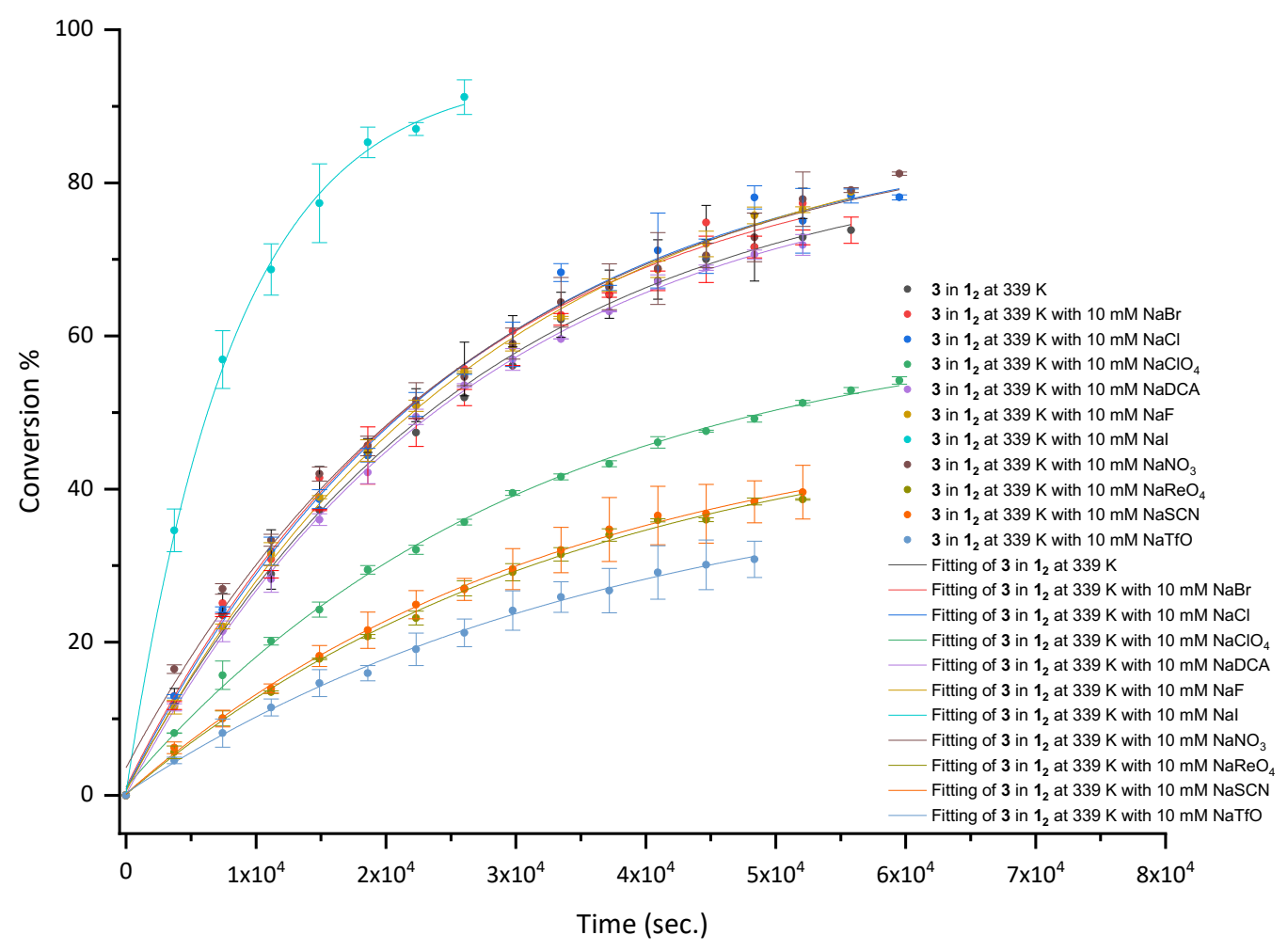

\begin{tabular}{|c|c|c|c|c|c|c|c|c|c|c|c|}
\hline Model & \multicolumn{11}{|c|}{ ExpDec1 } \\
\hline Equati & \multicolumn{11}{|c|}{$y=A 1^{*} \exp (-x / t 1)+y 0$} \\
\hline Plot & P1 & $\mathrm{Br}$ & $\mathrm{Cl}$ & $\mathrm{ClO} 4$ & DCA & $\mathrm{F}$ & I & NO3 & $\mathrm{ReO} 4$ & SCN & TfO \\
\hline y0 & $84.61 \pm 1$ & $85.55 \pm 2$ & $87.77 \pm 2$ & $62.39 \pm 1$ & $83.67 \pm 1$ & $89.37 \pm 1$ & $94.40 \pm 1$ & $88.13 \pm 2$ & $50.79 \pm 1$ & $50.54 \pm 1$ & $43.29 \pm 1$ \\
\hline A1 & $-83.88 \pm 1$ & $-84.49 \pm 2$ & $-86.97 \pm 2$ & $-61.35 \pm 1$ & $-83.57 \pm 1$ & $-88.86 \pm$ & $-94.06 \pm$ & $-84.52 \pm 2$ & $-50.68 \pm 1$ & $-50.34 \pm 1$ & $-42.99 \pm 1$ \\
\hline t1 & 26274.05 & 24578.43 & 25630.52 & 30768.66 & 26065.98 & 27075.47 & $8344.58 \pm$ & 26601.09 & 34990.47 & 33571.86 & 38064.53 \\
\hline Reduc & 1.30 & 2.71 & 3.44 & 0.45 & 0.48 & 0.69 & 1.36 & 3.65 & 0.31 & 0.25 & 0.24 \\
\hline R-Squ & 1.00 & 1.00 & 0.99 & 1.00 & 1.00 & 1.00 & 1.00 & 0.99 & 1.00 & 1.00 & 1.00 \\
\hline Adj. R- & 1.00 & 1.00 & 0.99 & 1.00 & 1.00 & 1.00 & 1.00 & 0.99 & 1.00 & 1.00 & 1.00 \\
\hline
\end{tabular}

Figure S39: Overall conversions as a function of time for the reaction of guest $\mathbf{3}$ in $\mathbf{1}_{2}$ in the presence of 10 equiv. different anions at $339 \mathrm{~K}$ (top), and summary of kinetic parameters from fitting to Eq. 2 (bottom). 
Table 2: The reaction rate $(k)$ of $\mathbf{3}$ in $\mathbf{1}_{\mathbf{2}}$ in the presence of different anions at $339 \mathrm{~K}$.

\begin{tabular}{cc}
\hline $\mathbf{N a}$ Salt & Rate Constant, $\boldsymbol{k}$ in $\mathbf{1 0}^{-\mathbf{5}} \mathbf{s}^{\mathbf{- 1}}$ \\
\hline $\mathrm{I}^{-}$ & 12.00 \\
$\mathrm{Br}$ & 4.07 \\
$\mathrm{Cl}^{-}$ & 3.91 \\
$\mathrm{DCA}^{-}$ & 3.83 \\
$\mathrm{no} \mathrm{salt}$ & 3.80 \\
$\mathrm{NO}_{3}^{-}$ & 3.76 \\
$\mathrm{~F}^{-}$ & 3.69 \\
$\mathrm{ClO}_{4}^{-}$ & 3.25 \\
$\mathrm{SCN}^{-}$ & 2.98 \\
$\mathrm{ReO}_{4}^{-}$ & 2.86 \\
$\mathrm{TfO}^{-}$ & 2.62 \\
\hline
\end{tabular}




\section{2) Anion effect: Individual data}

The reaction rate in each experiment was determined by tracking and integrating the " $d$ " peak in the ${ }^{1} \mathrm{H}$ NMR spectroscopy using Mnova, then fitted the integrations as a function of time to give the kinetic data with Origin Pro 2018. Lines fitted by the first order kinetic model are demonstrated in red and the standard deviations are shown as error bars. Each experiment was carried out in duplicates, with the average calculated to give the corresponding rate constants.

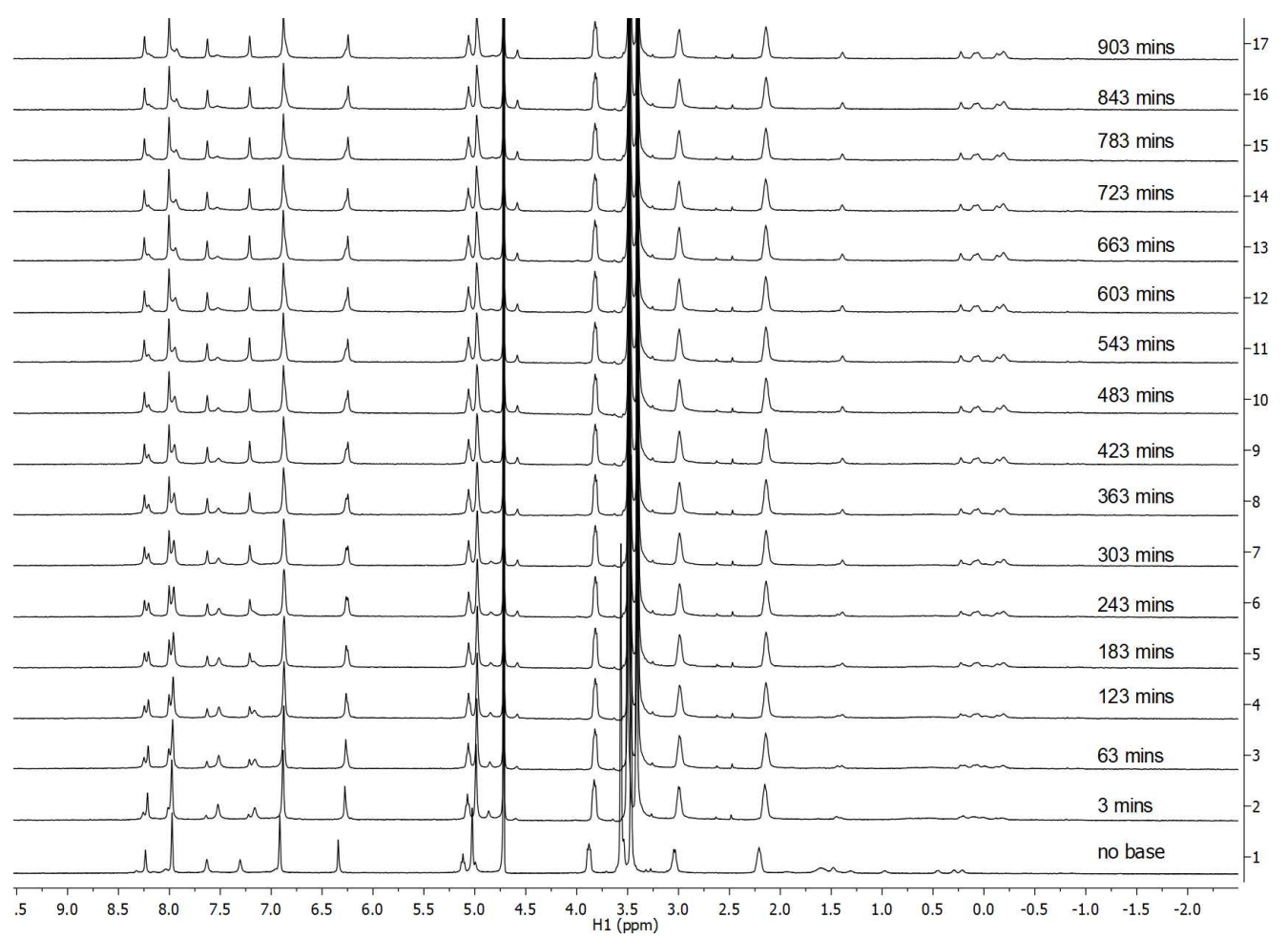

Figure S40: Stack of ${ }^{1} \mathrm{H}$ NMR spectra showing reaction of encapsulated guest 3 inside of $\mathbf{1}_{2}$ with 10 equiv. $\mathrm{NaCl}$ as a function of time. $\left(\mathrm{D}_{2} \mathrm{O}, 339 \mathrm{~K}\right.$, [Host 1] $=1 \mathrm{mM}$, [Guest 3] $\left.=0.5 \mathrm{mM},[\mathrm{NaOD}]=10 \mathrm{mM}\right)$. 


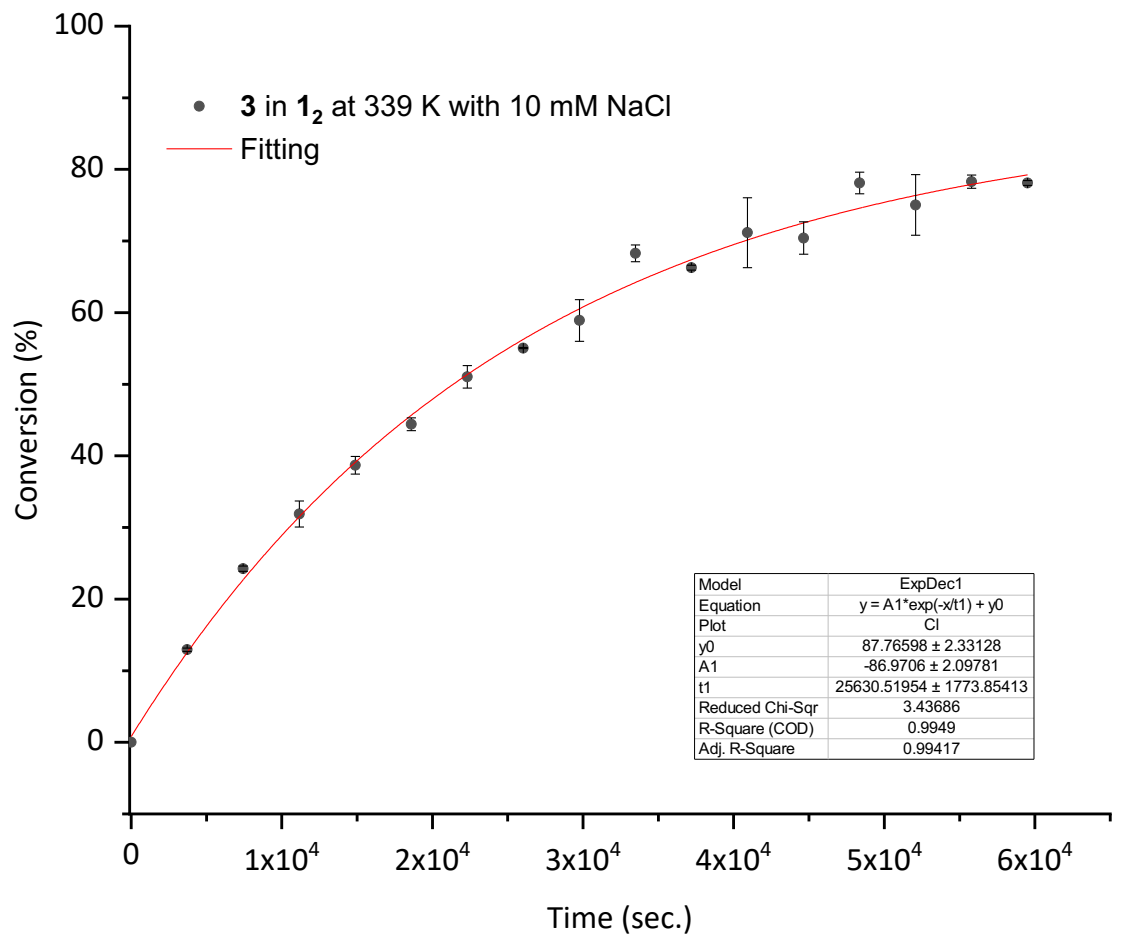

Figure S41: Conversion as a function of time plot for the reaction of guest $\mathbf{3}$ in $\mathbf{1}_{2}$ in the presence of 10 equiv. $\mathrm{NaCl}$ at $339 \mathrm{~K}$. 


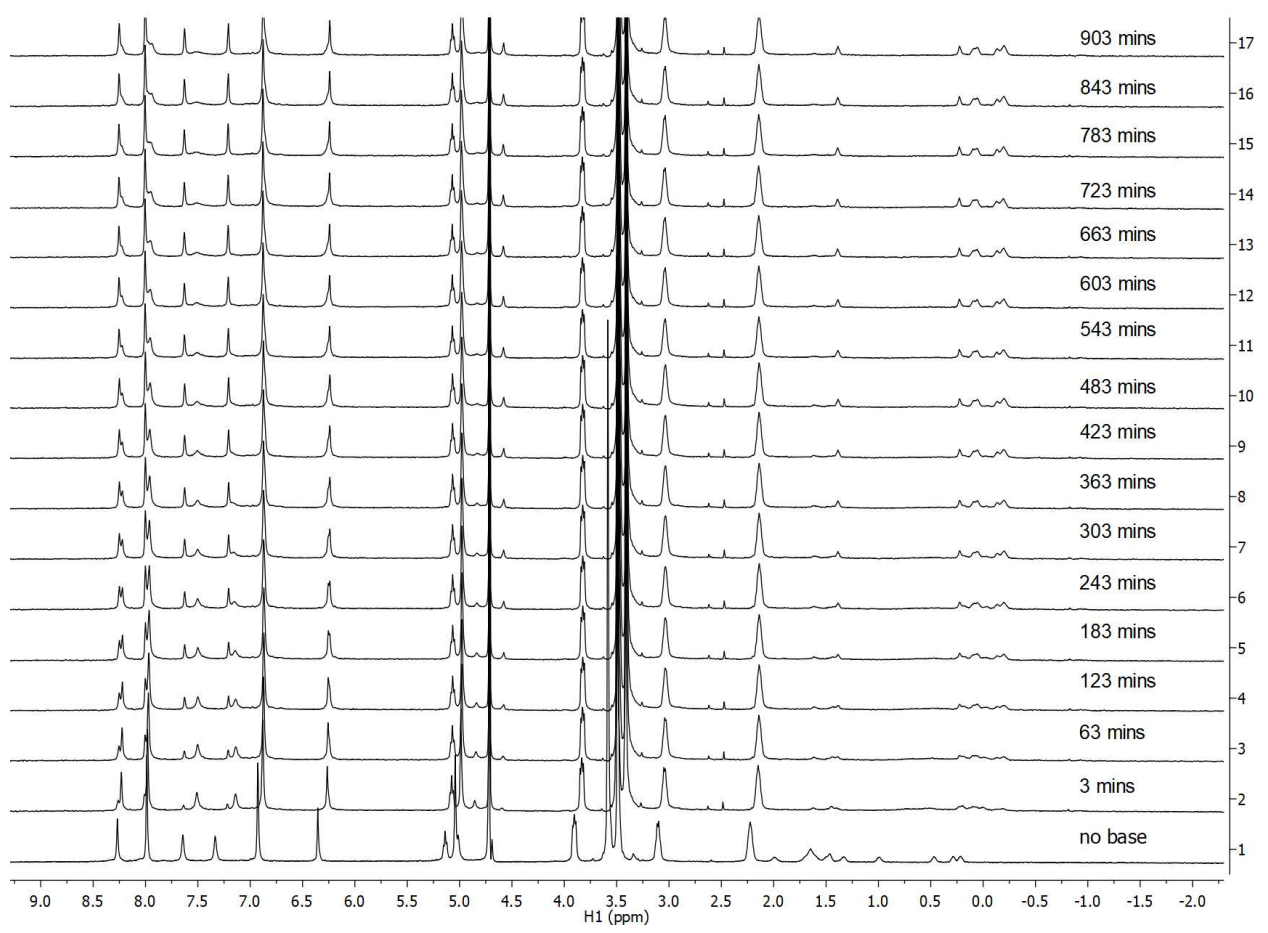

Figure S42: Stack of ${ }^{1} \mathrm{H}$ NMR spectra showing reaction of encapsulated guest 3 inside of $\mathbf{1}_{2}$ with 10 equiv. $\mathrm{NaBr}$ as a function of time. $\left(\mathrm{D}_{2} \mathrm{O}, 339 \mathrm{~K}\right.$, [Host 1] $=1 \mathrm{mM}$, [Guest 3] $=0.5 \mathrm{mM}$, [NaOD] =10 mM).

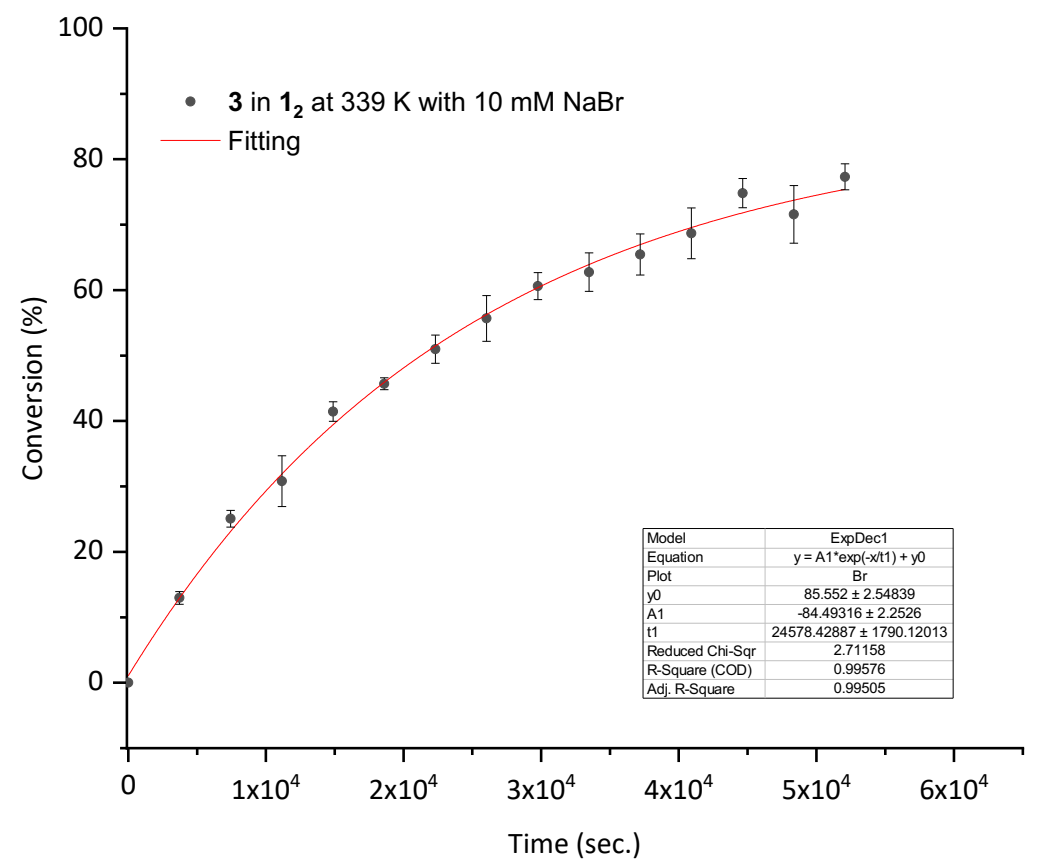

Figure S43: Conversion as a function of time plot for the reaction of guest 3 in $\mathbf{1}_{2}$ in the presence of 10 equiv. $\mathrm{NaBr}$ at $339 \mathrm{~K}$. 


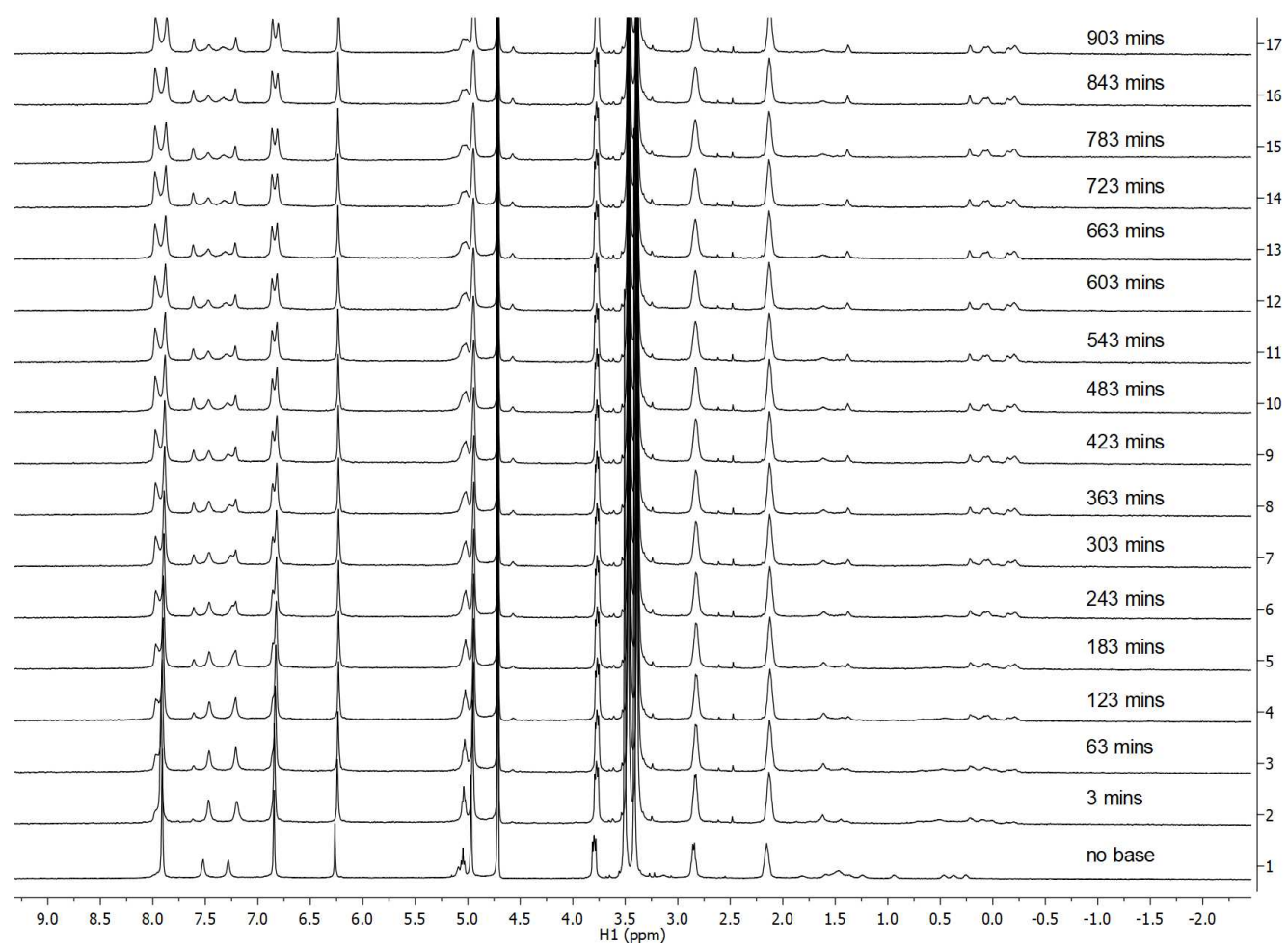

Figure S44: Stack of ${ }^{1} \mathrm{H}$ NMR spectra showing reaction of encapsulated guest $\mathbf{3}$ inside of $\mathbf{1}_{2}$ with 10 equiv. $\mathrm{NaClO}_{4}$ as a function of time. $\left(\mathrm{D}_{2} \mathrm{O}, 339 \mathrm{~K}\right.$, [Host 1] $=1 \mathrm{mM}$, [Guest 3] $=0.5 \mathrm{mM}$, [NaOD] $\left.=10 \mathrm{mM}\right)$.

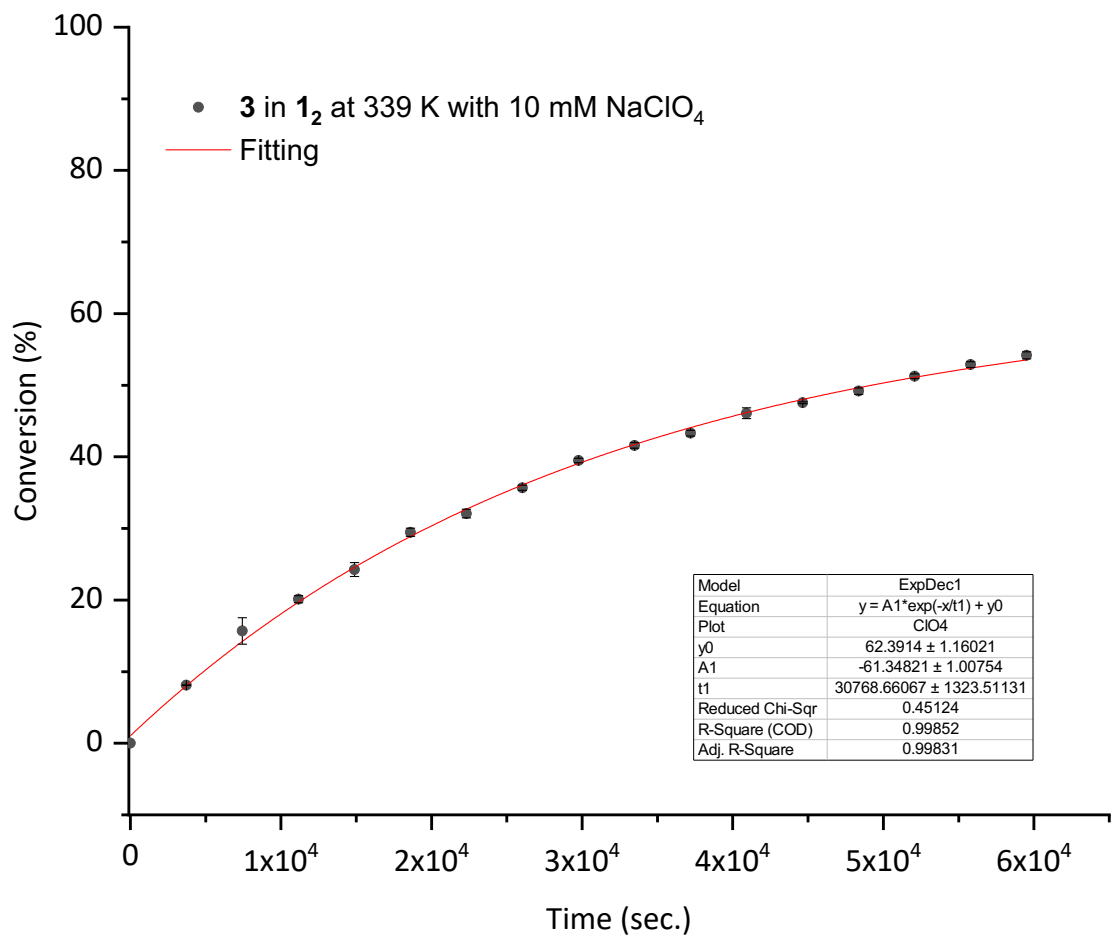

Figure S45: Conversion as a function of time plot for the reaction of guest 3 in $1_{2}$ in the presence of 10 equiv. $\mathrm{NaClO}_{4}$ at $339 \mathrm{~K}$. 


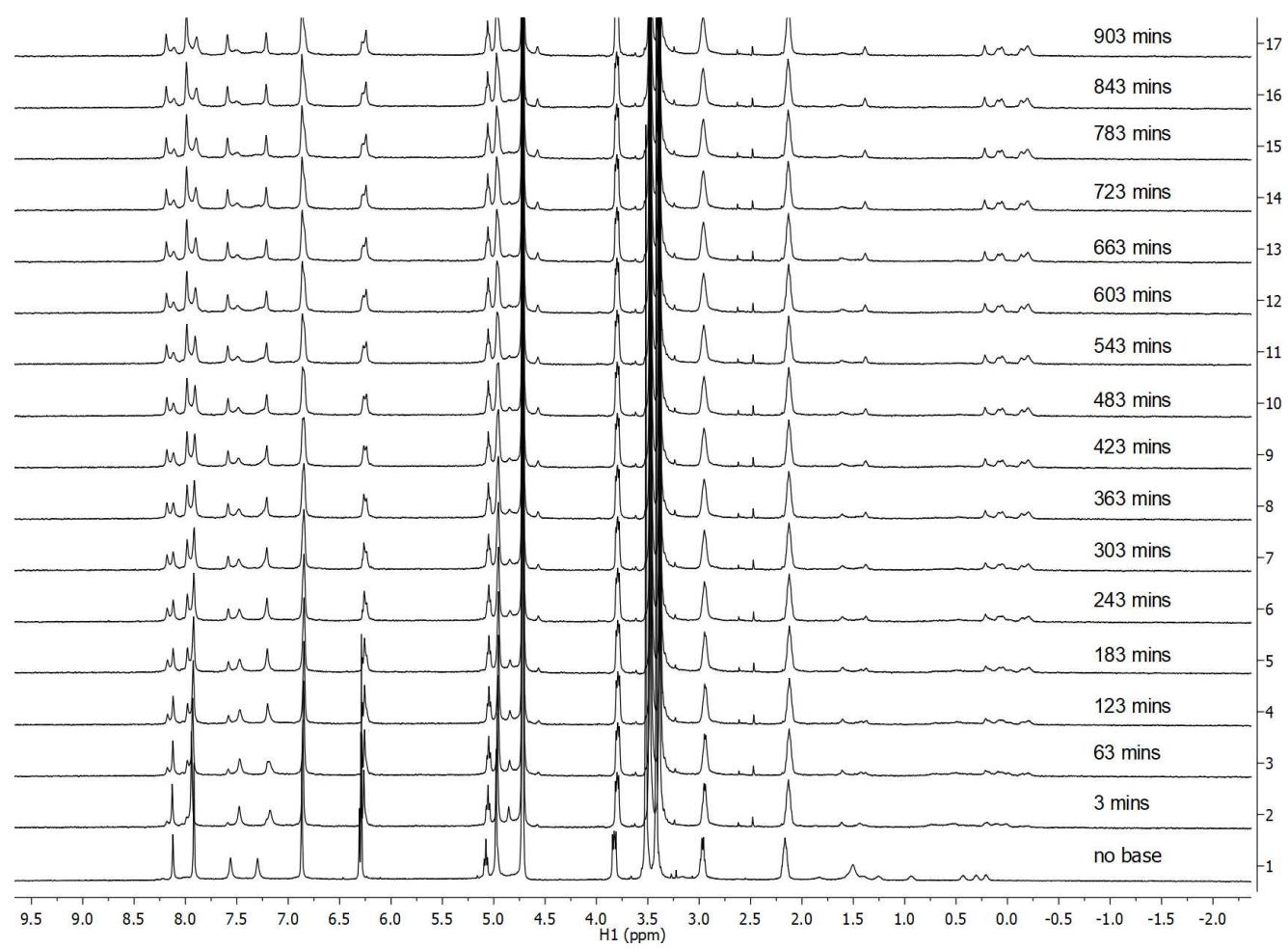

Figure S46: Stack of ${ }^{1} \mathrm{H}$ NMR spectra showing reaction of encapsulated guest $\mathbf{3}$ inside of $\mathbf{1}_{2}$ with 10 equiv. NaDCA as a function of time. $\left(\mathrm{D}_{2} \mathrm{O}, 339 \mathrm{~K}\right.$, [Host 1] $=1 \mathrm{mM}$, [Guest 3] $\left.=0.5 \mathrm{mM},[\mathrm{NaOD}]=10 \mathrm{mM}\right)$.

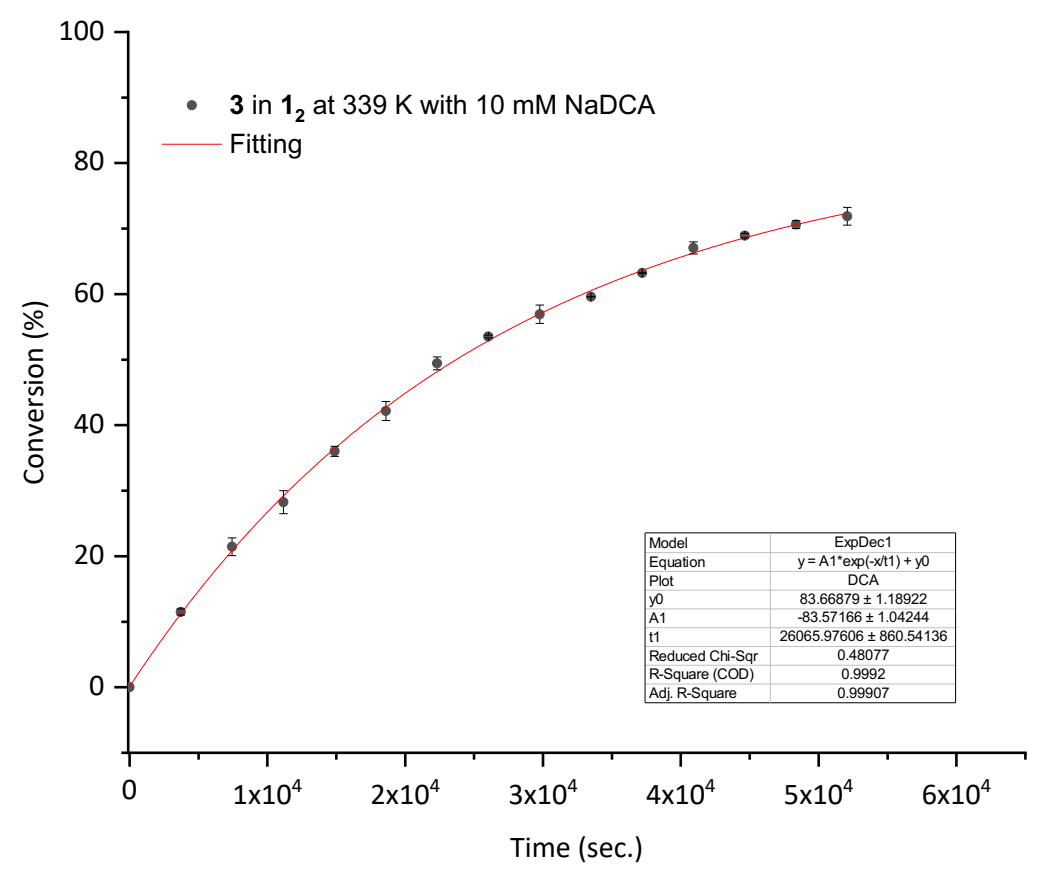

Figure S47: Conversion as a function of time plot for the reaction of guest $\mathbf{3}$ in $\mathbf{1}_{2}$ in the presence of 10 equiv. NaDCA at $339 \mathrm{~K}$. 


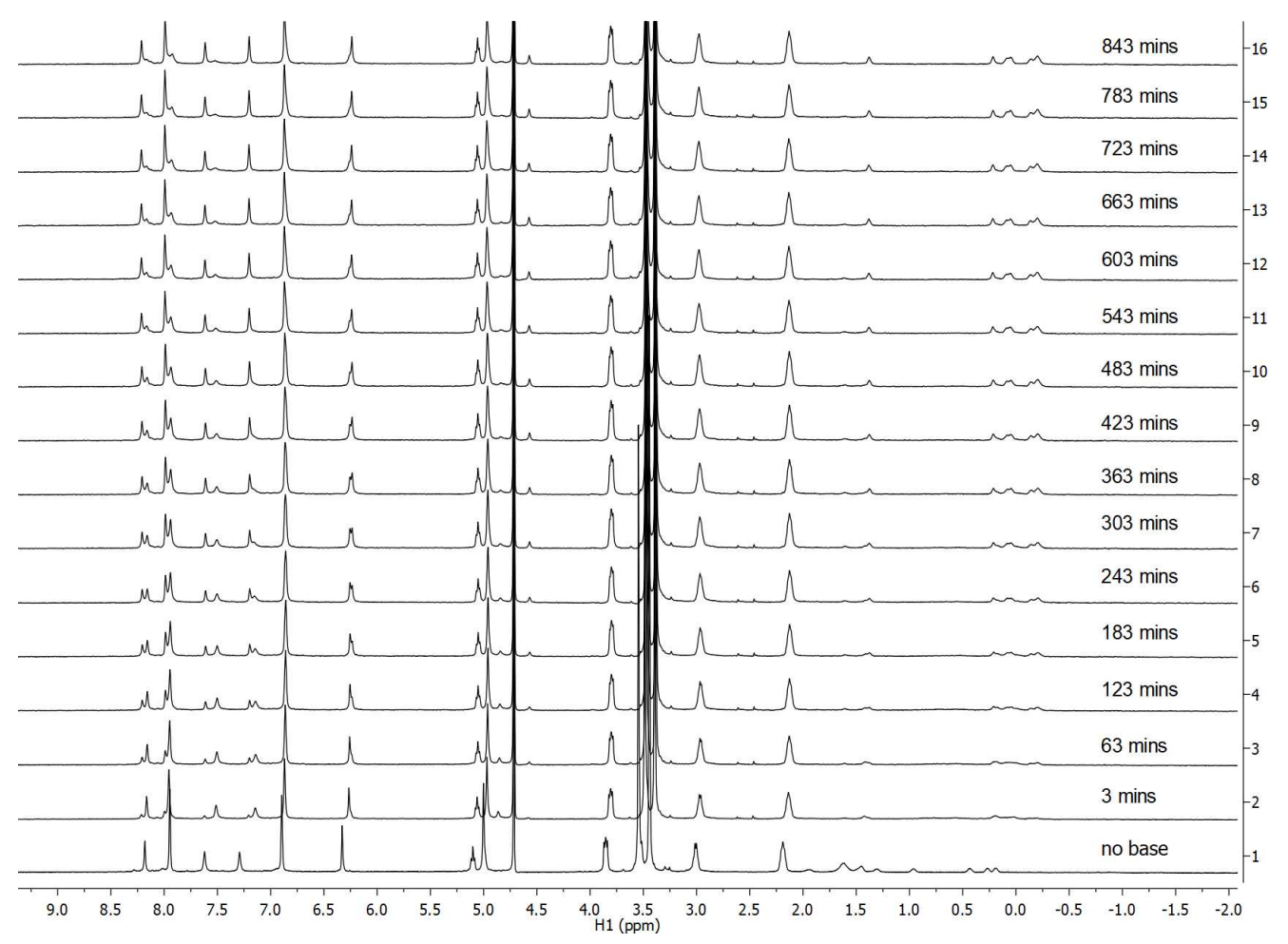

Figure S48: Stack of ${ }^{1} \mathrm{H}$ NMR spectra showing reaction of encapsulated guest 3 inside of $\mathbf{1}_{2}$ with 10 equiv. NaF as a function of time. $\left(\mathrm{D}_{2} \mathrm{O}, 339 \mathrm{~K}\right.$, [Host 1] $=1 \mathrm{mM}$, [Guest 3] $\left.=0.5 \mathrm{mM},[\mathrm{NaOD}]=10 \mathrm{mM}\right)$.

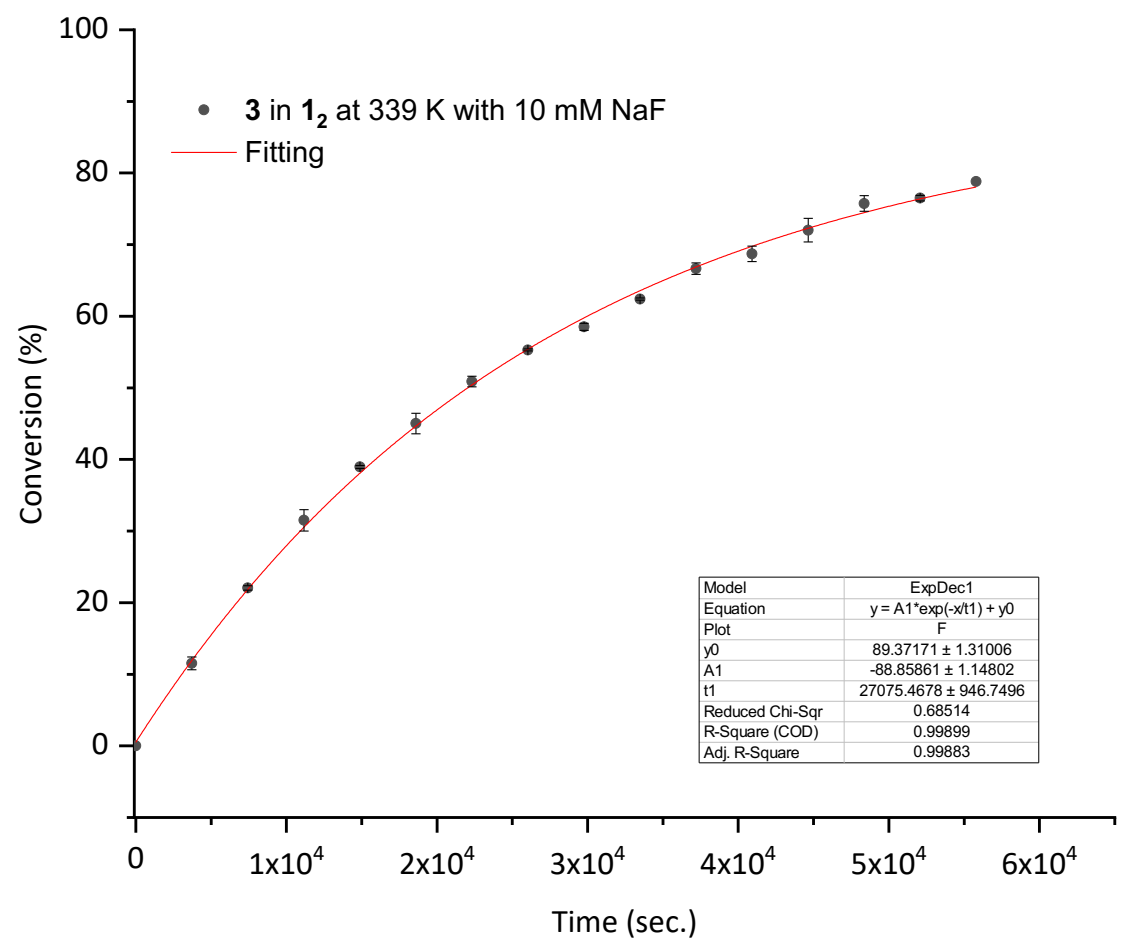

Figure S49: Conversion as a function of time plot for the reaction of guest 3 in $1_{2}$ in the presence of 10 equiv. $\mathrm{NaF}$ at $339 \mathrm{~K}$. 


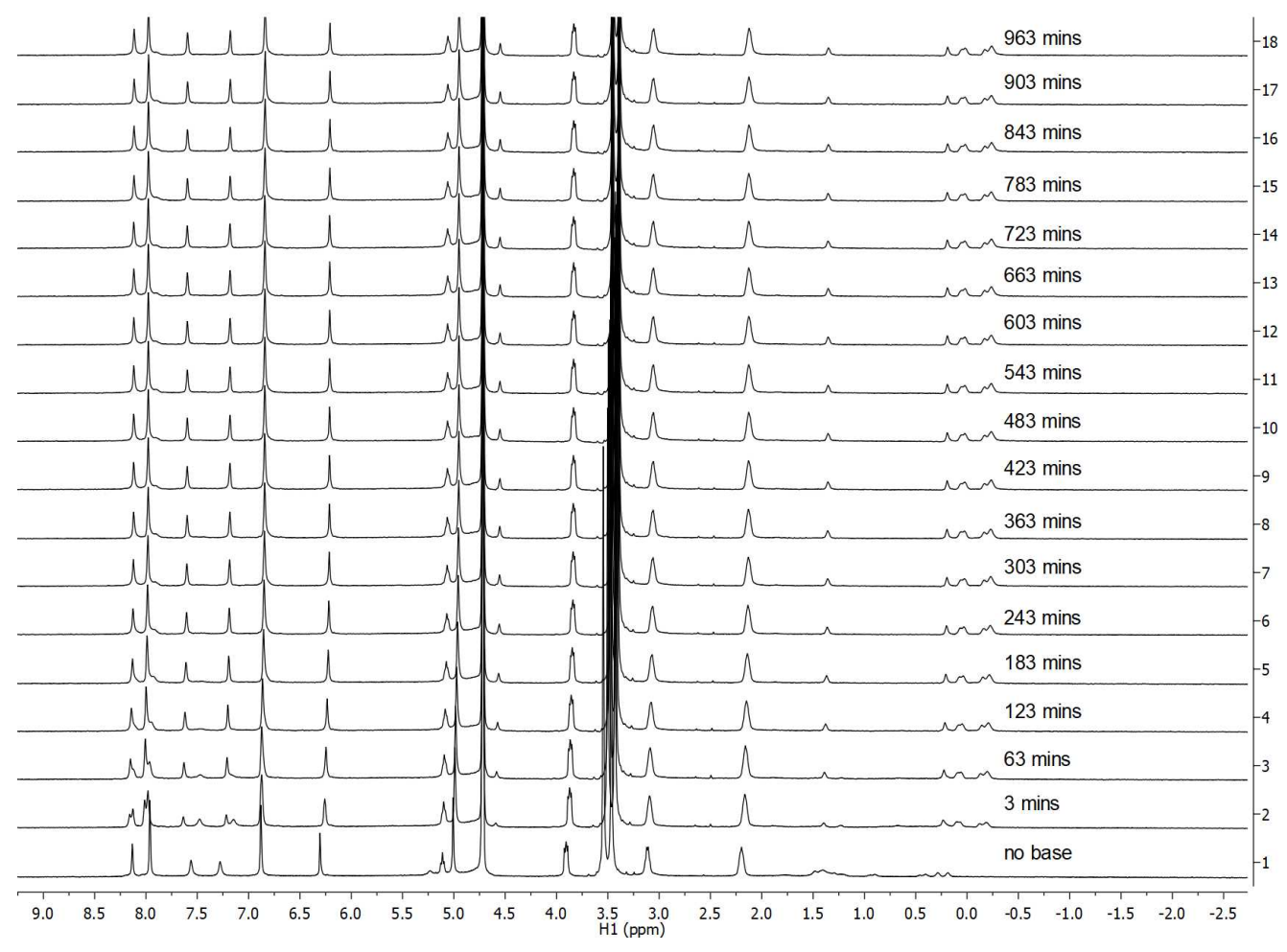

Figure S50: Stack of ${ }^{1} \mathrm{H}$ NMR spectra showing reaction of encapsulated guest 3 inside of $1_{2}$ with 10 equiv. Nal as a function of time. $\left(\mathrm{D}_{2} \mathrm{O}, 339 \mathrm{~K}\right.$, [Host 1] $=1 \mathrm{mM}$, [Guest 3] $\left.=0.5 \mathrm{mM},[\mathrm{NaOD}]=10 \mathrm{mM}\right)$.

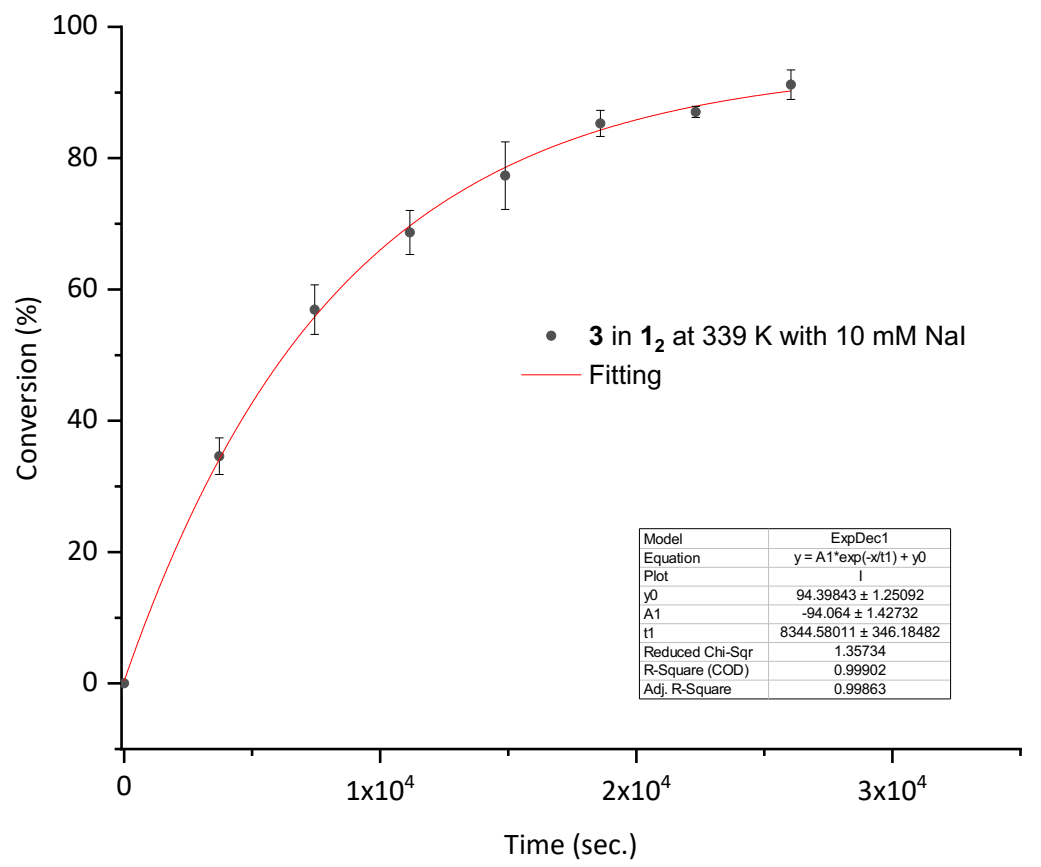

Figure S51: Conversion as a function of time plot for the reaction of guest $\mathbf{3}$ in $\mathbf{1}_{2}$ in the presence of 10 equiv. Nal at $339 \mathrm{~K}$. 


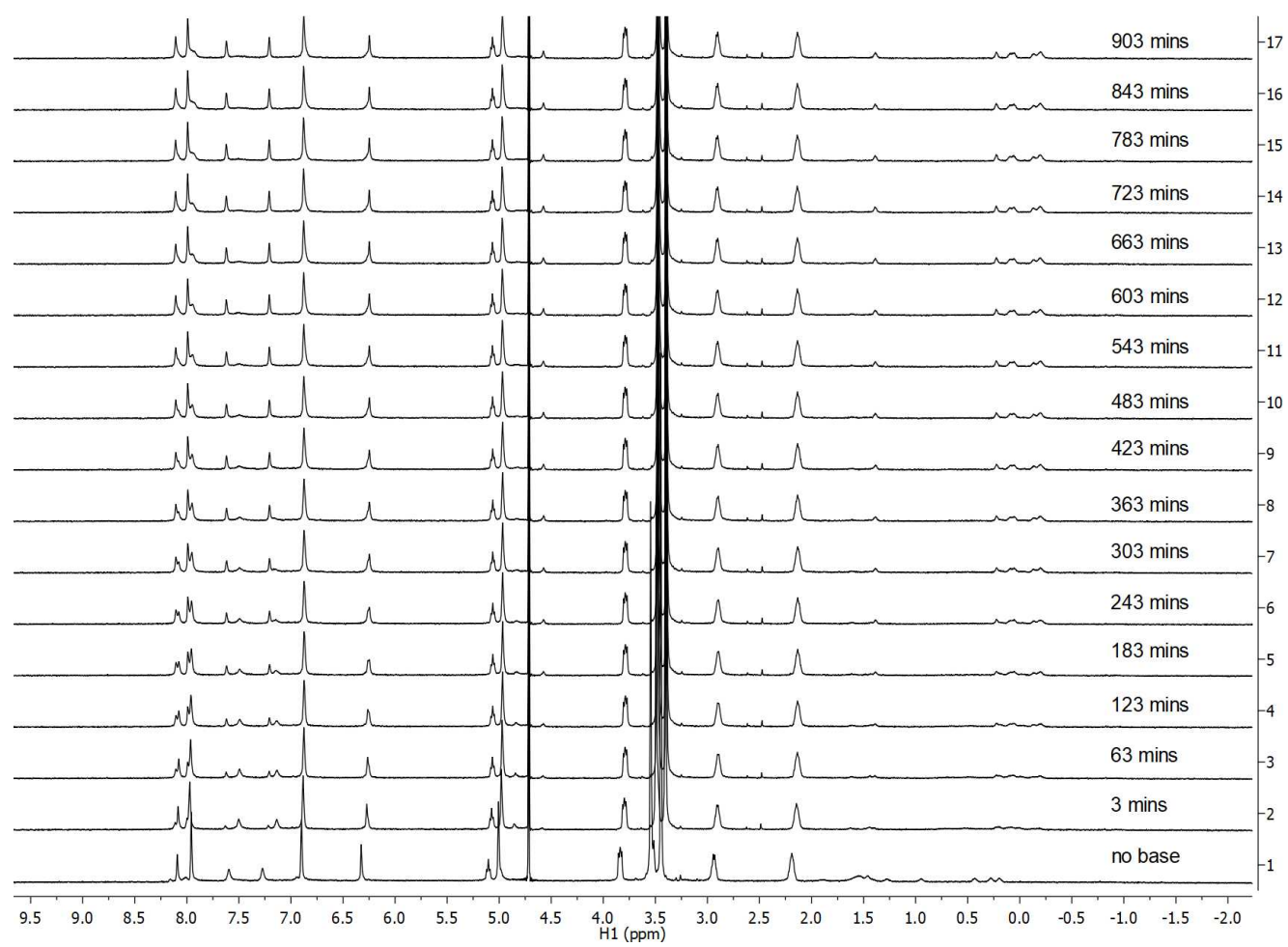

Figure S52: Stack of ${ }^{1} \mathrm{H}$ NMR spectra showing reaction of encapsulated guest 3 inside of $\mathbf{1}_{2}$ with 10 equiv. $\mathrm{NaNO}_{3}$ as a function of time. $\left(\mathrm{D}_{2} \mathrm{O}, 339 \mathrm{~K}\right.$, [Host 1] $=1 \mathrm{mM}$, [Guest 3] $\left.=0.5 \mathrm{mM},[\mathrm{NaOD}]=10 \mathrm{mM}\right)$.

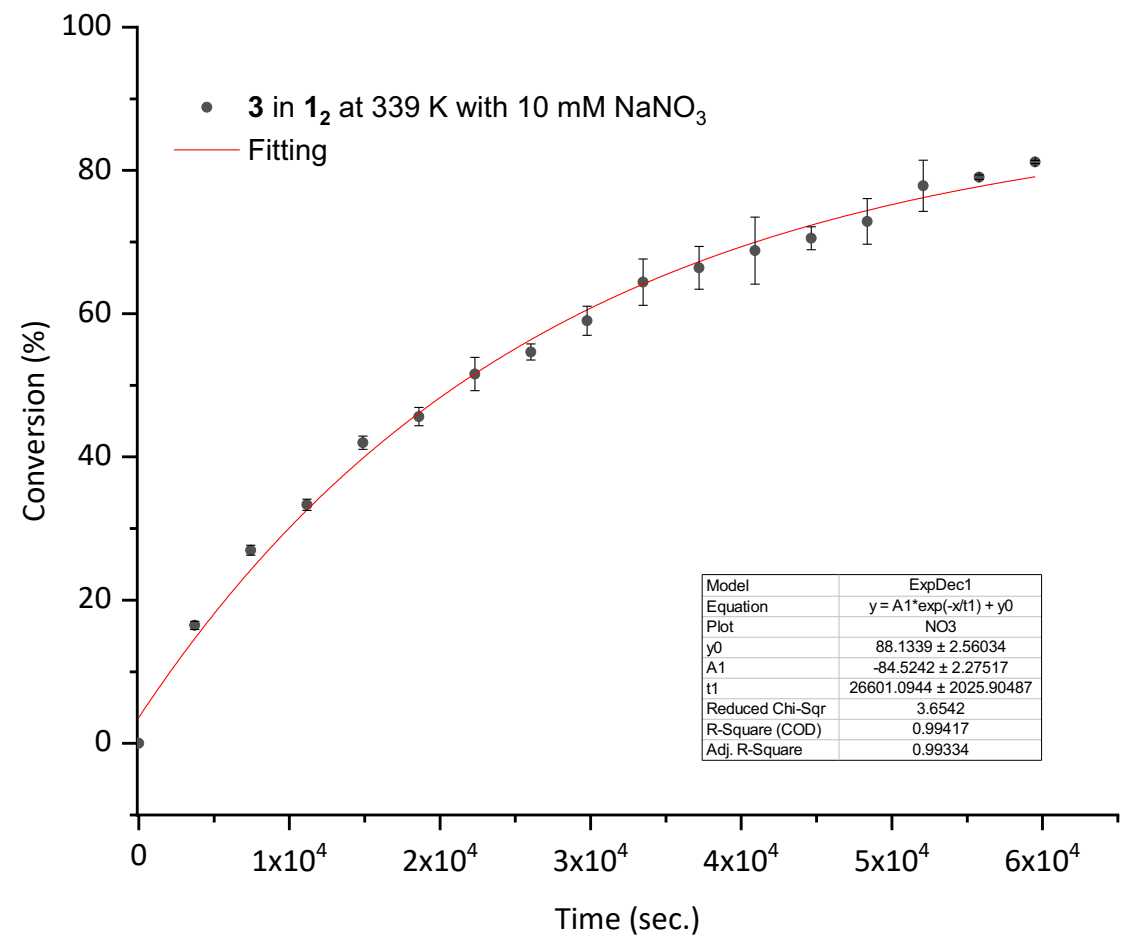

Figure S53: Conversion as a function of time plot for the reaction of guest $\mathbf{3}$ in $\mathbf{1}_{2}$ in the presence of 10 equiv. $\mathrm{NaNO}_{3}$ at $339 \mathrm{~K}$. 


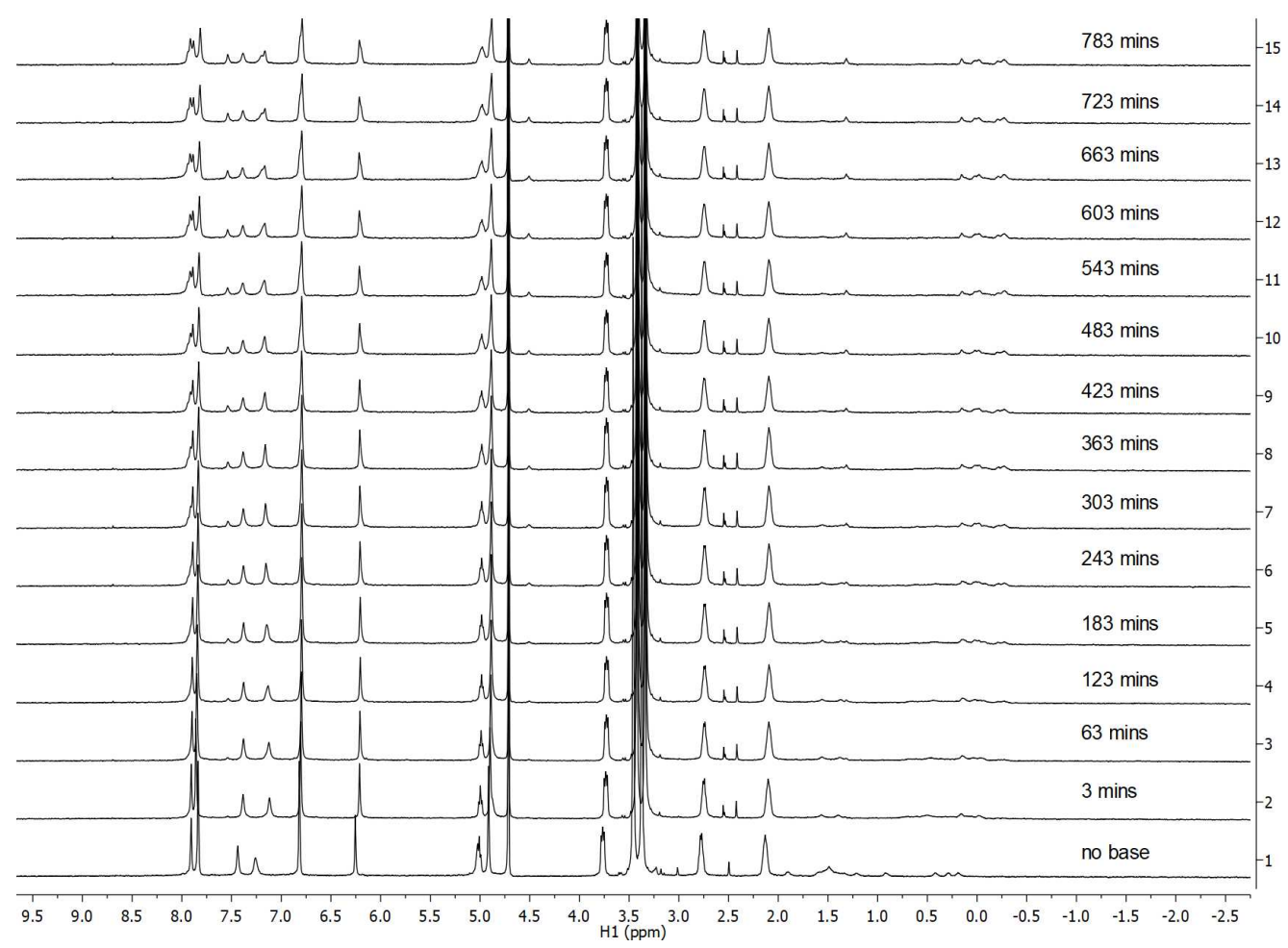

Figure S54: Stack of ${ }^{1} \mathrm{H}$ NMR spectra showing reaction of encapsulated guest 3 inside of $\mathbf{1}_{2}$ with 10 equiv. $\mathrm{NaReO}_{4}$ as a function of time. $\left(\mathrm{D}_{2} \mathrm{O}, 339 \mathrm{~K}\right.$, [Host 1] $=1 \mathrm{mM}$, [Guest 3] $\left.=0.5 \mathrm{mM},[\mathrm{NaOD}]=10 \mathrm{mM}\right)$.

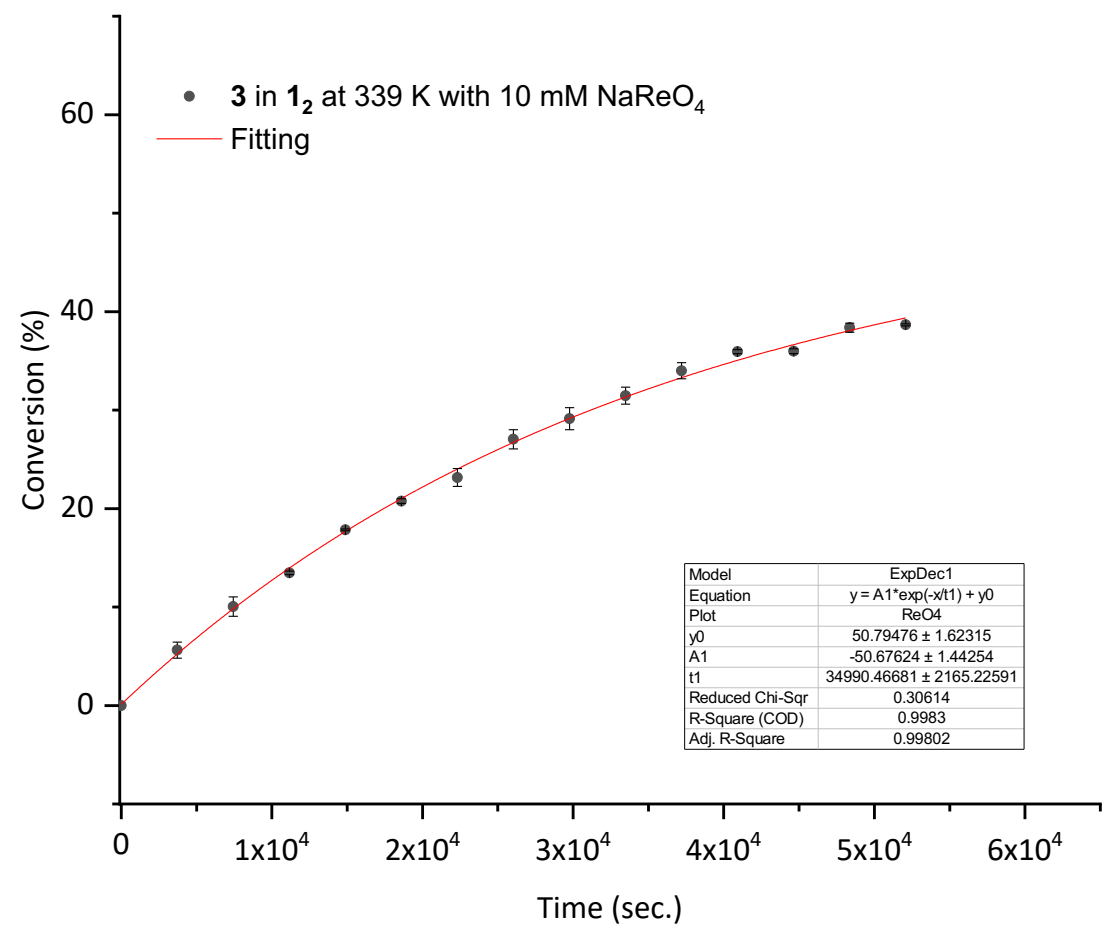

Figure S55: Conversion as a function of time plot for the reaction of guest $\mathbf{3}$ in $\mathbf{1}_{\mathbf{2}}$ in the presence of 10 equiv. $\mathrm{NaReO}_{4}$ at $339 \mathrm{~K}$. 


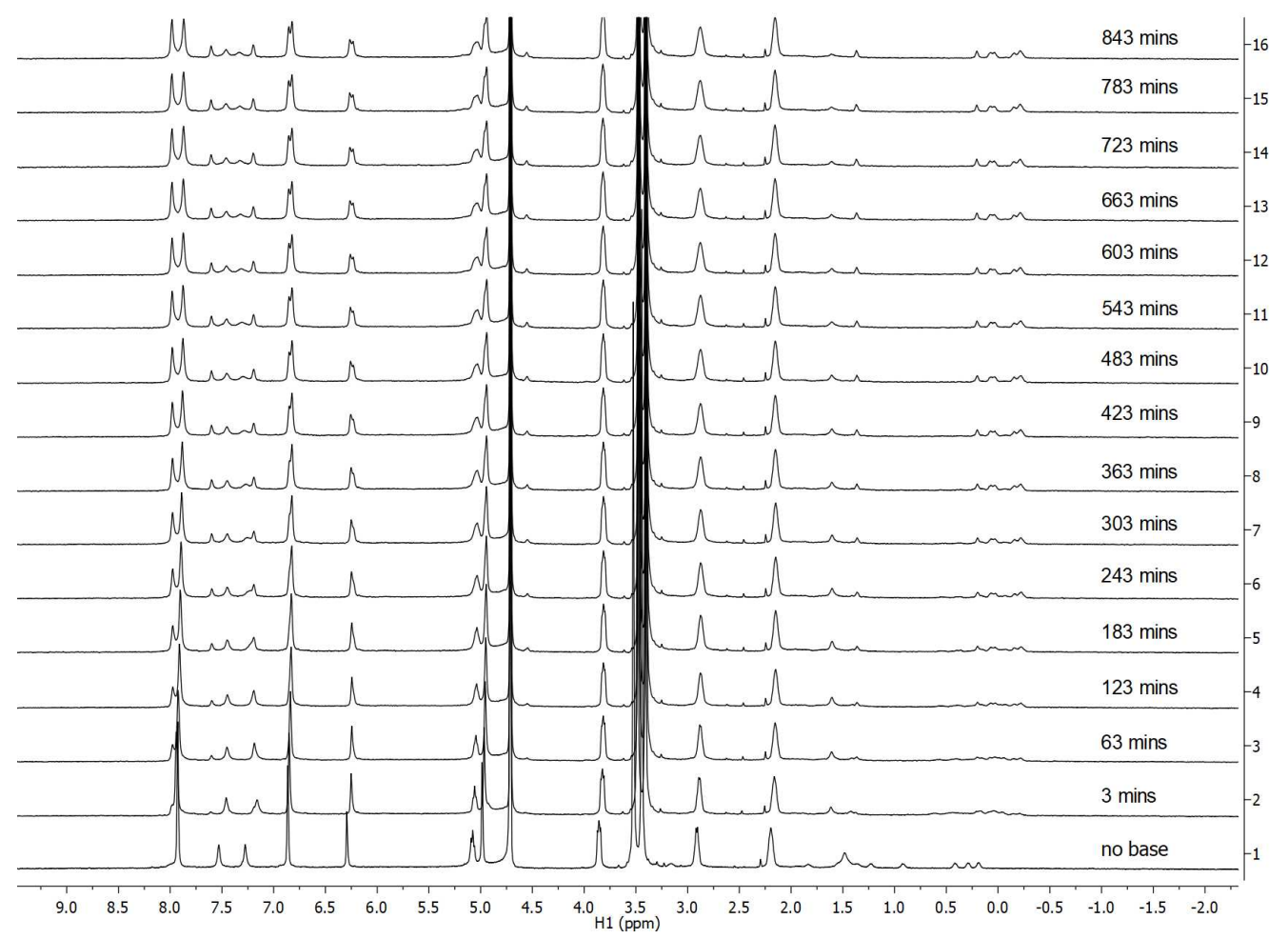

Figure S56: Stack of ${ }^{1} \mathrm{H}$ NMR spectra showing reaction of encapsulated guest $\mathbf{3}$ inside of $\mathbf{1}_{2}$ with 10 equiv. NaSCN as a function of time. $\left(\mathrm{D}_{2} \mathrm{O}, 339 \mathrm{~K}\right.$, [Host 1] $=1 \mathrm{mM}$, [Guest 3] $\left.=0.5 \mathrm{mM},[\mathrm{NaOD}]=10 \mathrm{mM}\right)$.

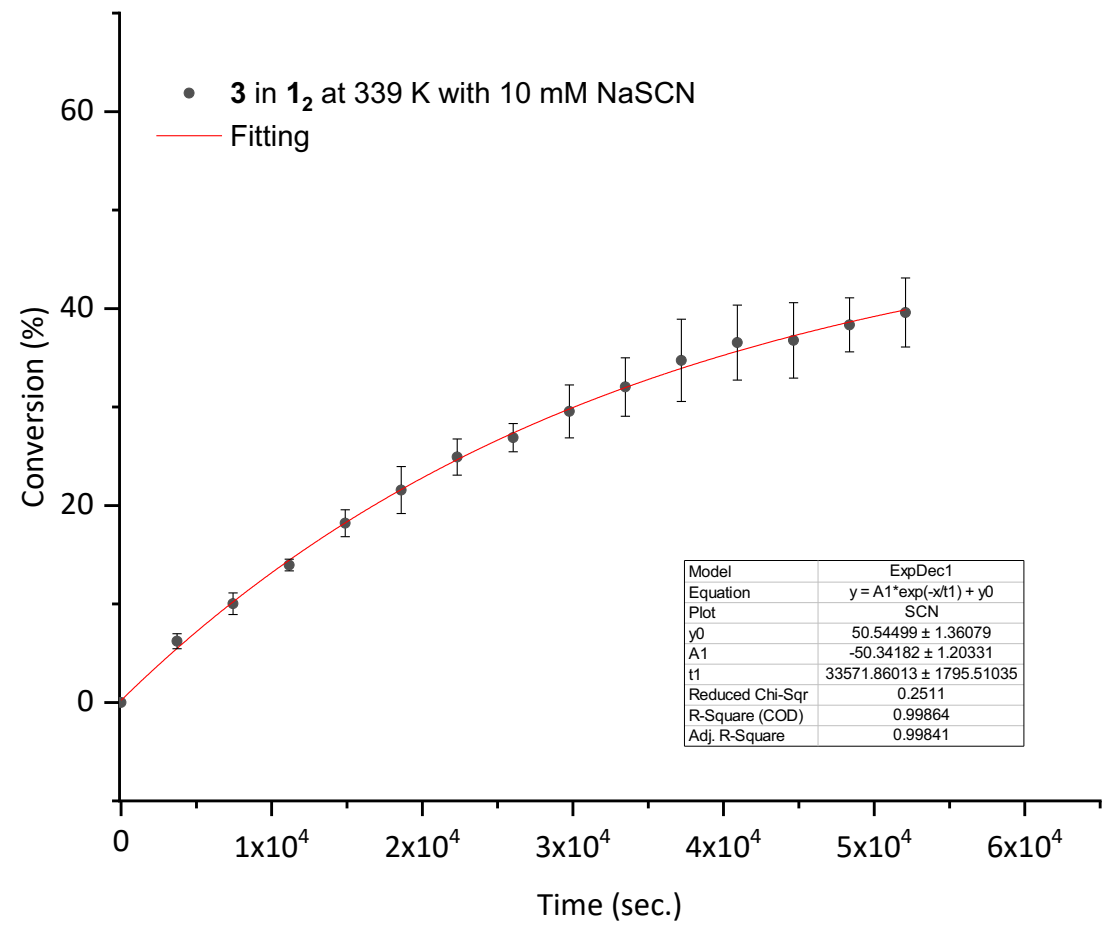

Figure S57 Conversion as a function of time plot for the reaction of guest $\mathbf{3}$ in $\mathbf{1}_{2}$ in the presence of 10 equiv. NaSCN at $339 \mathrm{~K}$. 


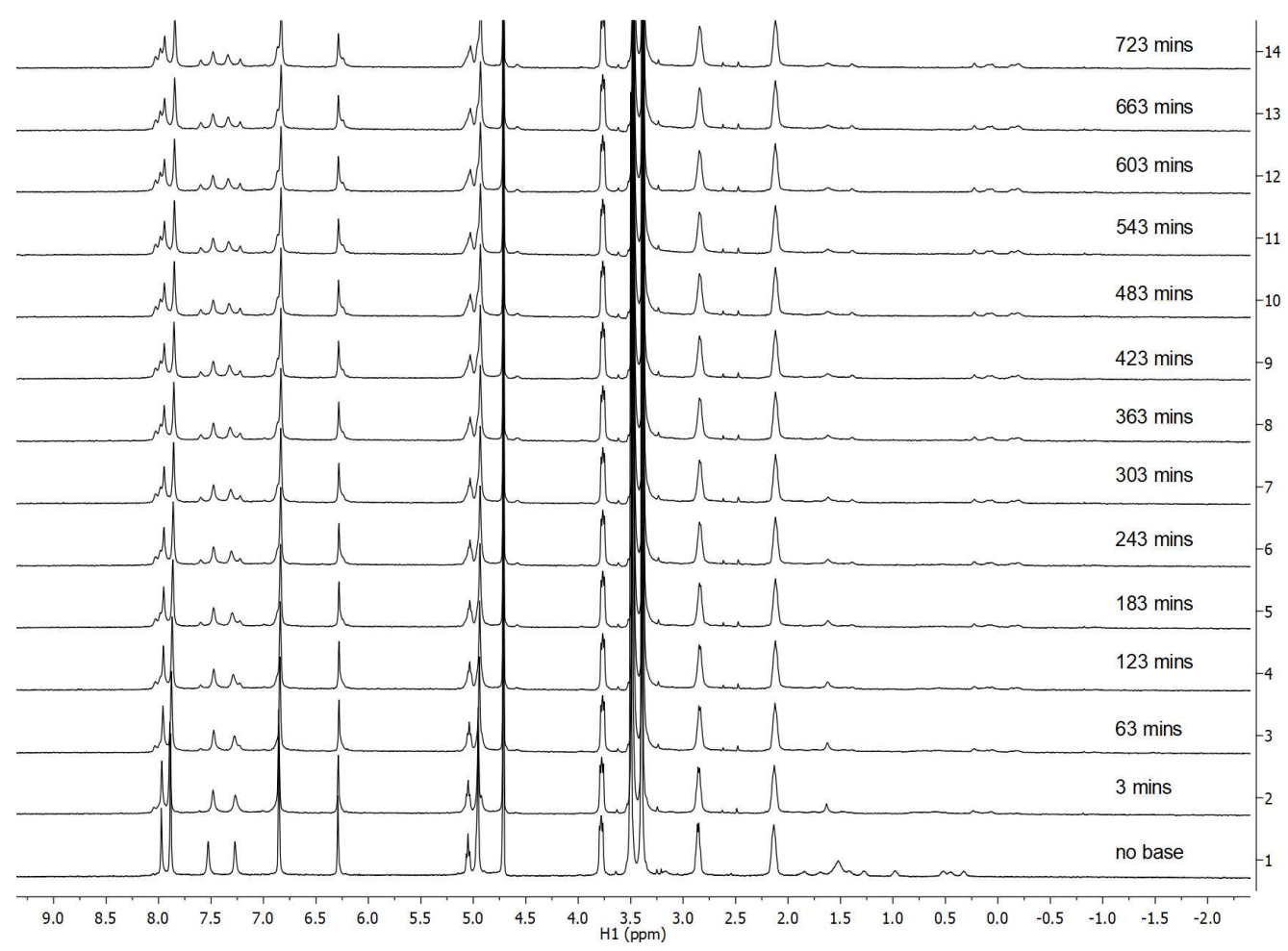

Figure S58 Stack of ${ }^{1} \mathrm{H}$ NMR spectra showing reaction of encapsulated guest 3 inside of $\mathbf{1}_{2}$ with 10 equiv. NaOTf as a function of time. $\left(\mathrm{D}_{2} \mathrm{O}, 339 \mathrm{~K}\right.$, [Host 1] $=1 \mathrm{mM}$, [Guest 3] $\left.=0.5 \mathrm{mM},[\mathrm{NaOD}]=10 \mathrm{mM}\right)$.

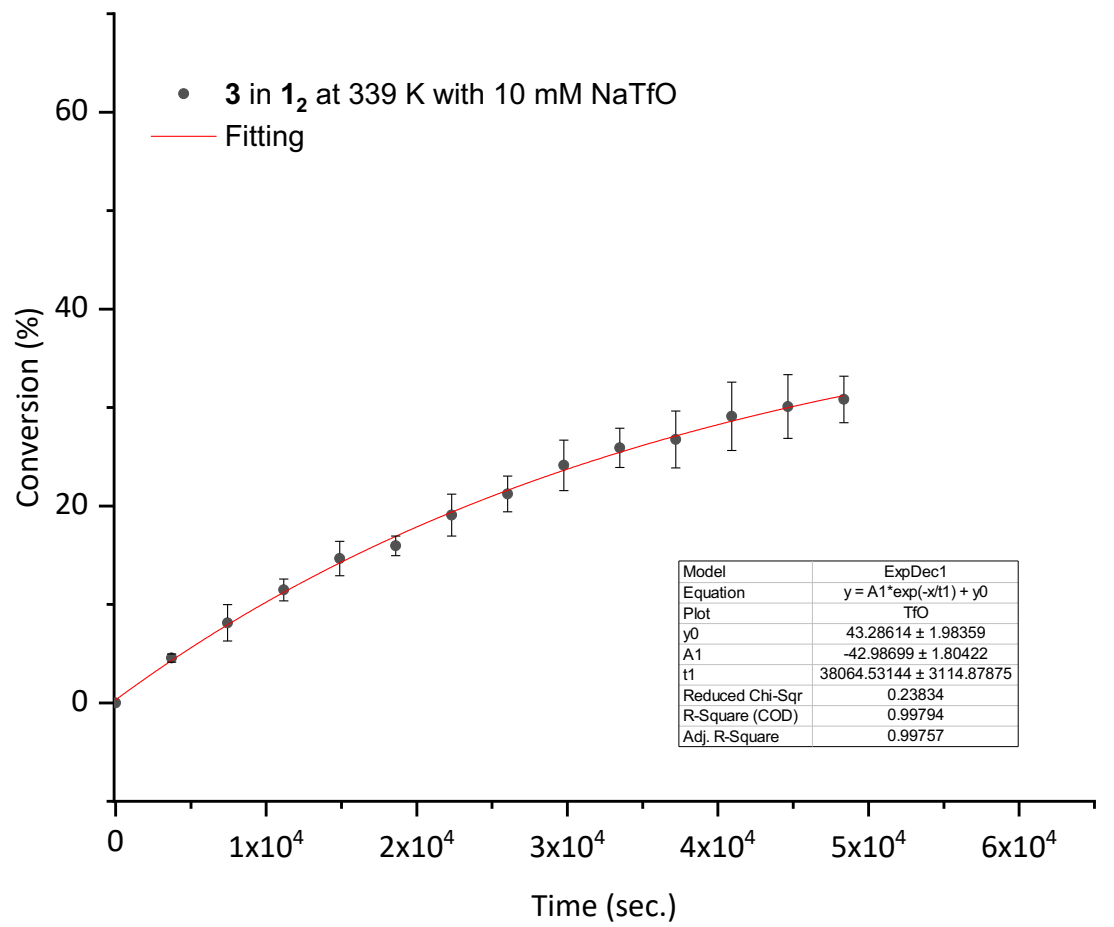

Figure S59: Conversion as a function of time plot for the reaction of guest 3 in $1_{2}$ in the presence of 10 equiv. NaOTf at $339 \mathrm{~K}$. 


\section{6) Cyclization of 3 within $2_{2}$ in the presence of various salts}

We also studied how the presence of cations impacted the cyclization rate of $\mathbf{3}$ within the capsule formed by 2 . Six cations were selected: $\mathrm{Na}^{+}, \mathrm{Li}^{+}, \mathrm{K}^{+}, \mathrm{Rb}^{+}, \mathrm{Cs}^{+}$and tetramethylammonium $\left(\mathrm{TMA}^{+}\right)$. Figures $\mathbf{S 6 0}-\mathbf{S 7 6}$ show the corresponding data for reactions carried out with the same protocol but in the presence of $10 \mathrm{mM}$ of the cations (as their chloride salts). The experiments were performed with $0.5 \mathrm{~mL}$ samples of $1.0 \mathrm{mM}$ host 2 in $\mathrm{D}_{2} \mathrm{O}$ at $336 \mathrm{~K}$. In each case, a small volume of $400 \mathrm{mM}$ salt solution was added to make a $10 \mathrm{mM}$ salt solution of the complex. 


\section{1) Cation effect: Summary of Data}

Figures S60 and S61 show the ${ }^{1} \mathrm{H}$ NMR spectra of the complex with $\mathbf{2}_{2}$ in the presence of $10 \mathrm{mM}$ salt.

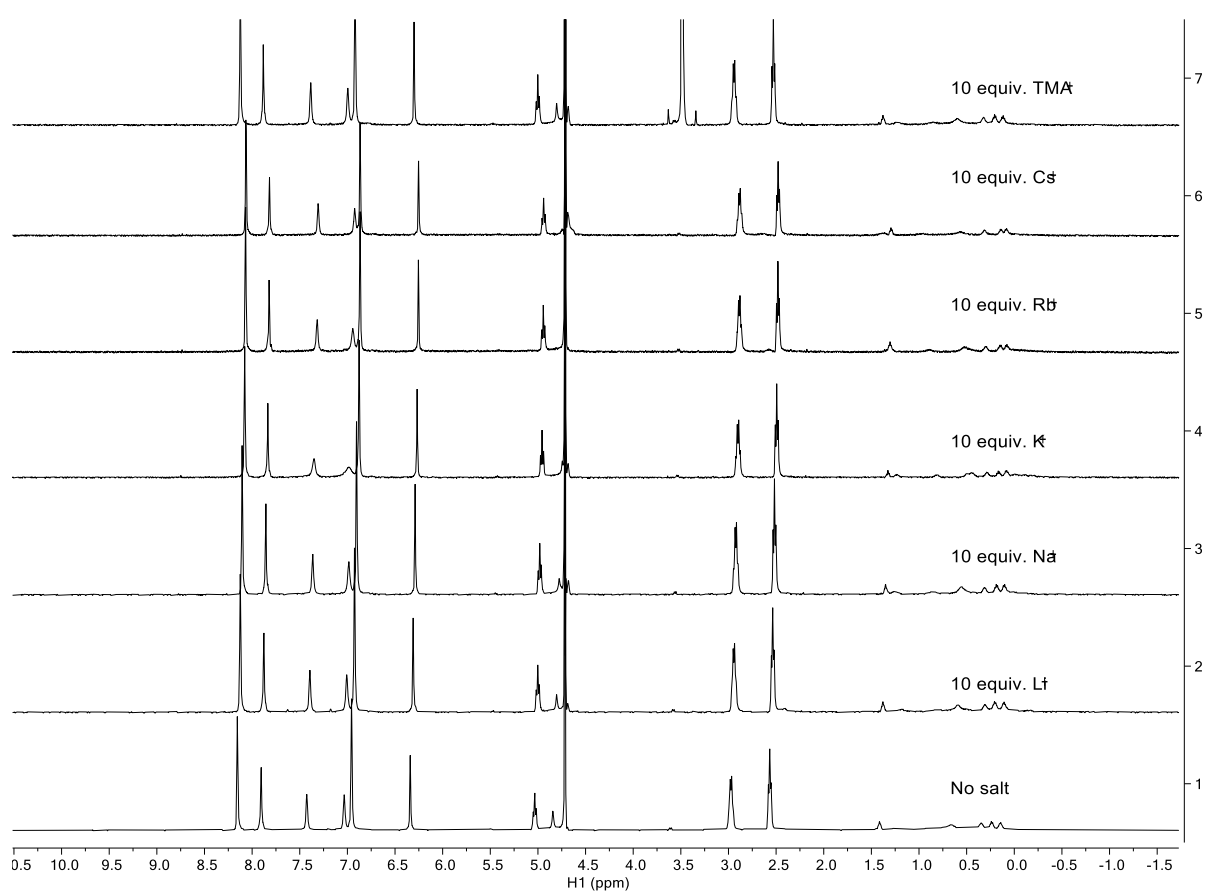

Figure S60: Stack of ${ }^{1} \mathrm{H}$ NMR spectra of $\mathbf{3}$ in $\mathbf{2}_{2}$ in the presence of various of cation at $336 \mathrm{~K}$

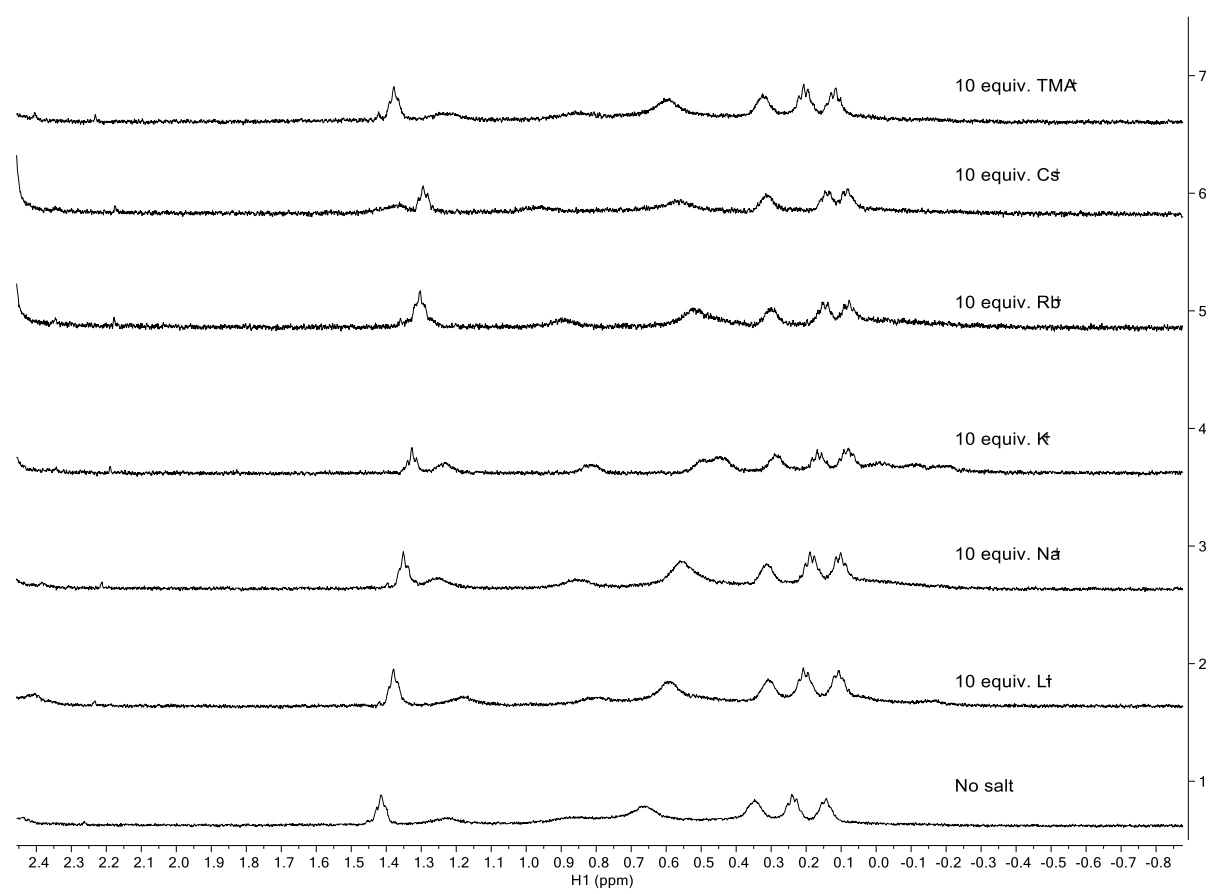

Figure S61: Stack of ${ }^{1} \mathrm{H}$ NMR spectra of 3 in $2_{2}$ guest region in the presence of various of cation at $336 \mathrm{~K}$ 
The extent of reaction of each experiment was determined by tracking and integrating the ${ }^{1} \mathrm{H}$ NMR signal from the $\mathrm{H}_{\mathrm{d}}$ proton (Mnova), and fitting this data as a function of time to give the rate constant data (Origin Pro 2018. Figure S39 shows the cumulative data for all the salts. Each experiment was carried out in duplicate (error bars shown), with the average calculated used to give the rate constant (Table 3). Errors were $<10 \%$.

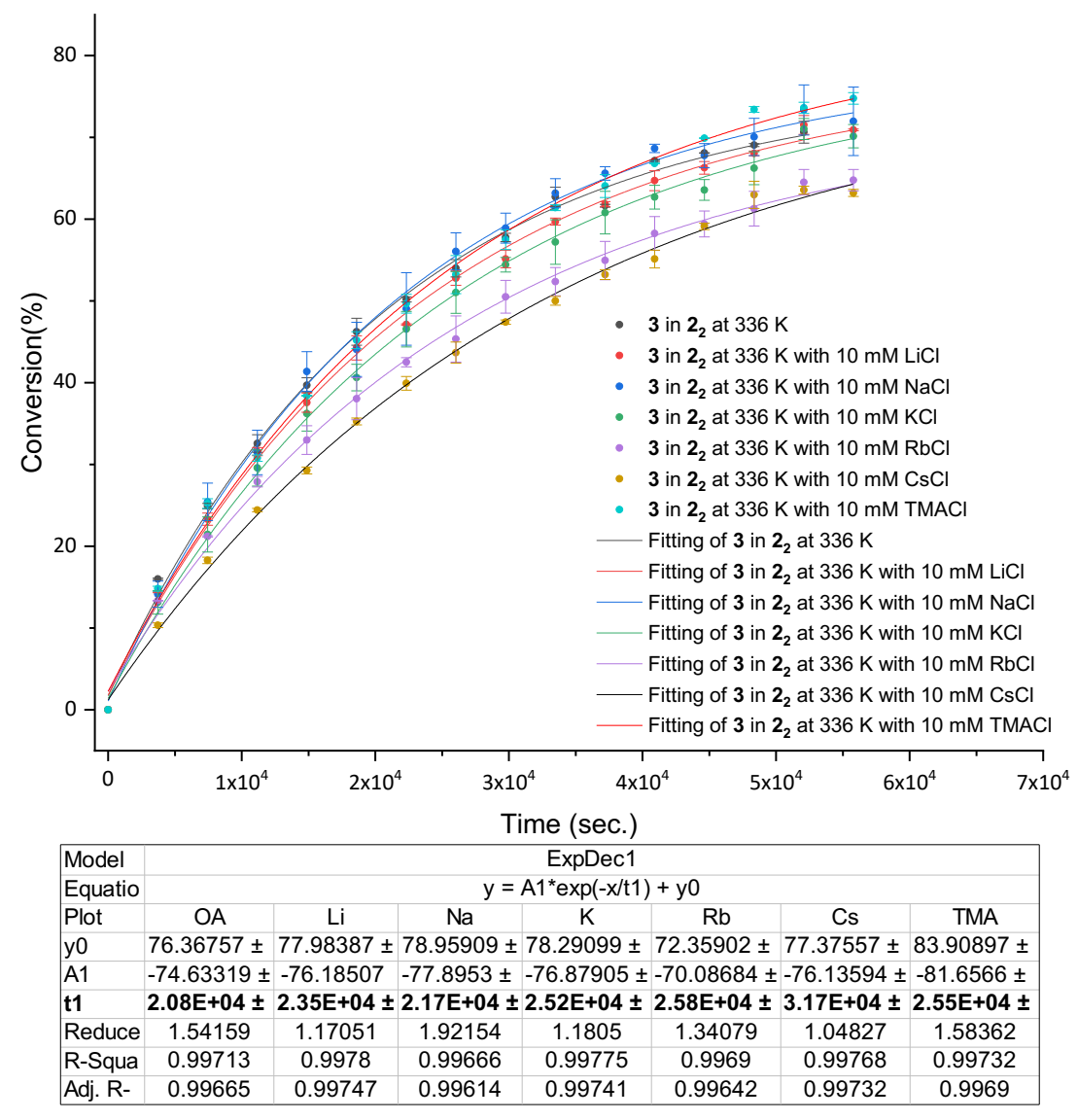

Figure S62: Overall conversions as a function of time for the reaction of guest $\mathbf{3}$ in $\mathbf{2}_{2}$ in the presence of 10 equiv. different cation at $336 \mathrm{~K}$ (top), and summary of kinetic parameters from fitting to Eq. 2 (bottom).

Table 3. The reaction rate $(k)$ of $\mathbf{3}$ in $\mathbf{2}$ in the presence of different cations at $336 \mathrm{~K}$.

\begin{tabular}{cc}
\hline Salt & Rate Constant, $\boldsymbol{k}$ in $\mathbf{1 0}^{-5} \mathbf{s}^{-\mathbf{1}}$ \\
\hline No salt & 4.81 \\
$\mathrm{Na}^{+}$ & 4.61 \\
$\mathrm{Li}^{+}$ & 4.26 \\
$\mathrm{~K}^{+}$ & 3.97 \\
$\mathrm{TMA}^{+}$ & 3.92 \\
$\mathrm{Rb}^{+}$ & 3.88 \\
$\mathrm{Cs}^{+}$ & 3.15 \\
\hline
\end{tabular}




\section{2) Cation effect: Individual data}

The reaction rate in each experiment was determined by tracking and integrating the " $d$ " peak in the ${ }^{1} \mathrm{H}$ NMR spectroscopy using Mnova, then fitted the integrations as a function of time to give the kinetic data with Origin Pro 2018. Lines fitted by the first order kinetic model are demonstrated in red and the standard deviations are shown as error bars. Each experiment was carried out in duplicates, with the average calculated to give the corresponding rate constants. Errors were $<10 \%$.

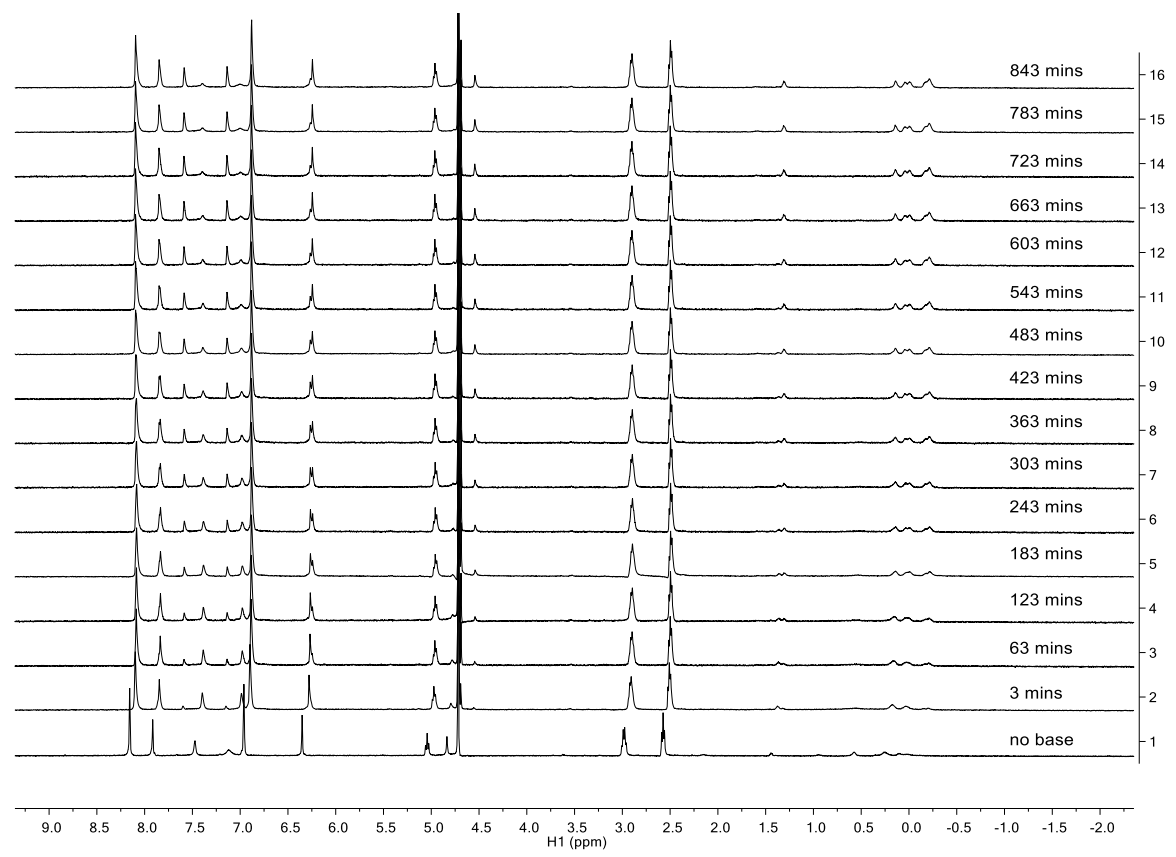

Figure S63: Stack of ${ }^{1} \mathrm{H}$ NMR spectra showing reaction of encapsulated guest $\mathbf{3}$ inside of $\mathbf{2}_{2}$ as a function of time. $\left(\mathrm{D}_{2} \mathrm{O}, 336 \mathrm{~K},[\right.$ Host 2] $=1 \mathrm{mM},[$ Guest 3] $=0.5 \mathrm{mM},[\mathrm{NaOD}]=10 \mathrm{mM})$.

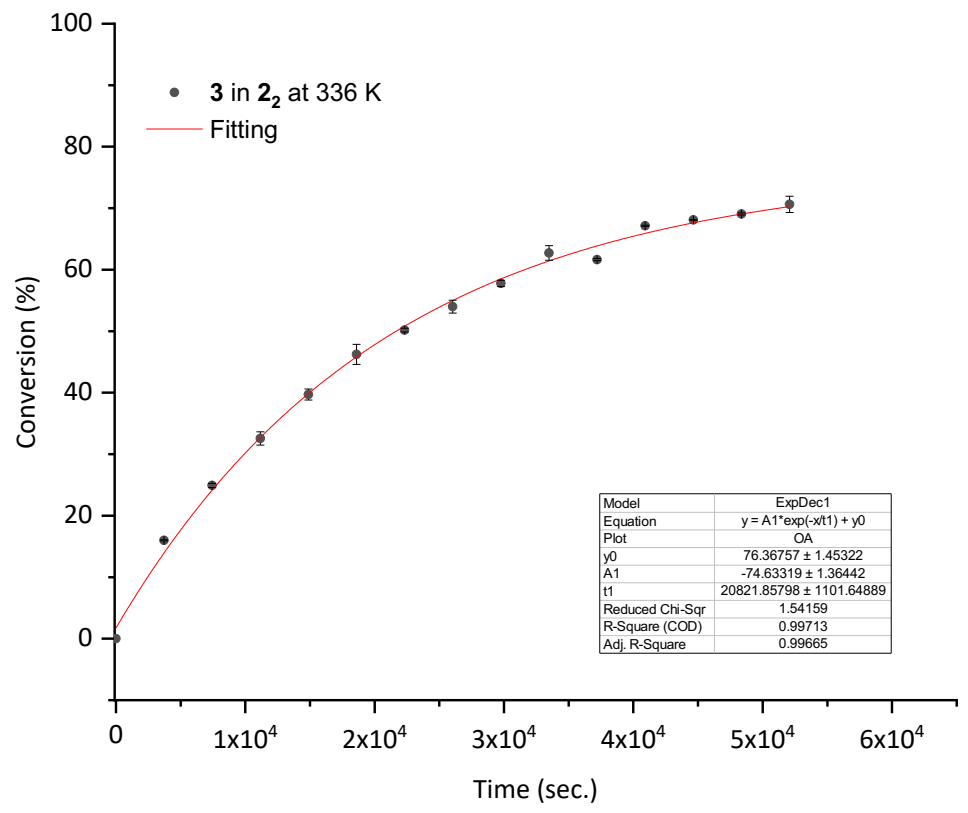

Figure S64: Conversion as a function of time plot for the reaction of guest 3 in $\mathbf{2}_{2}$ at $336 \mathrm{~K}$. 


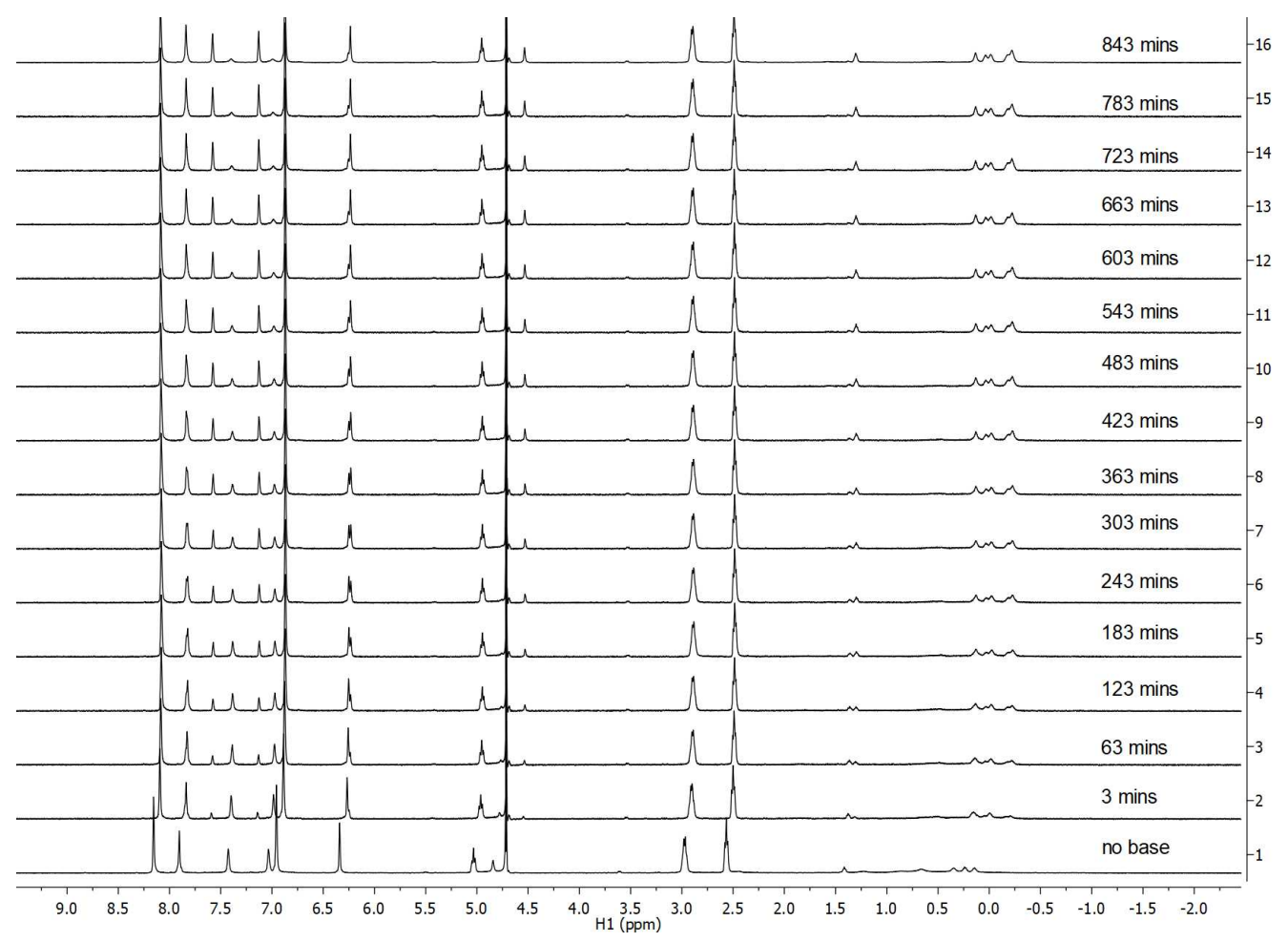

Figure S65: Stack of ${ }^{1} \mathrm{H}$ NMR spectra showing reaction of encapsulated guest 3 inside of $\mathbf{2}_{2}$ with 10 equiv. LiCl as a function of time. $\left(\mathrm{D}_{2} \mathrm{O}, 336 \mathrm{~K}\right.$, [Host 2] $=1 \mathrm{mM}$, [Guest 3] $\left.=0.5 \mathrm{mM},[\mathrm{NaOD}]=10 \mathrm{mM}\right)$.

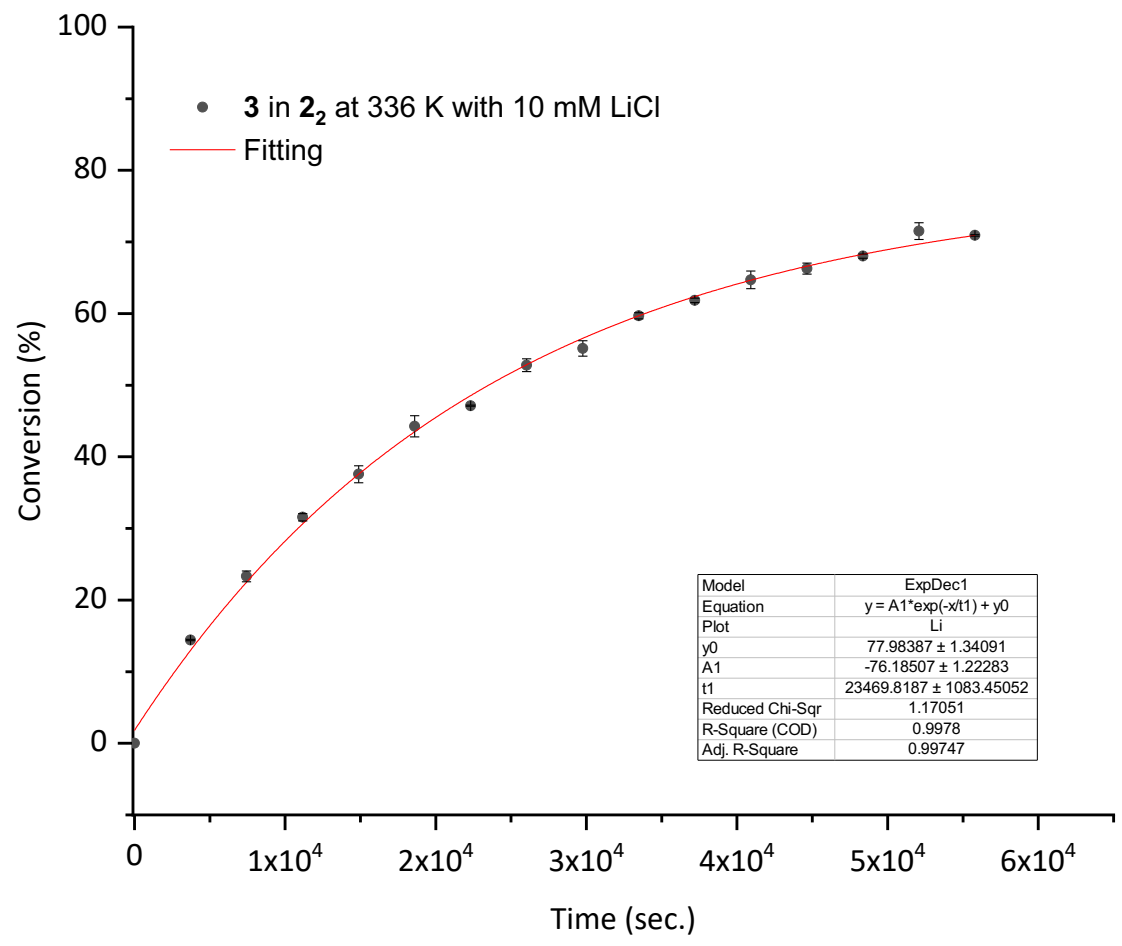

Figure S66: Conversion as a function of time plot for the reaction of guest $\mathbf{3}$ in $\mathbf{2}_{2}$ in the presence of 10 equiv. LiCl at $336 \mathrm{~K}$. 


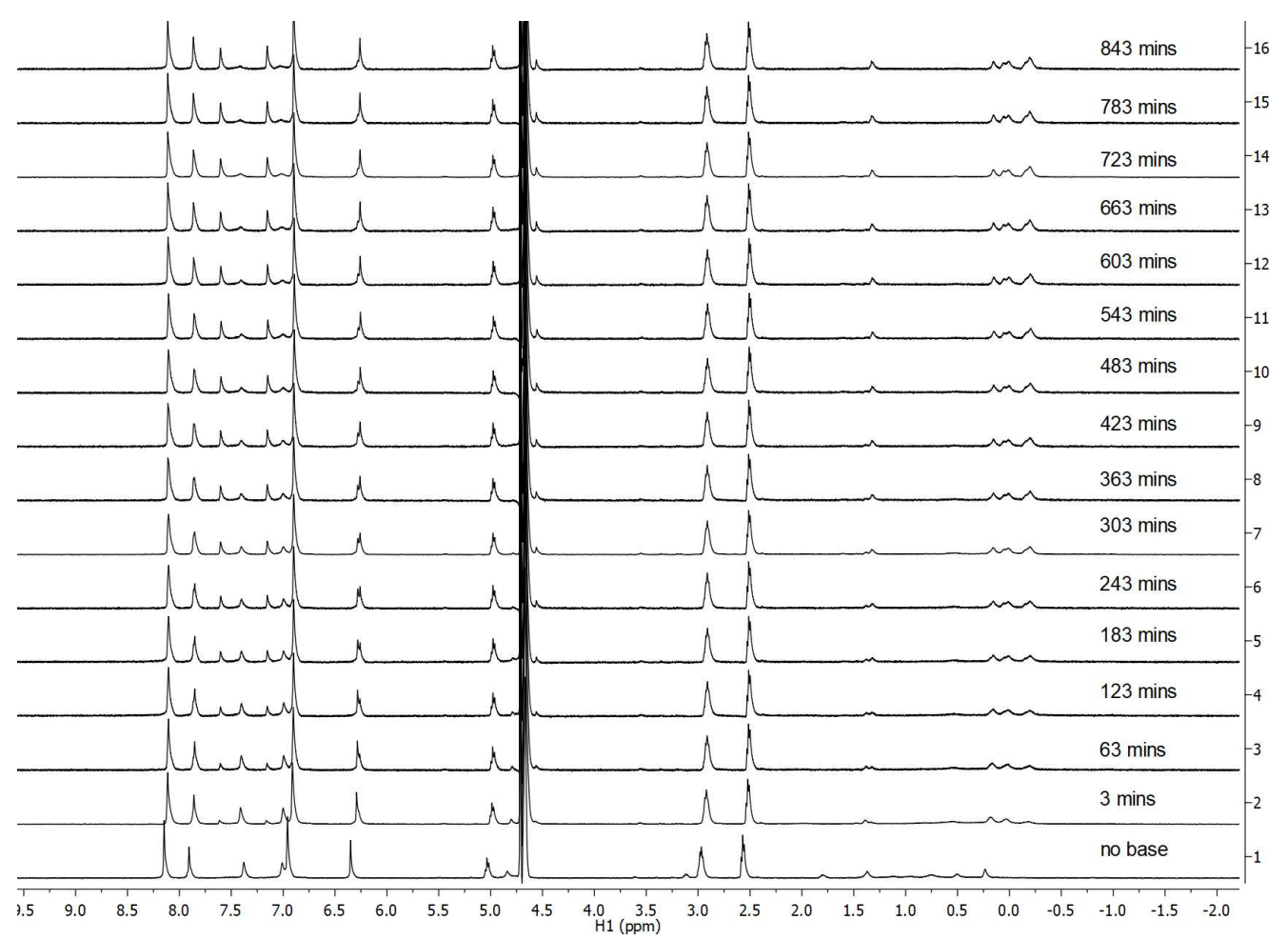

Figure S67: Stack of ${ }^{1} \mathrm{H}$ NMR spectra showing reaction of encapsulated guest $\mathbf{3}$ inside of $\mathbf{2}_{2}$ with 10 equiv. $\mathrm{NaCl}$ as a function of time. $\left(\mathrm{D}_{2} \mathrm{O}, 336 \mathrm{~K}\right.$, [Host 2] $=1 \mathrm{mM}$, [Guest 3] $\left.=0.5 \mathrm{mM},[\mathrm{NaOD}]=10 \mathrm{mM}\right)$.

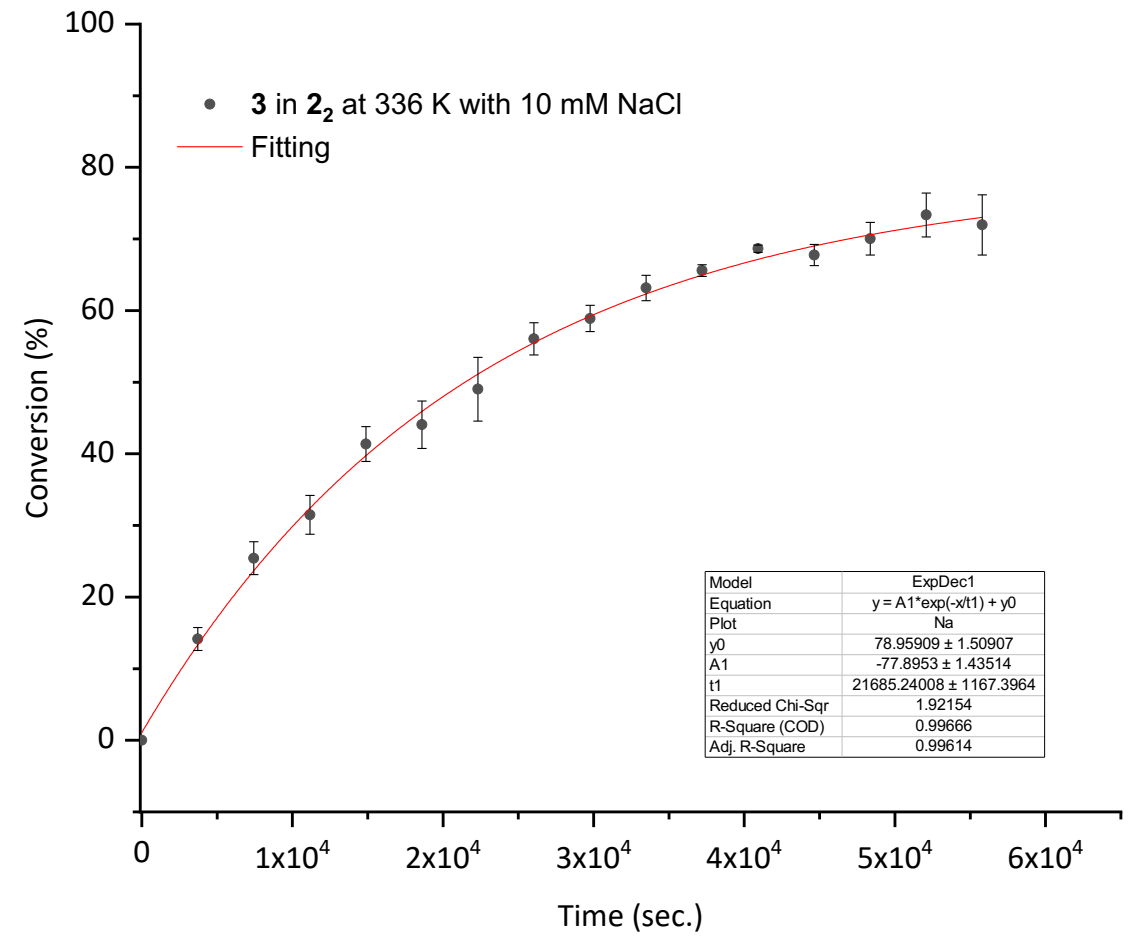

Figure S68: Conversion as a function of time plot for the reaction of guest $\mathbf{3}$ in $\mathbf{2}_{2}$ in the presence of 10 equiv. $\mathrm{NaCl}$ at $336 \mathrm{~K}$. 


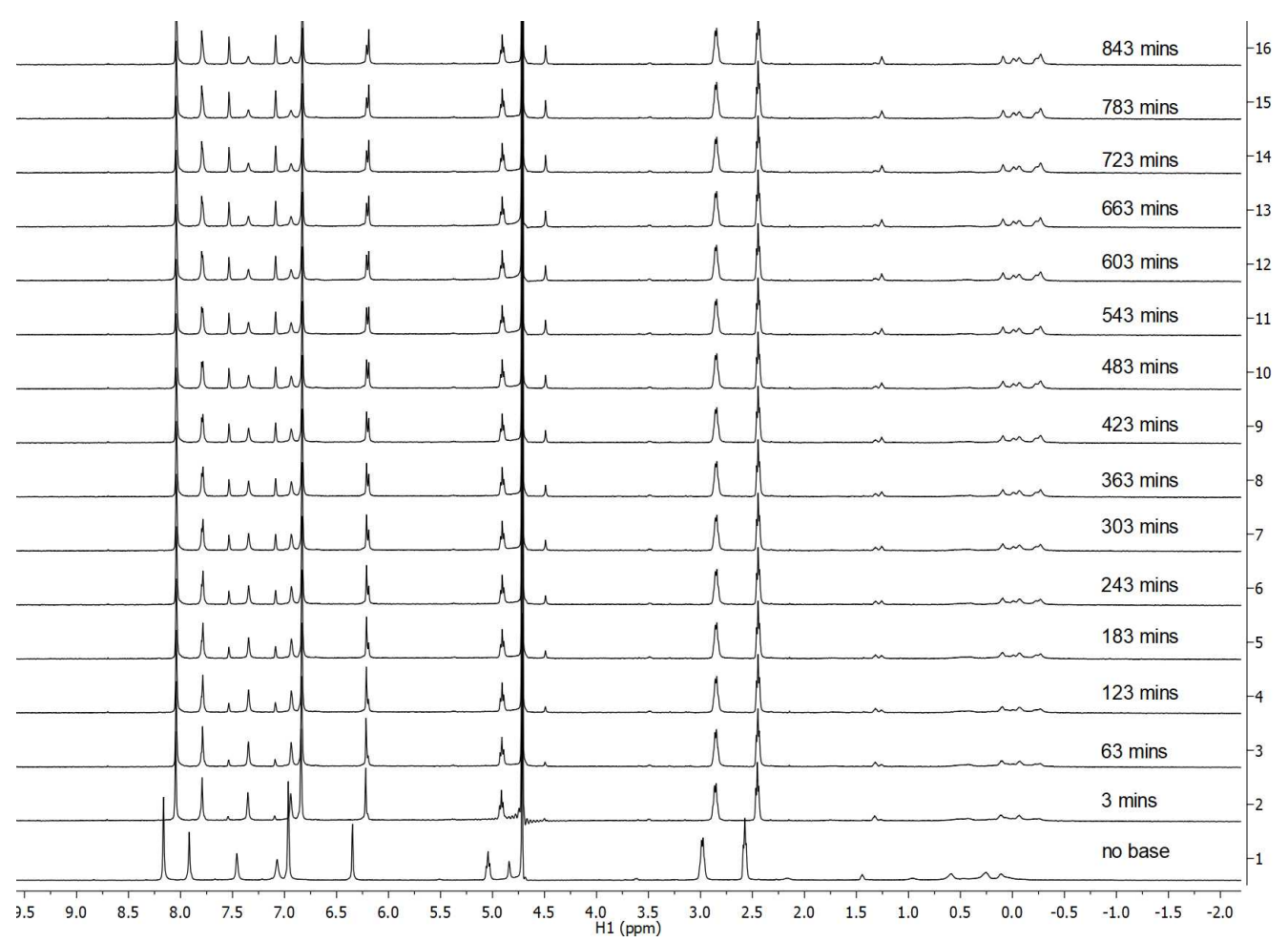

Figure S69: Stack of ${ }^{1} \mathrm{H}$ NMR spectra showing reaction of encapsulated guest 3 inside of $\mathbf{2}_{2}$ with 10 equiv. $\mathrm{KCl}$ as a function of time. $\left(\mathrm{D}_{2} \mathrm{O}, 336 \mathrm{~K}\right.$, [Host 2] $=1 \mathrm{mM}$, [Guest 3] $\left.=0.5 \mathrm{mM},[\mathrm{NaOD}]=10 \mathrm{mM}\right)$.

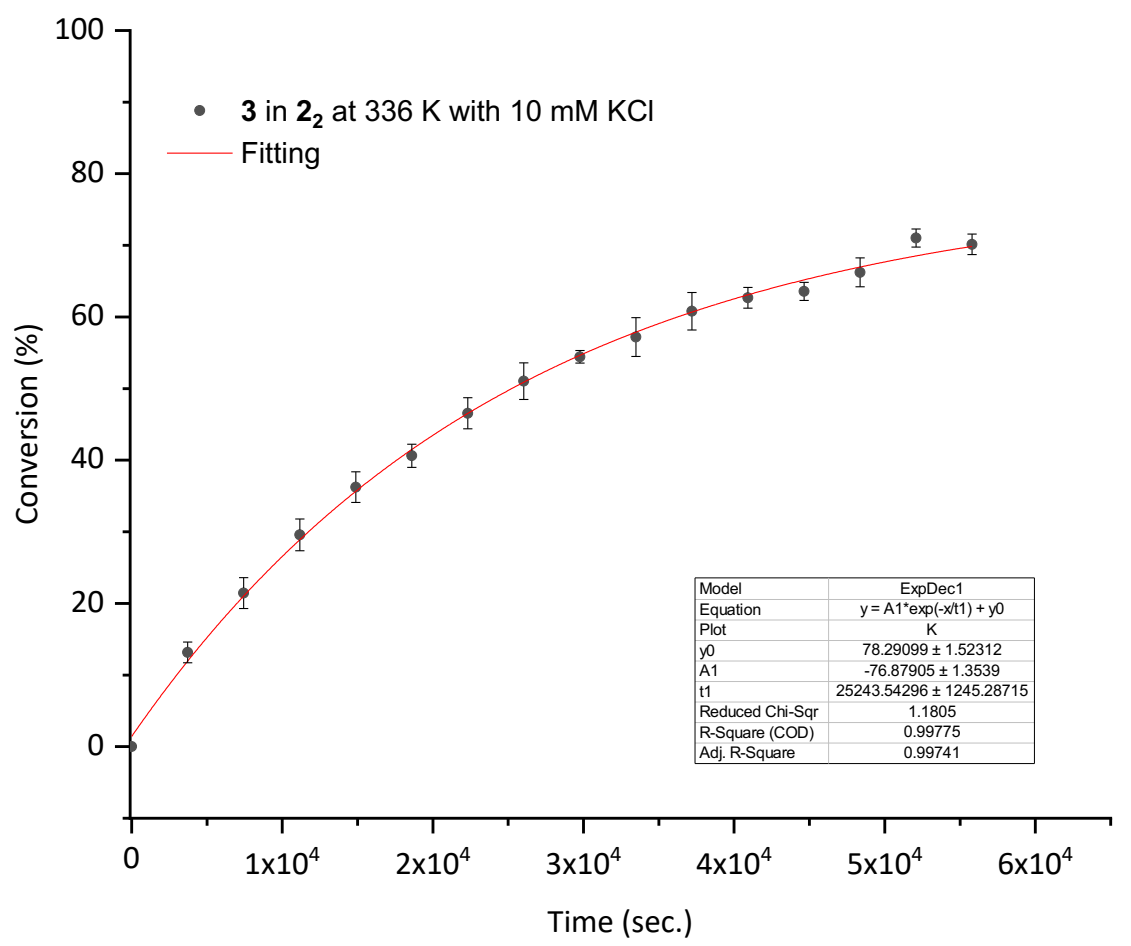

Figure S70: Conversion as a function of time plot for the reaction of guest $\mathbf{3}$ in $\mathbf{2}_{2}$ in the presence of 10 equiv. $\mathrm{KCl}$ at $336 \mathrm{~K}$. 


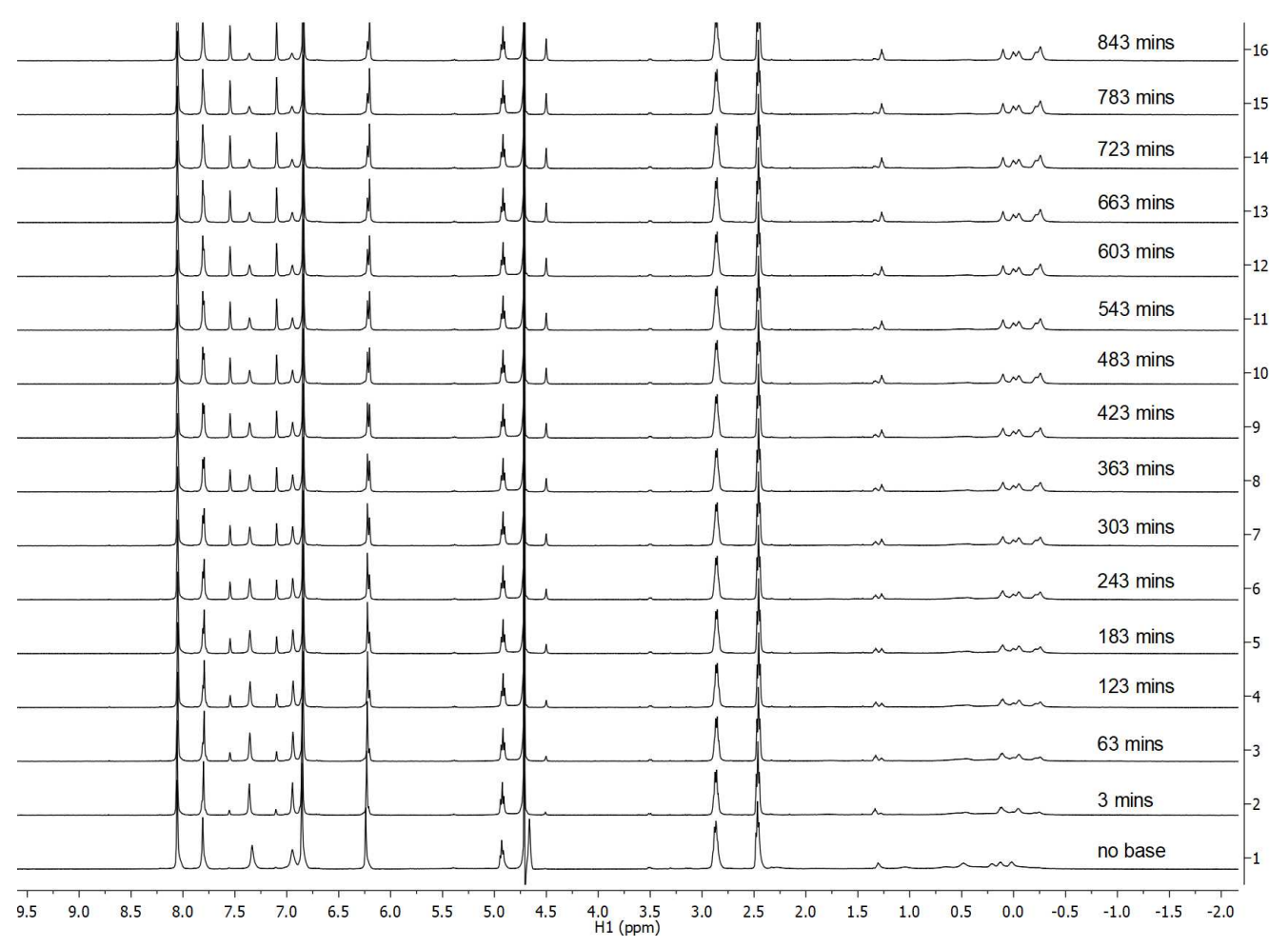

Figure S71: Stack of ${ }^{1} \mathrm{H}$ NMR spectra showing reaction of encapsulated guest 3 inside of $\mathbf{2}_{2}$ with 10 equiv. CsCl as a function of time. $\left(\mathrm{D}_{2} \mathrm{O}, 336 \mathrm{~K}\right.$, [Host 2] $=1 \mathrm{mM}$, [Guest 3] = $\left.0.5 \mathrm{mM},[\mathrm{NaOD}]=10 \mathrm{mM}\right)$.

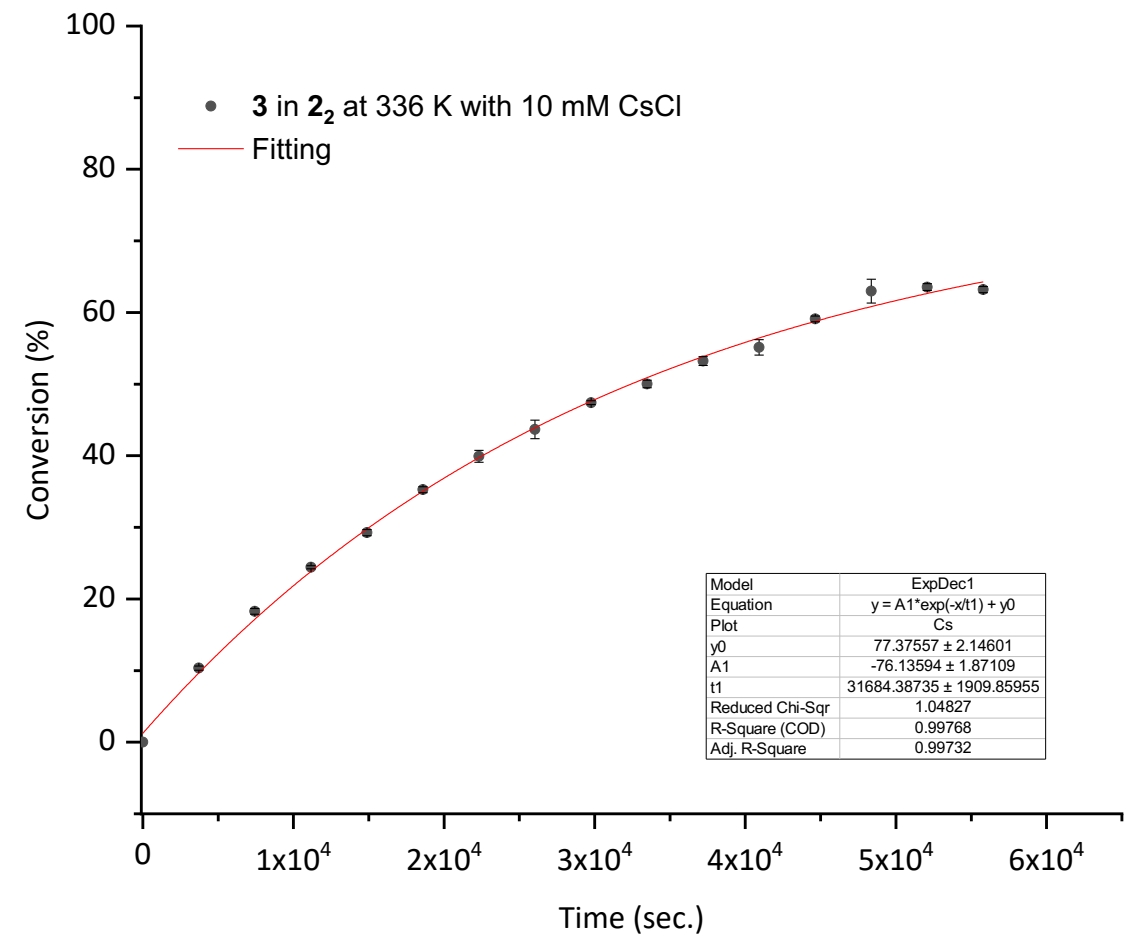

Figure S72: Conversion as a function of time plot for the reaction of guest $\mathbf{3}$ in $\mathbf{2}_{2}$ in the presence of 10 equiv. $\mathrm{CsCl}$ at $336 \mathrm{~K}$. 


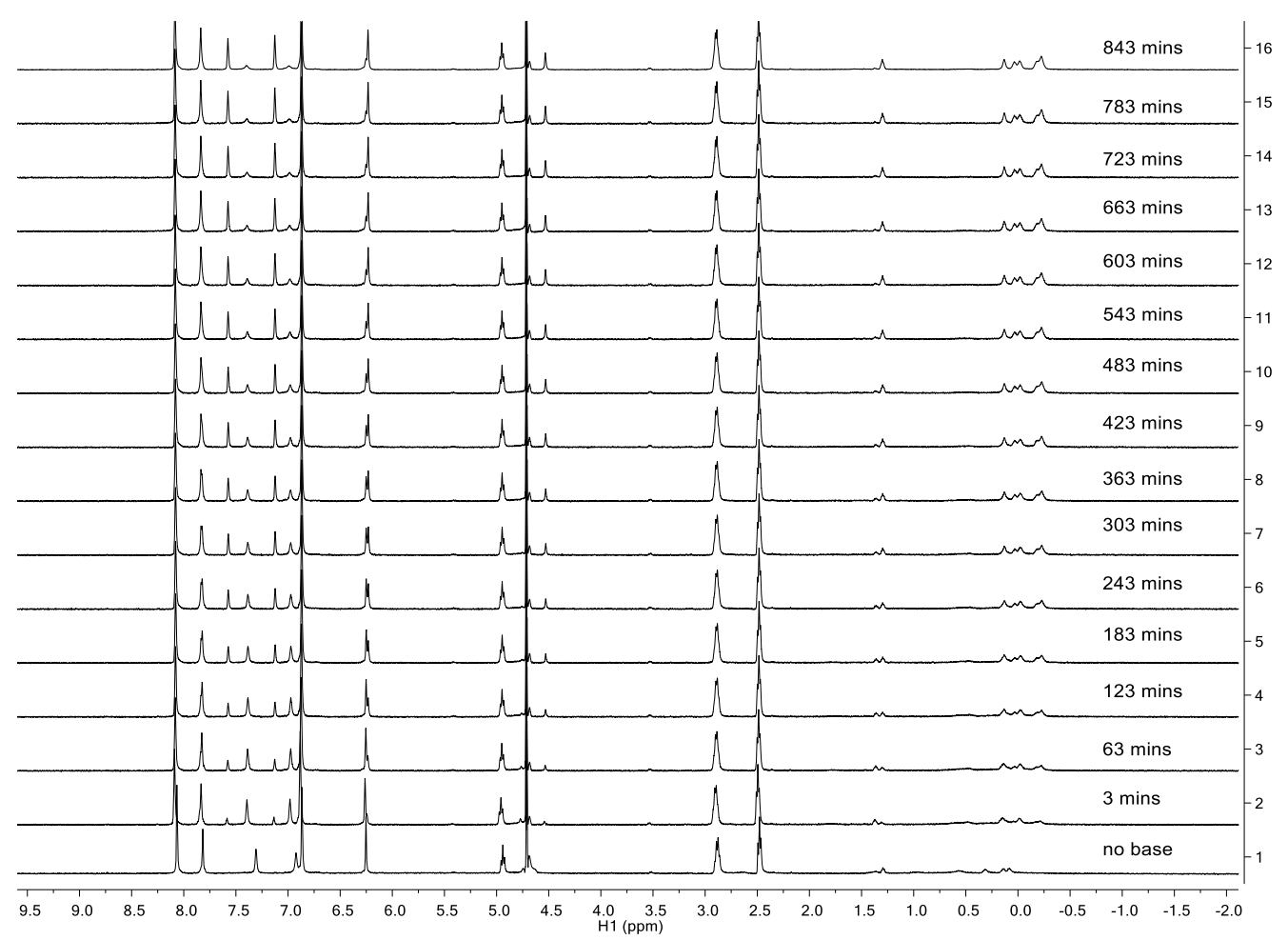

Figure S73: Stack of ${ }^{1} \mathrm{H}$ NMR spectra showing reaction of encapsulated guest $\mathbf{3}$ inside of $\mathbf{2}_{2}$ with 10 equiv. $\mathrm{RbCl}$ as a function of time. $\left(\mathrm{D}_{2} \mathrm{O}, 336 \mathrm{~K}\right.$, [Host 2] $=1 \mathrm{mM}$, [Guest 3] $\left.=0.5 \mathrm{mM},[\mathrm{NaOD}]=10 \mathrm{mM}\right)$.

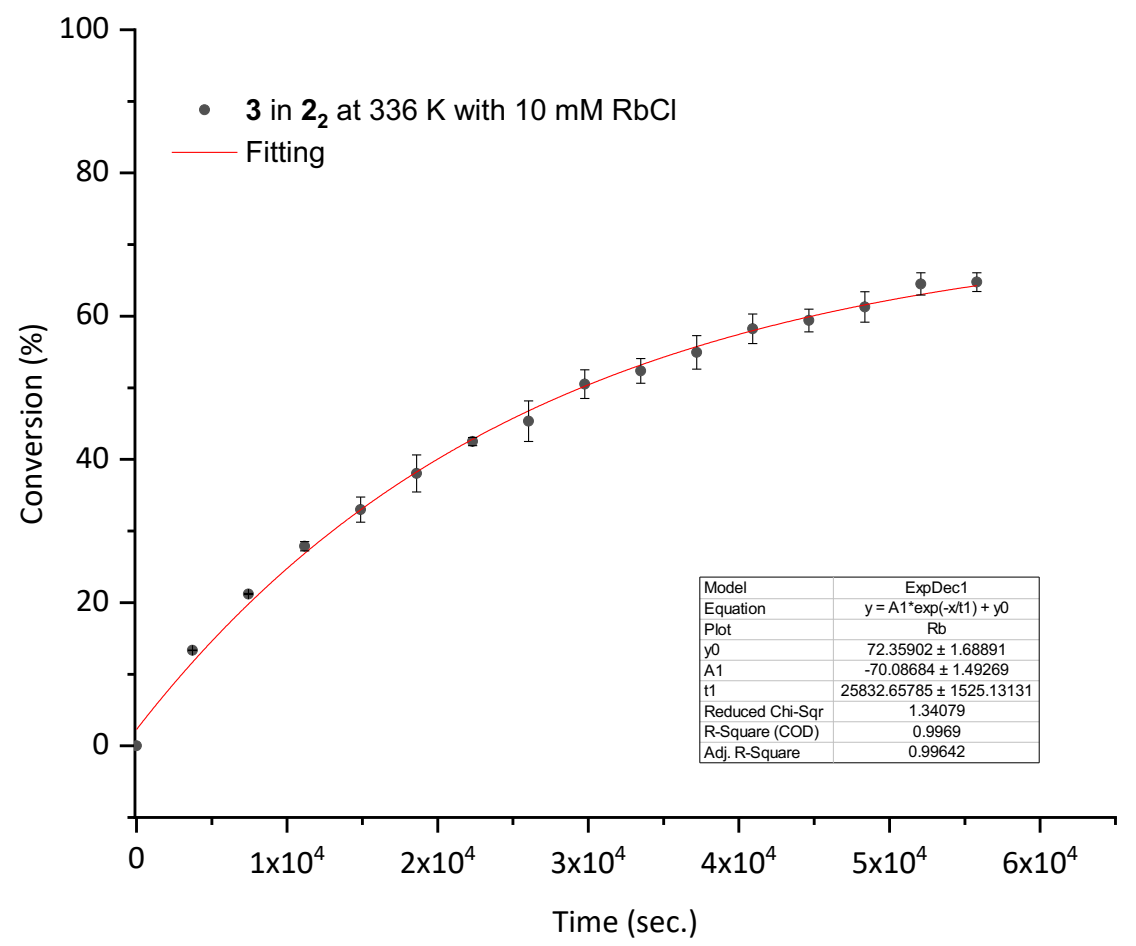

Figure S74: Conversion as a function of time plot for the reaction of guest $\mathbf{3}$ in $\mathbf{2}_{2}$ in the presence of 10 equiv. $\mathrm{RbCl}$ at $336 \mathrm{~K}$. 


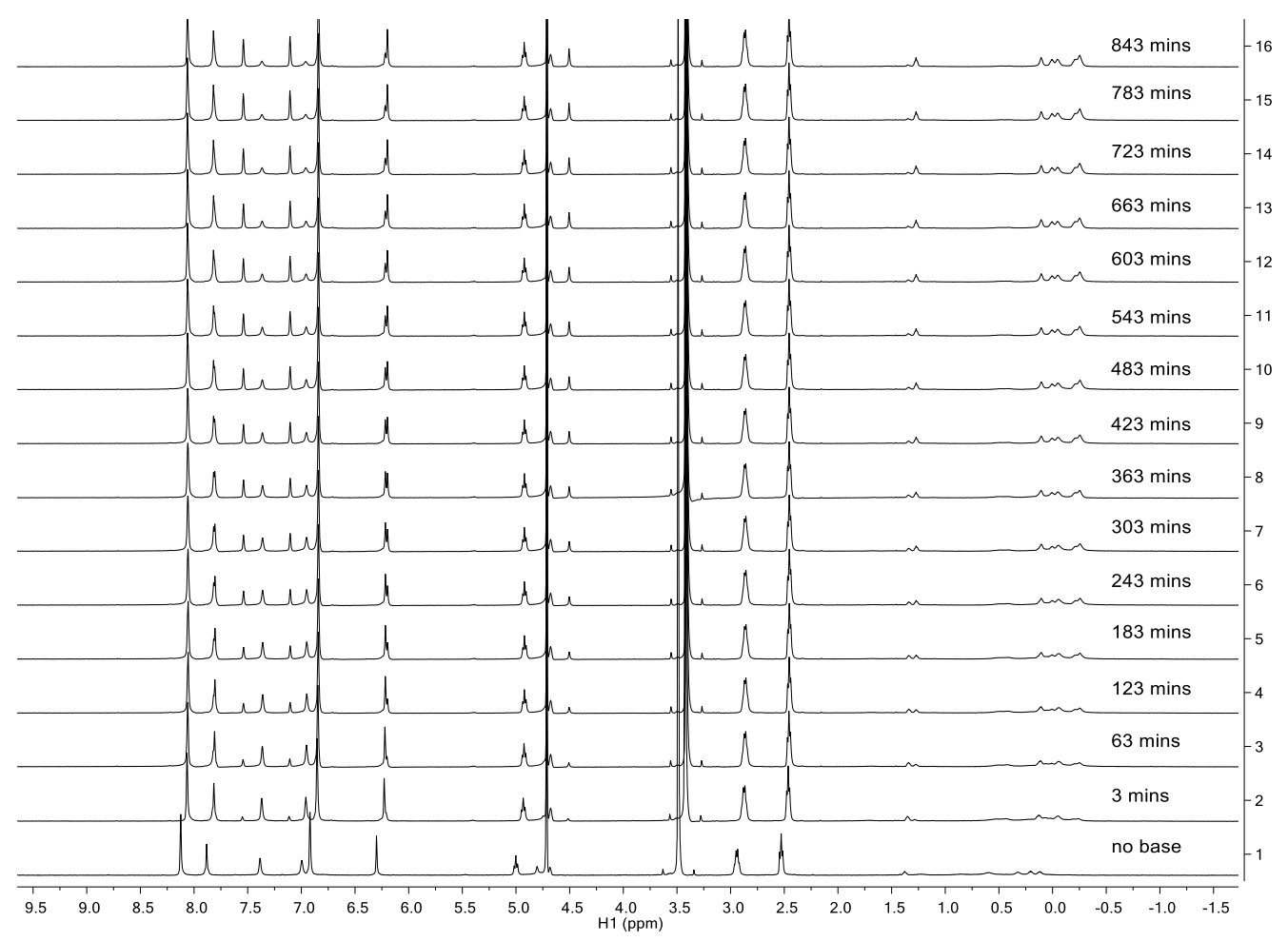

Figure S75: Stack of ${ }^{1} \mathrm{H}$ NMR spectra showing reaction of encapsulated guest 3 inside of $\mathbf{2}_{2}$ with 10 equiv. TMACl as a function of time. $\left(\mathrm{D}_{2} \mathrm{O}, 336 \mathrm{~K}\right.$, [Host 2] $=1 \mathrm{mM}$, [Guest 3] $=0.5 \mathrm{mM}$, [NaOD] $\left.=10 \mathrm{mM}\right)$.

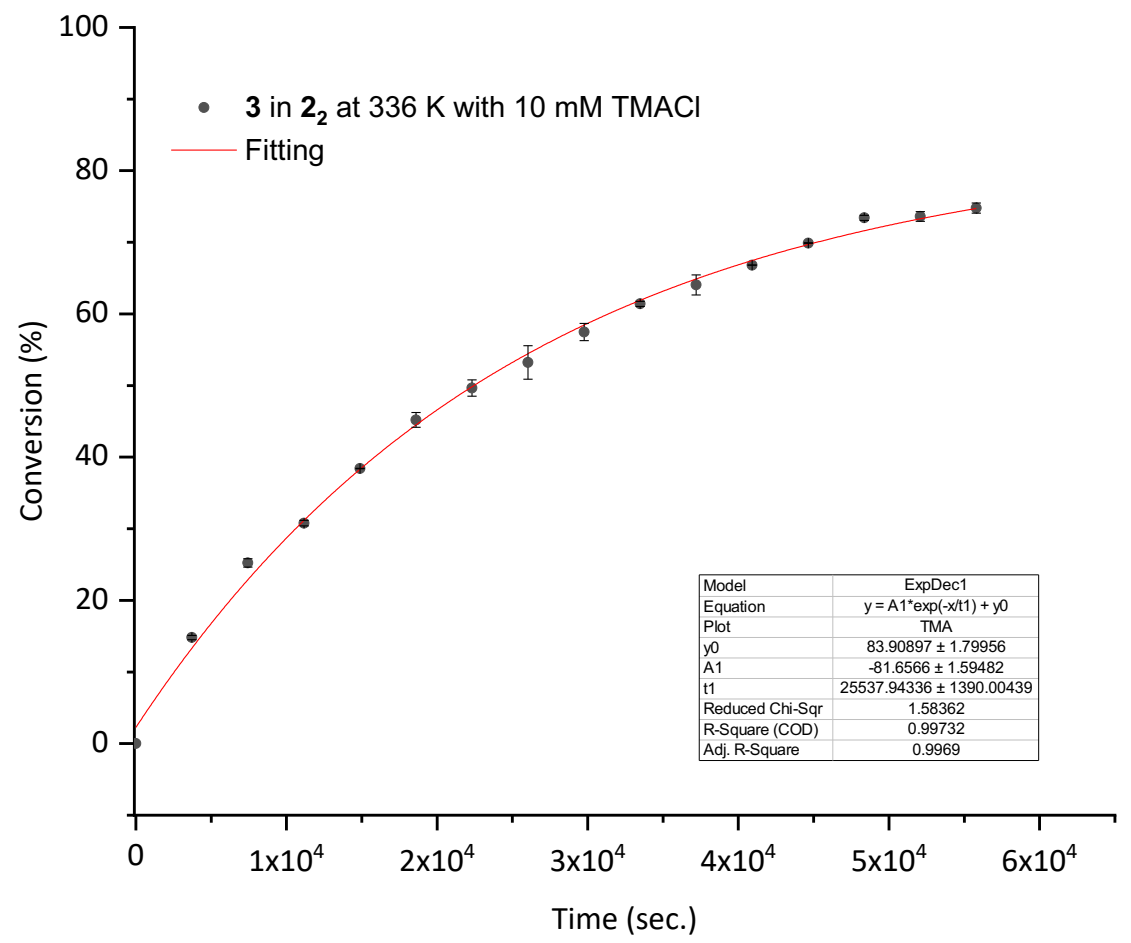

Figure S76 Conversion as a function of time plot for the reaction of guest $\mathbf{3}$ in $\mathbf{2}_{2}$ in the presence of 10 equiv. TMACI at $336 \mathrm{~K}$. 
7) Eyring analysis for the cyclization of 3 presence of $10 \mathrm{mM} \mathrm{NaClO}_{4}$ or $\mathrm{CsCl}$

The reaction rate in each experiment was determined by tracking and integrating the "d" peak in the ${ }^{1} \mathrm{H}$ NMR spectroscopy using Mnova, then fitted the integrations as a function of time to give the kinetic data with Origin Pro 2018. Lines fitted by the first order kinetic model are demonstrated in red and the standard deviations are shown as error bars. Each experiment was carried out in duplicates, with the average calculated to give the corresponding rate constants. Errors in individual rate constant were $<10 \%$. Gradient error in the Eyring analysis was $5 \%$ (Excel LINEST function). Figures $\mathbf{S 7 7} \mathbf{- S 8 8}$ show the data for the cyclization of $\mathbf{3}$ in $\mathbf{1}_{2}$ in the presence of $\mathrm{NaClO}_{4}$, whilst Figures $\mathbf{S} 89-\mathbf{S} 100$ show the data for the cyclization of $\mathbf{3}$ in $\mathbf{2}_{2}$ in the presence of $\mathrm{CsCl}$.

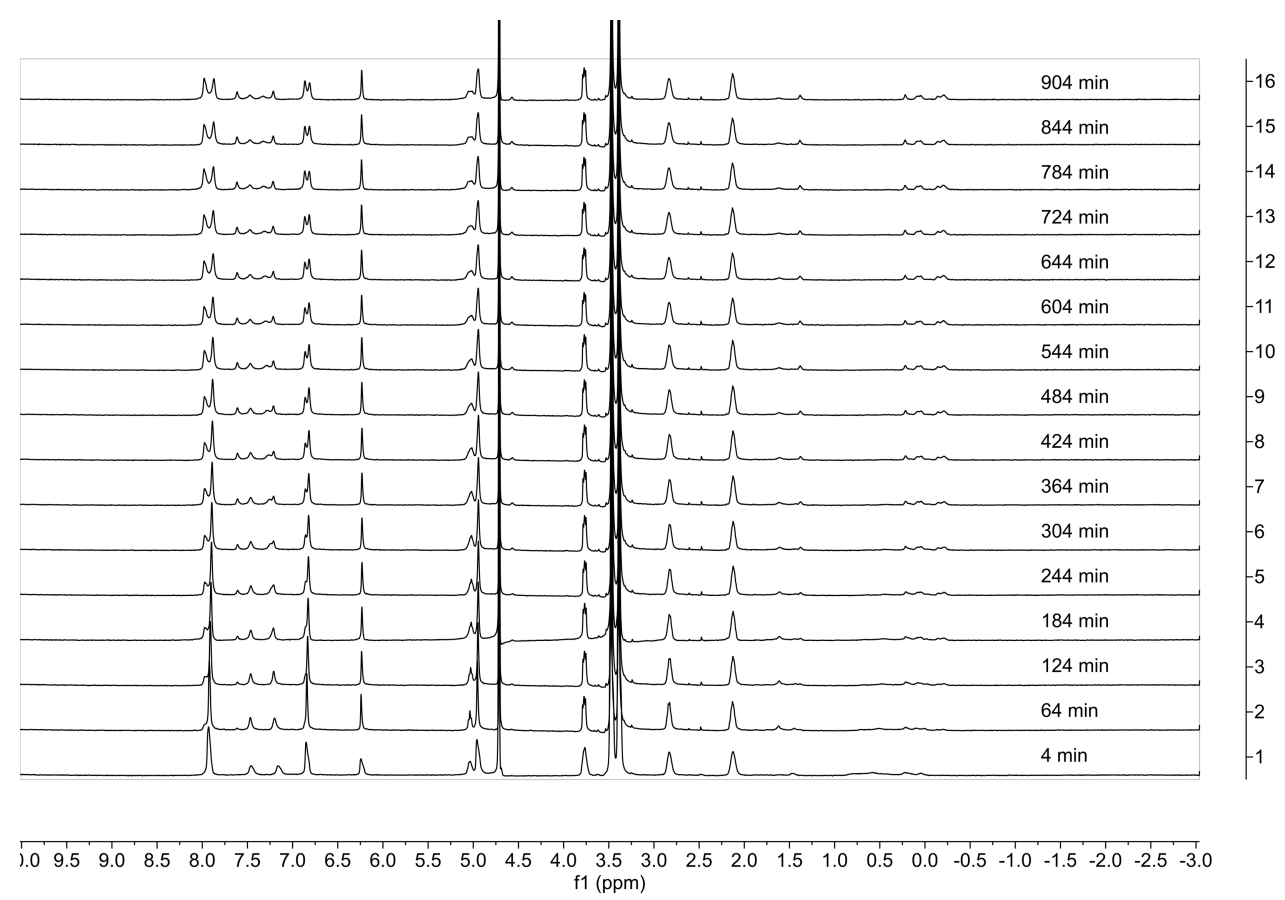

Figure S77: Stack of ${ }^{1} \mathrm{H}$ NMR spectra showing reaction of encapsulated guest 3 inside of $\mathbf{1}_{\mathbf{2}}$ as a function of time. $\left(\mathrm{D}_{2} \mathrm{O}, 339 \mathrm{~K},[\right.$ Host 1$]=1 \mathrm{mM},\left[\right.$ Guest 3] $\left.=0.5 \mathrm{mM},[\mathrm{NaOD}]=10 \mathrm{mM},\left[\mathrm{NaClO}_{4}\right]=10 \mathrm{mM}\right)$. 


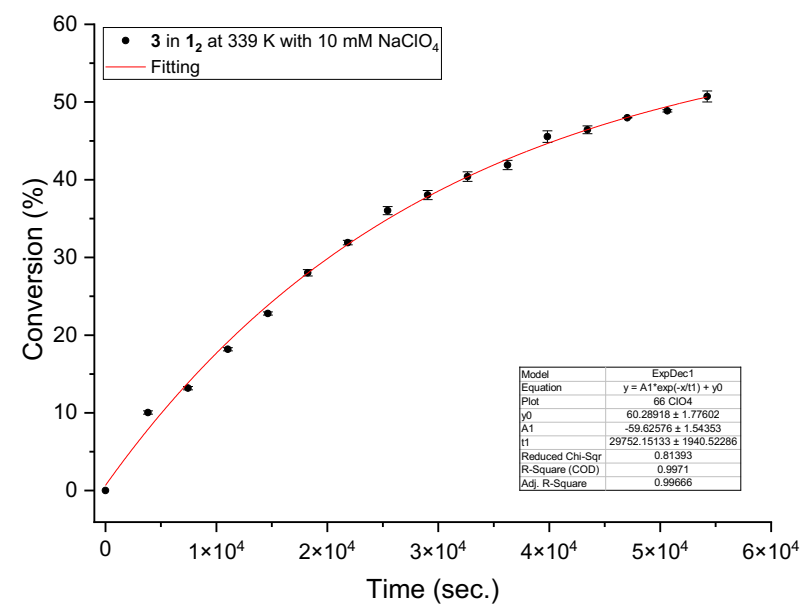

Figure S78: Reaction kinetics for guest 3 inside of host $\mathbf{1}_{\mathbf{2}}$ in presence of $10 \mathrm{mM} \mathrm{NaClO}_{4}$ at $339 \mathrm{~K}$.

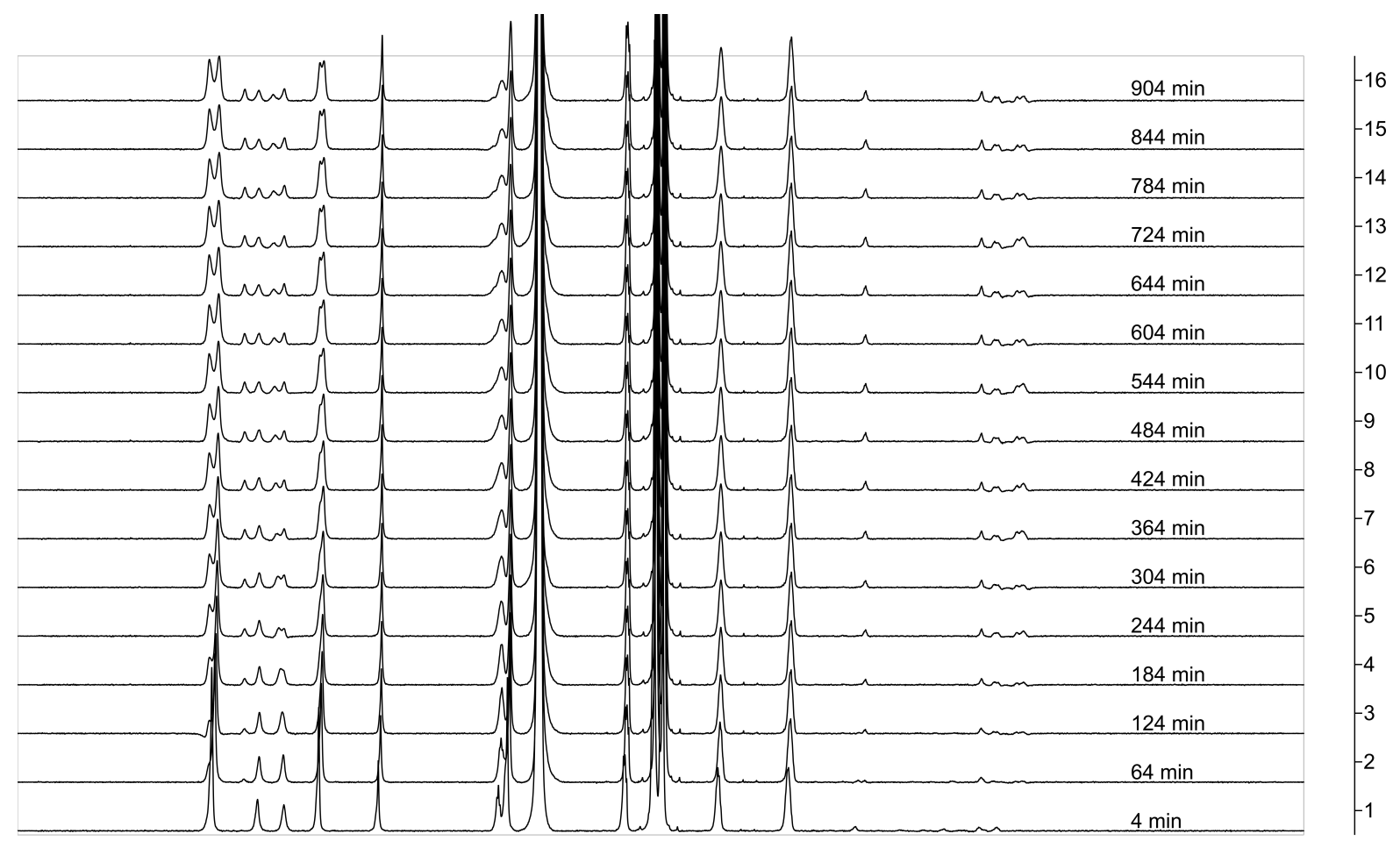

$\begin{array}{lllllllllllllllllllllllllll}9.5 & 9.0 & 8.5 & 8.0 & 7.5 & 7.0 & 6.5 & 6.0 & 5.5 & 5.0 & 4.5 & 4.0 & 3.5 & 3.0 & 2.5 & 2.0 & 1.5 & 1.0 & 0.5 & 0.0 & -0.5 & -1.0 & -1.5 & -2.0 & -2.5\end{array}$

Figure S79: Stack of ${ }^{1} \mathrm{H}$ NMR spectra showing reaction of encapsulated guest 3 inside of $\mathbf{1}_{\mathbf{2}}$ as a function of time. $\left(\mathrm{D}_{2} \mathrm{O}, 342 \mathrm{~K},[\right.$ Host 1$]=1 \mathrm{mM}$, [Guest 3] $\left.=0.5 \mathrm{mM},[\mathrm{NaOD}]=10 \mathrm{mM},\left[\mathrm{NaClO}_{4}\right]=10 \mathrm{mM}\right)$. 


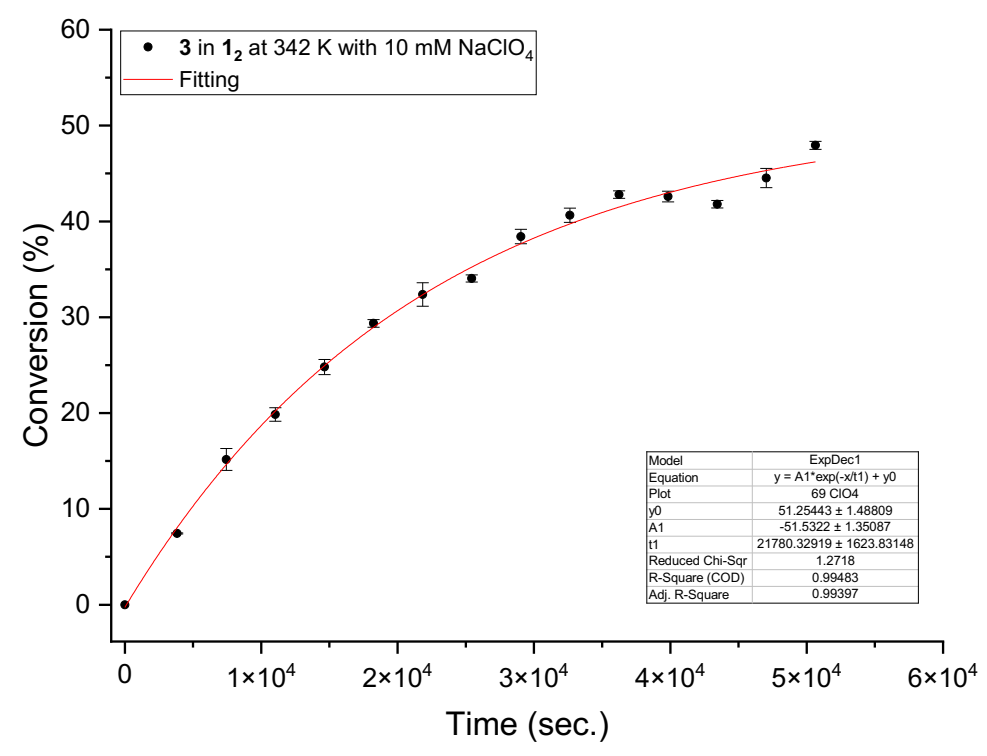

Figure S80: Reaction kinetics for guest 3 inside of host $\mathbf{1}_{\mathbf{2}}$ in presence of $10 \mathrm{mM} \mathrm{NaClO}$ at $342 \mathrm{~K}$.

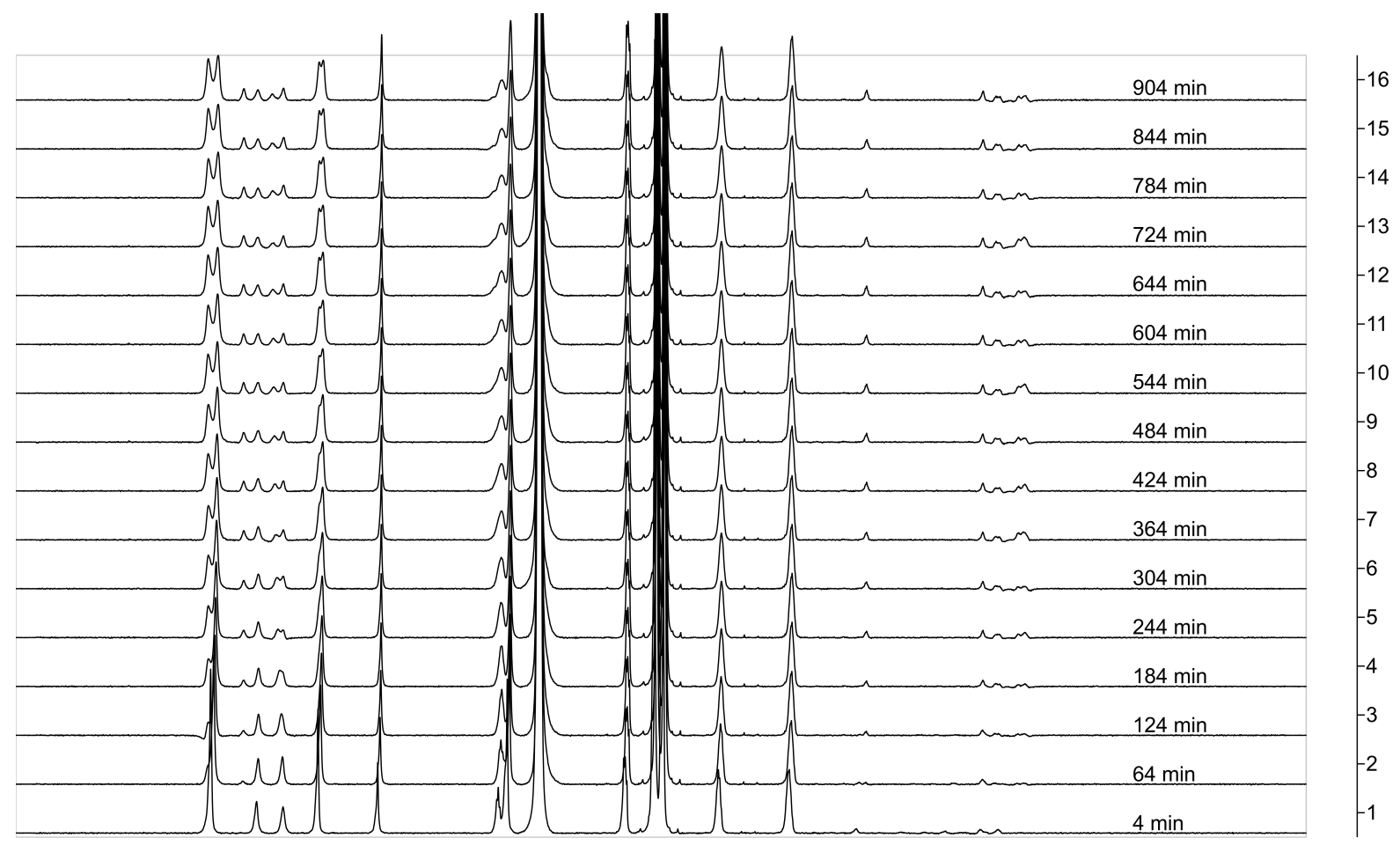

$\begin{array}{llllllllllllllllllllllllllllllll}9.5 & 9.0 & 8.5 & 8.0 & 7.5 & 7.0 & 6.5 & 6.0 & 5.5 & 5.0 & 4.5 & 4.0 & 3.5 & 3.0 & 2.5 & 2.0 & 1.5 & 1.0 & 0.5 & 0.0 & -0.5 & -1.0 & -1.5 & -2.0 & -2.5\end{array}$

Figure S81: Stack of ${ }^{1} \mathrm{H}$ NMR spectra showing reaction of encapsulated guest $\mathbf{3}$ inside of $\mathbf{1}_{\mathbf{2}}$ as a function of time. $\left(\mathrm{D}_{2} \mathrm{O}, 345 \mathrm{~K},[\right.$ Host 1$]=1 \mathrm{mM},[$ Guest 3$\left.]=0.5 \mathrm{mM},[\mathrm{NaOD}]=10 \mathrm{mM},\left[\mathrm{NaClO}_{4}\right]=10 \mathrm{mM}\right)$. 


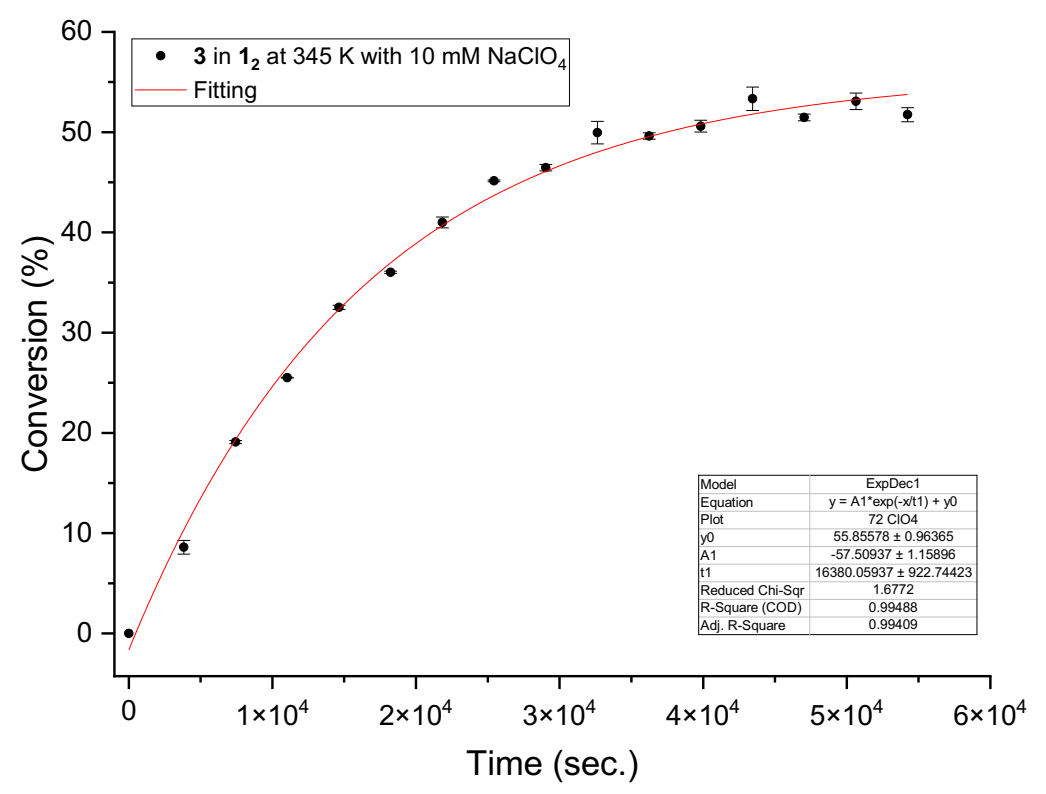

Figure S82: Reaction kinetics for guest 3 inside of host $\mathbf{1}_{\mathbf{2}}$ in presence of $10 \mathrm{mM} \mathrm{NaClO}_{4}$ at $345 \mathrm{~K}$.

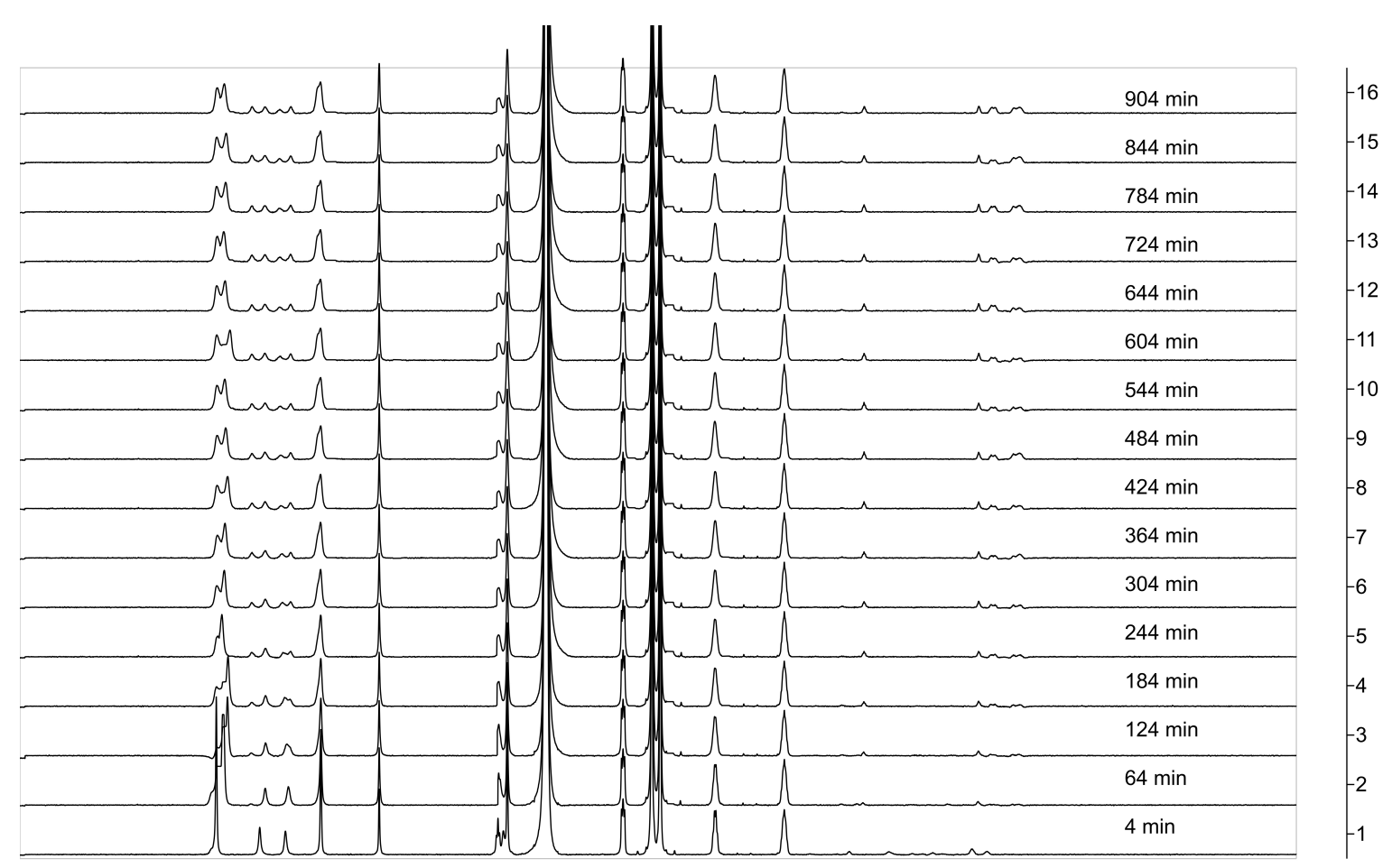

\begin{tabular}{lllllllllllllllllllllllllllllllllll}
\hline .0 & 9.5 & 9.0 & 8.5 & 8.0 & 7.5 & 7.0 & 6.5 & 6.0 & 5.5 & 5.0 & 4.5 & 4.0 & 3.5 & 3.0 & 2.5 & 2.0 & 1.5 & 1.0 & 0.5 & 0.0 & -0.5 & -1.0 & -1.5 & -2.0 & -2.5
\end{tabular}

Figure S83: Stack of ${ }^{1} \mathrm{H}$ NMR spectra showing reaction of encapsulated guest $\mathbf{3}$ inside of $\mathbf{1}_{2}$ as a function of time. $\left(\mathrm{D}_{2} \mathrm{O}, 348 \mathrm{~K},[\right.$ Host 1] $=1 \mathrm{mM}$, [Guest 3] $=0.5 \mathrm{mM},[\mathrm{NaOD}]=10 \mathrm{mM},[\mathrm{NaClO} 4]=10 \mathrm{mM})$. 


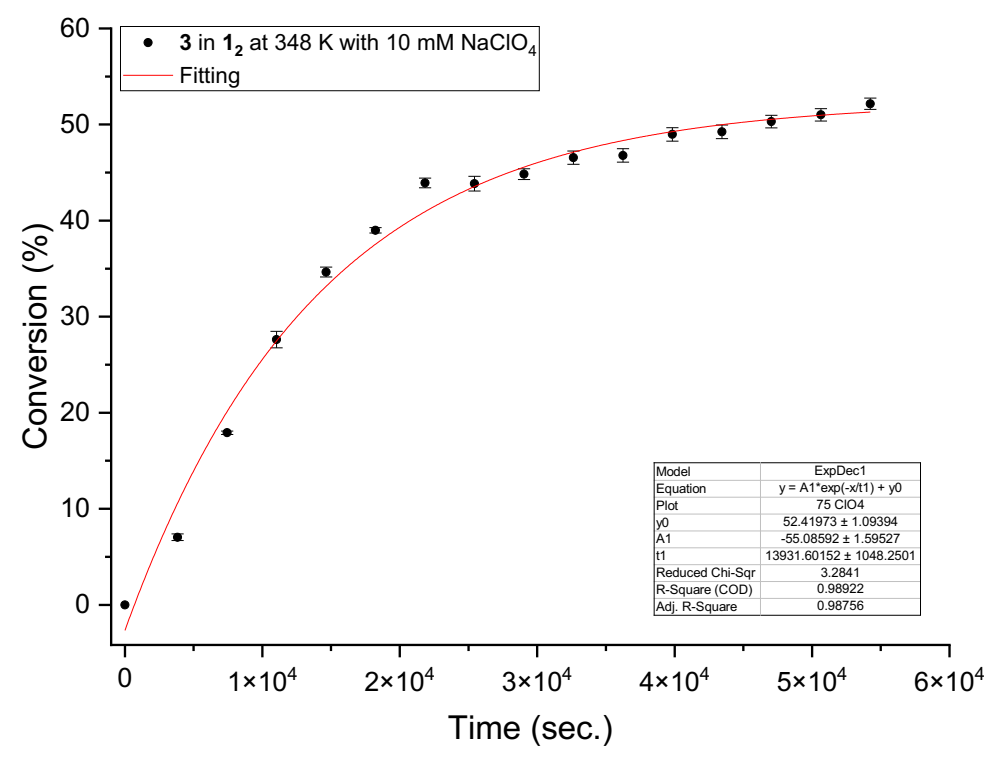

Figure S84: Reaction kinetics for guest 3 inside of host $\mathbf{1}_{\mathbf{2}}$ in presence of $10 \mathrm{mM} \mathrm{NaClO}_{4}$ at $348 \mathrm{~K}$.

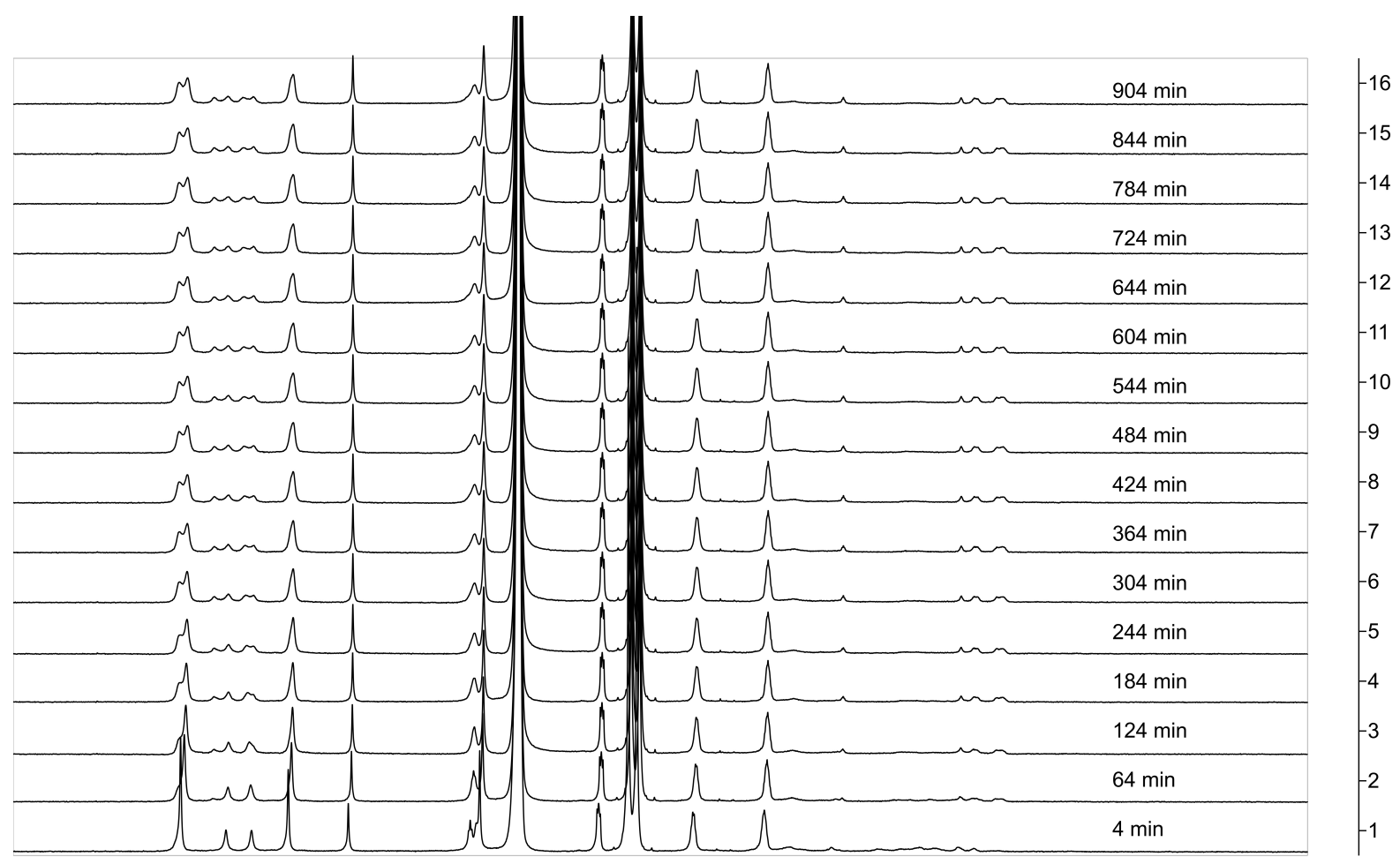

$\begin{array}{llllllllllllllllllllllllllll}9.5 & 9.0 & 8.5 & 8.0 & 7.5 & 7.0 & 6.5 & 6.0 & 5.5 & 5.0 & 4.5 & 4.0 & 3.5 & 3.0 & 2.5 & 2.0 & 1.5 & 1.0 & 0.5 & 0.0 & -0.5 & -1.0 & -1.5 & -2.0 & -2.5 & -3.0\end{array}$

Figure S85: Stack of ${ }^{1} \mathrm{H}$ NMR spectra showing reaction of encapsulated guest $\mathbf{3}$ inside of $\mathbf{1}_{\mathbf{2}}$ as a function of time. $\left(\mathrm{D}_{2} \mathrm{O}, 351 \mathrm{~K},[\right.$ Host 1$]=1 \mathrm{mM},\left[\right.$ Guest 3] $\left.=0.5 \mathrm{mM},[\mathrm{NaOD}]=10 \mathrm{mM},\left[\mathrm{NaClO}_{4}\right]=10 \mathrm{mM}\right)$. 


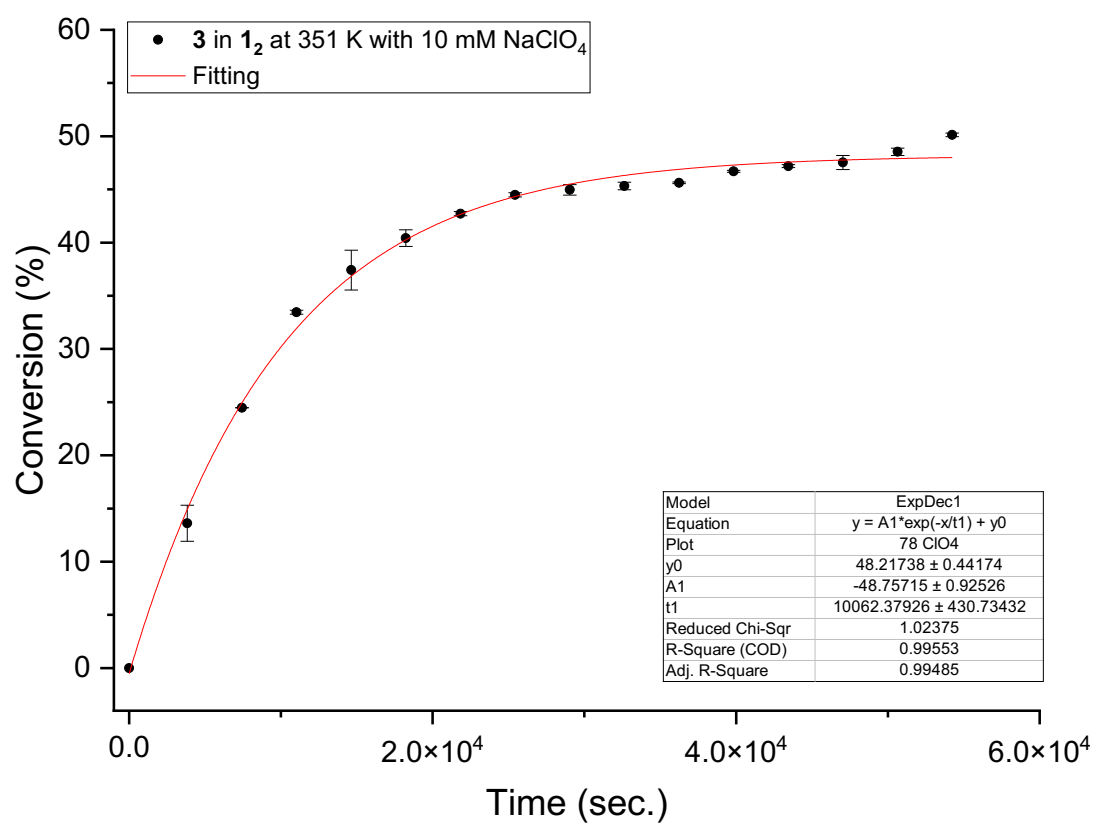

Figure S86: Reaction kinetics for guest $\mathbf{3}$ inside of host $\mathbf{1}_{\mathbf{2}}$ in presence of $10 \mathrm{mM} \mathrm{NaClO}_{4}$ at $351 \mathrm{~K}$.

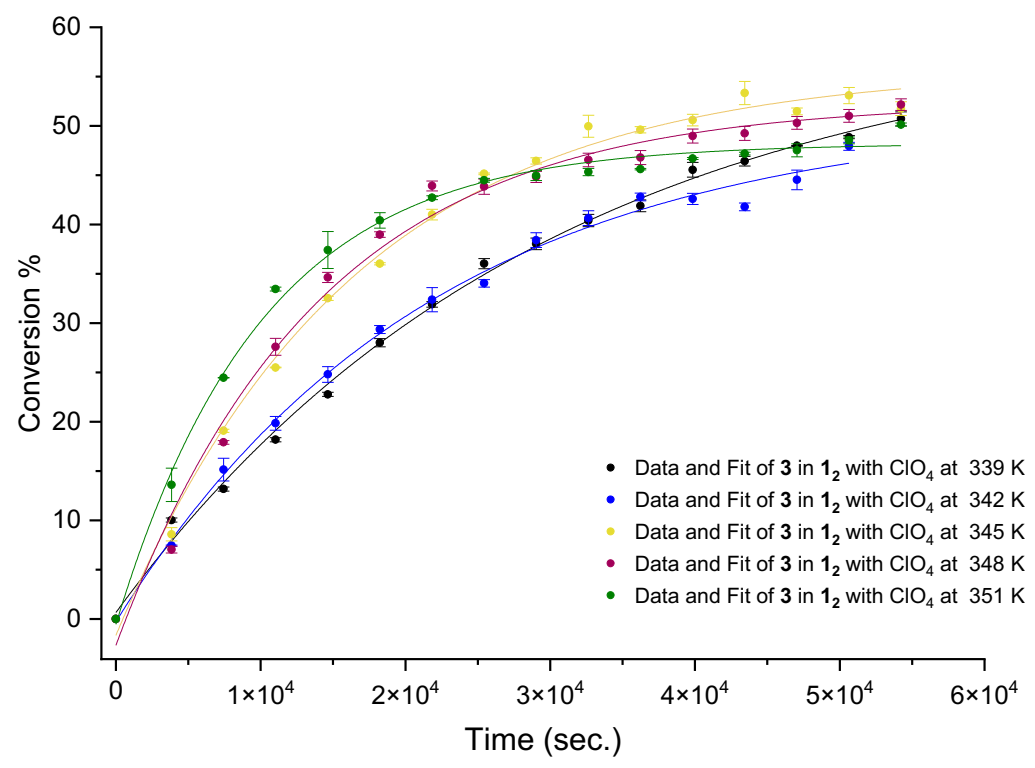

Figure S87: Fitting for the cyclization of guest $\mathbf{3}$ inside of $\mathbf{1}_{\mathbf{2}}$ in presence of $10 \mathrm{mM} \mathrm{NaClO}_{4}$ at five different temperatures. 


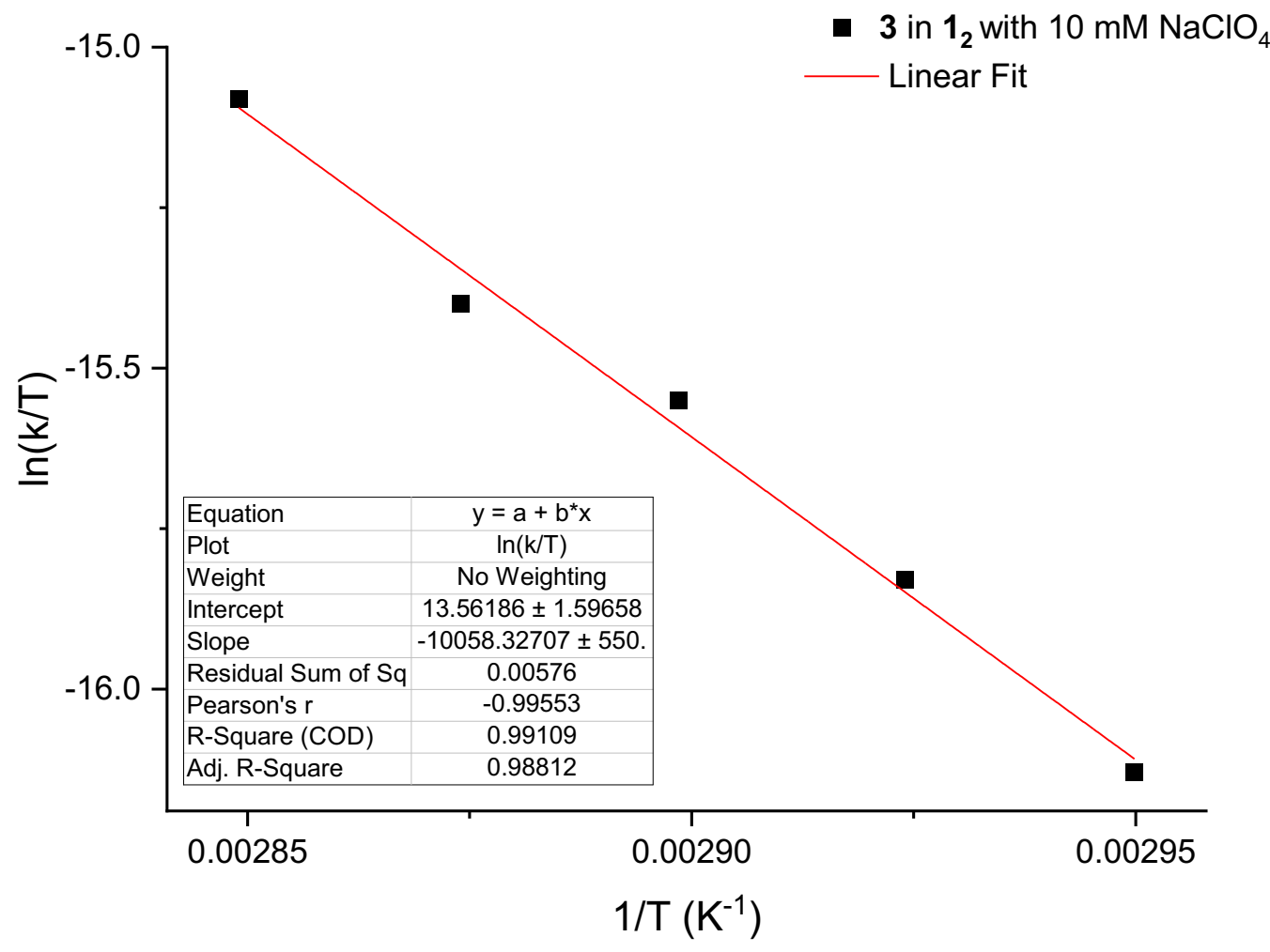

Figure S88: Eyring plot for the cyclization of guest 3 in $\mathbf{1}_{2}$ in the presence of $\mathrm{NaClO}_{4}$ at five different temperatures. 


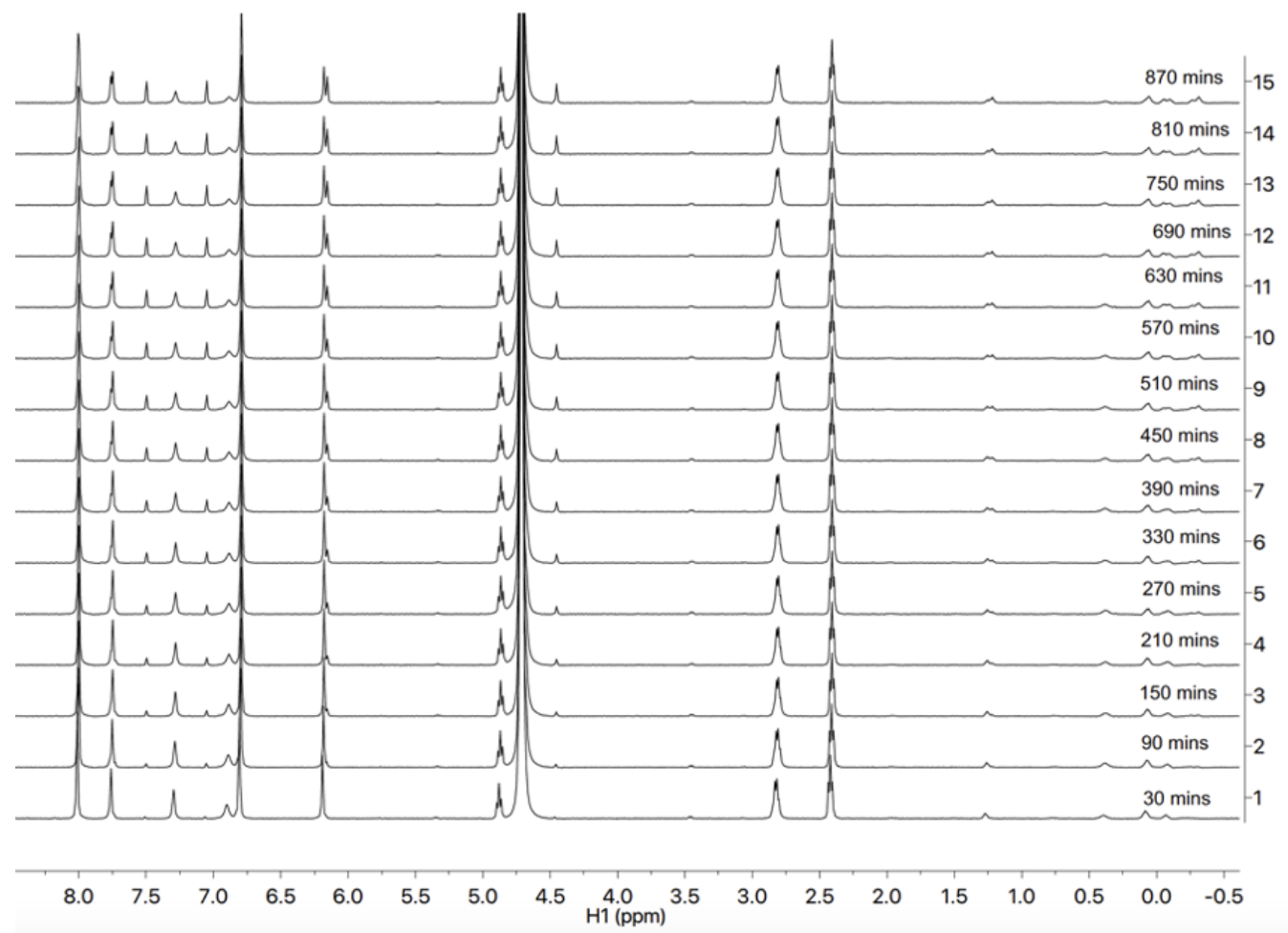

Figure S89: Stack of ${ }^{1} \mathrm{H}$ NMR spectra showing reaction of encapsulated guest $\mathbf{3}$ inside of $\mathbf{2}_{\mathbf{2}}$ as a function of time. $\left(\mathrm{D}_{2} \mathrm{O}, 325 \mathrm{~K},[\right.$ Host 2$]=1 \mathrm{mM}$, [Guest 3] $\left.=0.5 \mathrm{mM},[\mathrm{NaOD}]=10 \mathrm{mM},[\mathrm{CsCl}]=10 \mathrm{mM}\right)$.

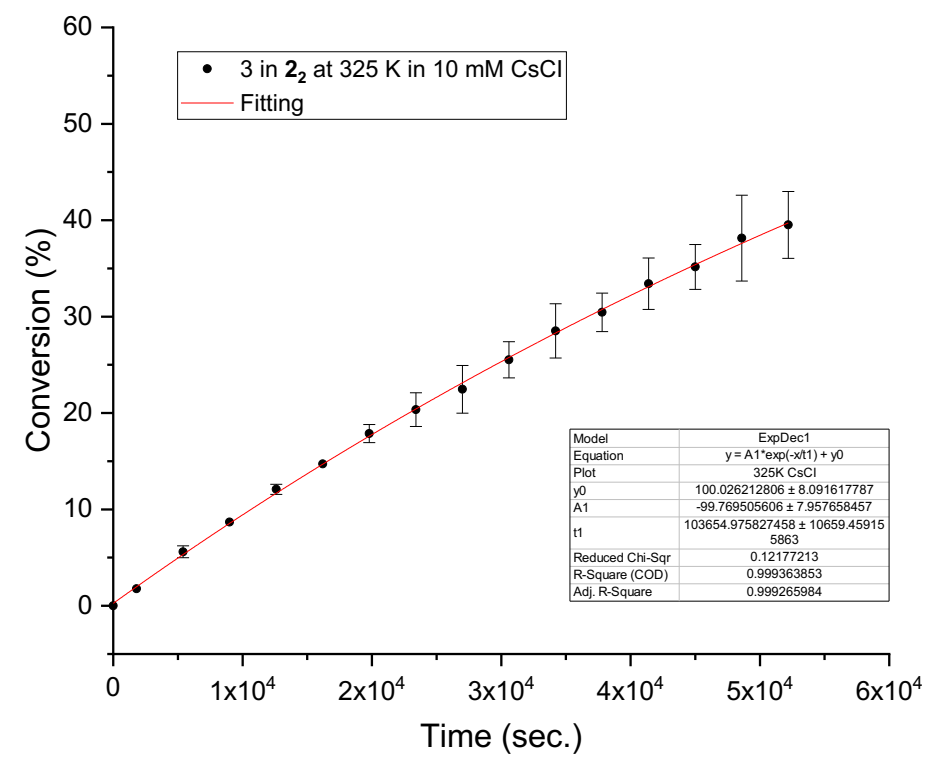

Figure S90: Reaction kinetics for guest 3 inside of host $2 \mathbf{2}$ in presence of $10 \mathrm{mM} \mathrm{CsCl}$ at $325 \mathrm{~K}$ 


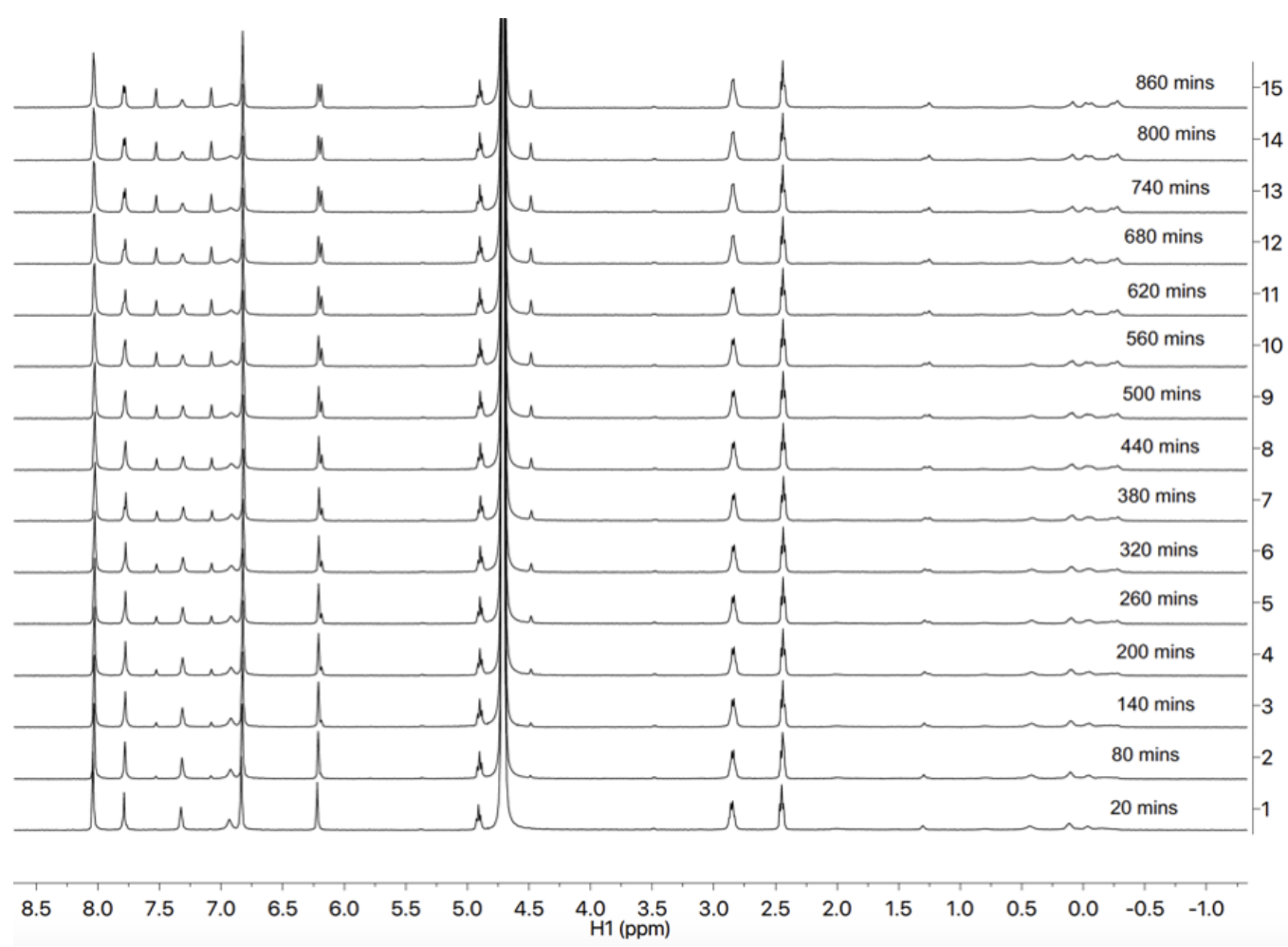

Figure S91: Stack of ${ }^{1} \mathrm{H}$ NMR spectra showing reaction of encapsulated guest $\mathbf{3}$ inside of $\mathbf{2}_{\mathbf{2}}$ as a function of time. $\left(\mathrm{D}_{2} \mathrm{O}, 328 \mathrm{~K},[\right.$ Host 2] $=1 \mathrm{mM},[$ Guest 3] $=0.5 \mathrm{mM},[\mathrm{NaOD}]=10 \mathrm{mM},[\mathrm{CsCl}]=10 \mathrm{mM})$.

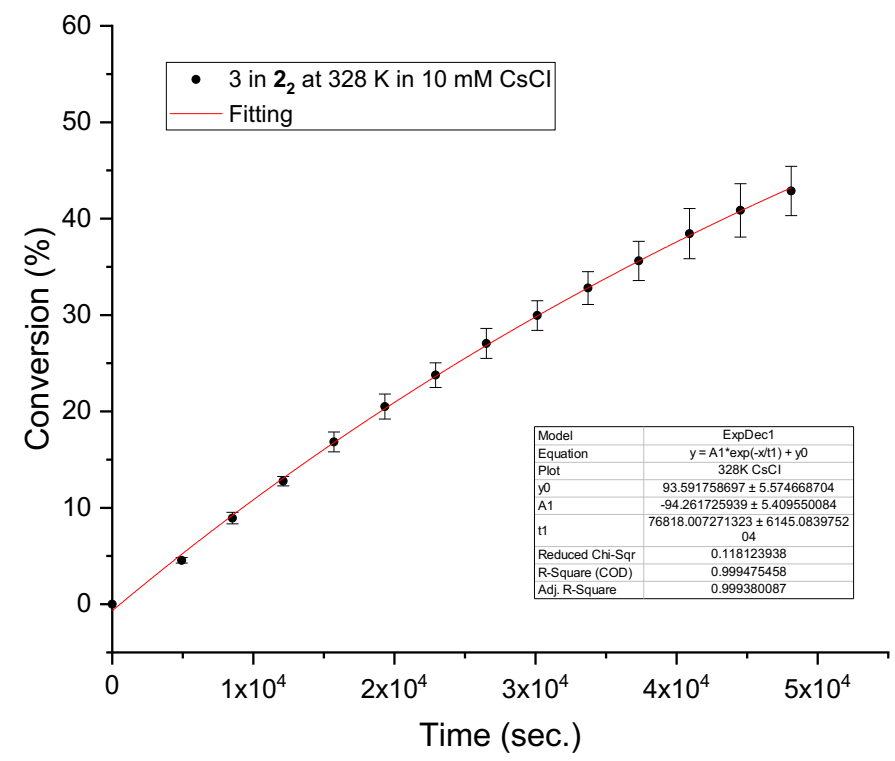

Figure S92: Reaction kinetics for guest 3 inside of host $\mathbf{2}_{\mathbf{2}}$ in presence of $10 \mathrm{mM} \mathrm{CsCl}$ at $328 \mathrm{~K}$ 


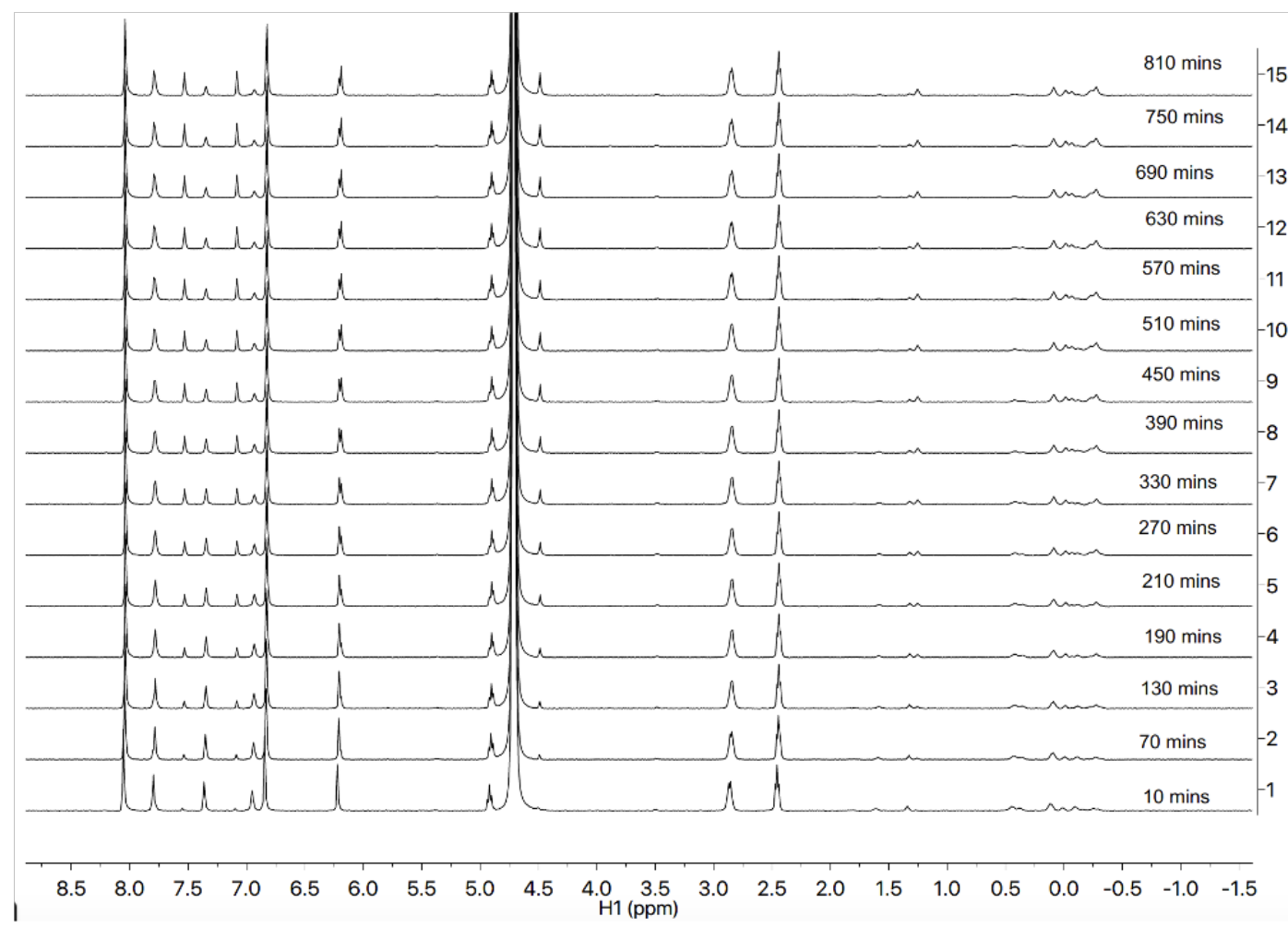

Figure S93: Stack of ${ }^{1} \mathrm{H}$ NMR spectra showing reaction of encapsulated guest $\mathbf{3}$ inside of $\mathbf{2}_{\mathbf{2}}$ as a function of time. $\left(\mathrm{D}_{2} \mathrm{O}, 332 \mathrm{~K},[\right.$ Host 2] $=1 \mathrm{mM}$, [Guest 3] $=0.5 \mathrm{mM},[\mathrm{NaOD}]=10 \mathrm{mM},[\mathrm{CsCl}]=10 \mathrm{mM})$.

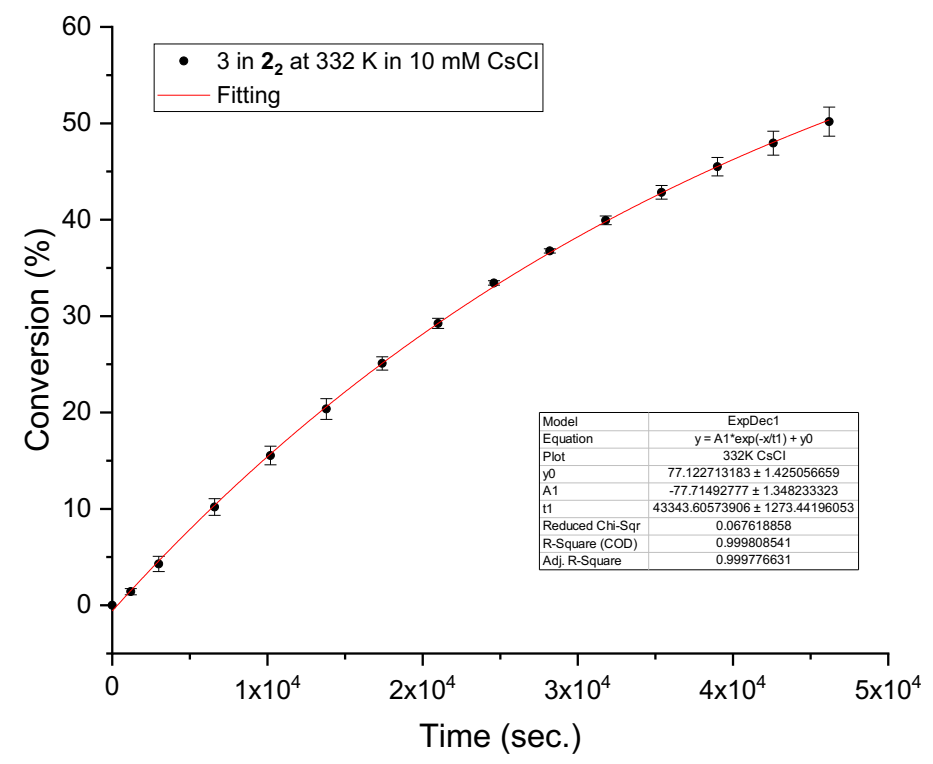

Figure S94: Reaction kinetics for guest 3 inside of host $\mathbf{2}_{2}$ in presence of $10 \mathrm{mM} \mathrm{CsCl}$ at $332 \mathrm{~K}$ 


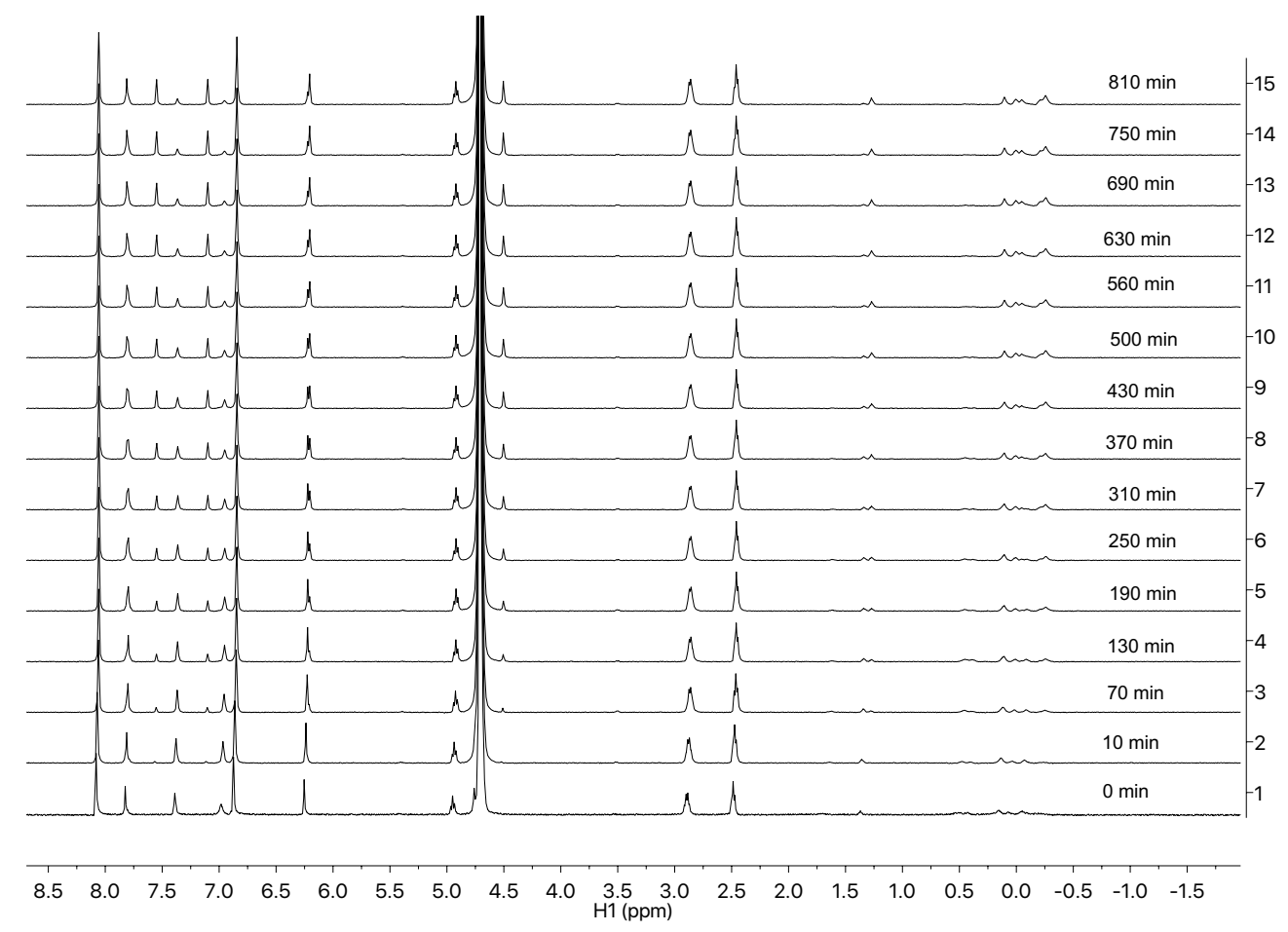

Figure S95: Stack of ${ }^{1} \mathrm{H}$ NMR spectra showing reaction of encapsulated guest $\mathbf{3}$ inside of $\mathbf{2}_{\mathbf{2}}$ as a function of time. $\left(\mathrm{D}_{2} \mathrm{O}, 334 \mathrm{~K},[\right.$ Host 2] $=1 \mathrm{mM}$, [Guest 3] $=0.5 \mathrm{mM},[\mathrm{NaOD}]=10 \mathrm{mM},[\mathrm{CsCl}]=10 \mathrm{mM})$.

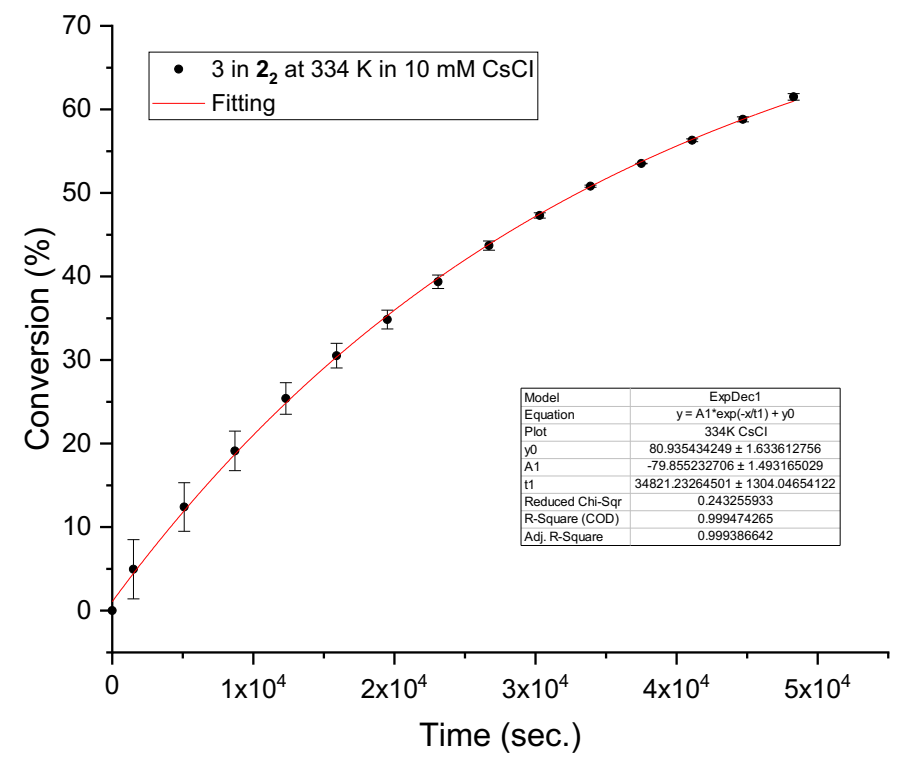

Figure S96: Reaction kinetics for guest 3 inside of host $\mathbf{2}_{2}$ in presence of $10 \mathrm{mM} \mathrm{CsCl}$ at $334 \mathrm{~K}$ 


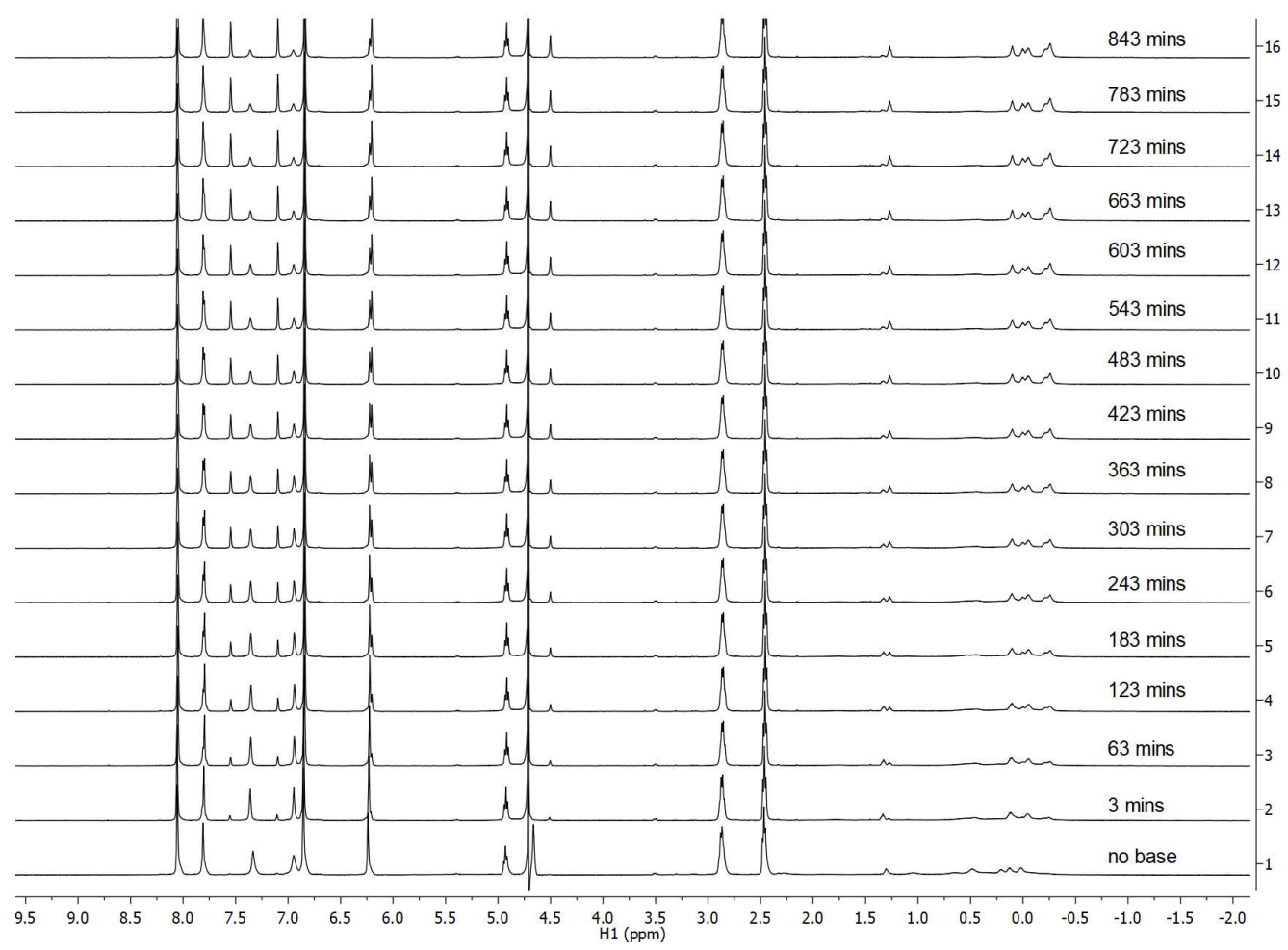

Figure S97: Stack of ${ }^{1} \mathrm{H}$ NMR spectra showing reaction of encapsulated guest 3 inside of 22 as a function of time. $\left(\mathrm{D}_{2} \mathrm{O}, 336 \mathrm{~K},[\right.$ Host 2] $=1 \mathrm{mM},[$ Guest 3$]=0.5 \mathrm{mM},[\mathrm{NaOD}]=10 \mathrm{mM},[\mathrm{CsCl}]=10 \mathrm{mM})$.

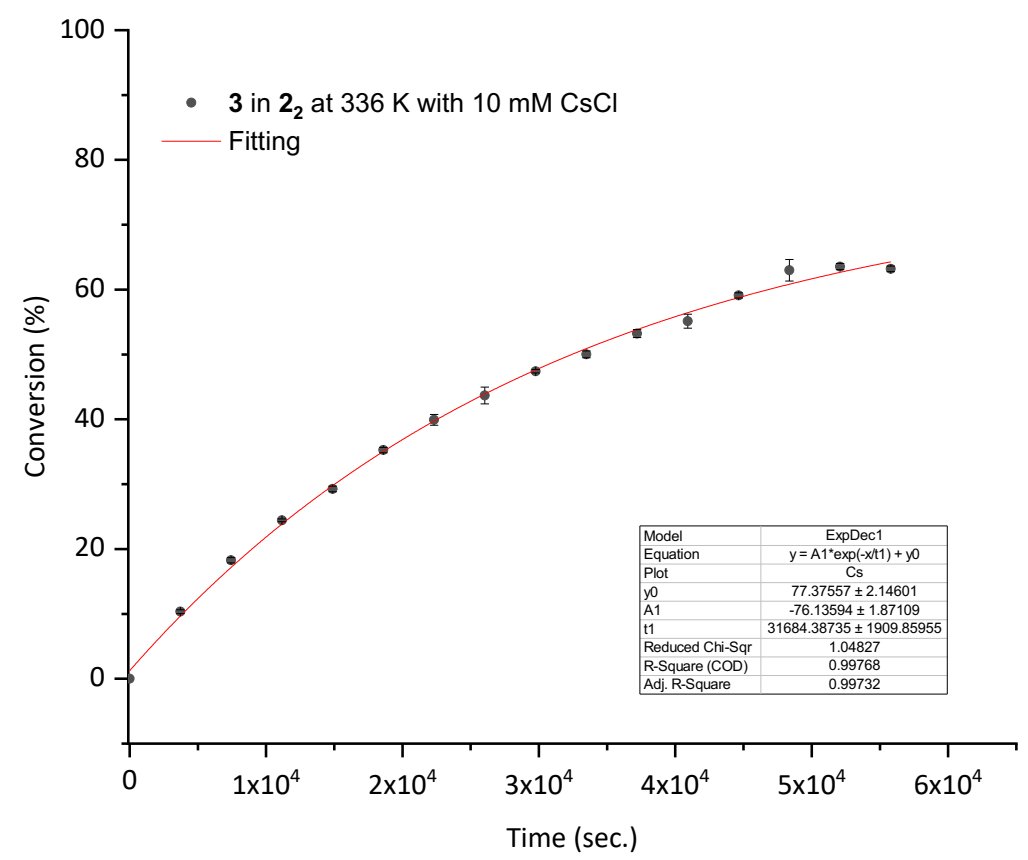

Figure S98: Reaction kinetics for guest 3 inside of host $\mathbf{2}_{\mathbf{2}}$ in presence of $10 \mathrm{mM} \mathrm{CsCl}$ at $336 \mathrm{~K}$ 


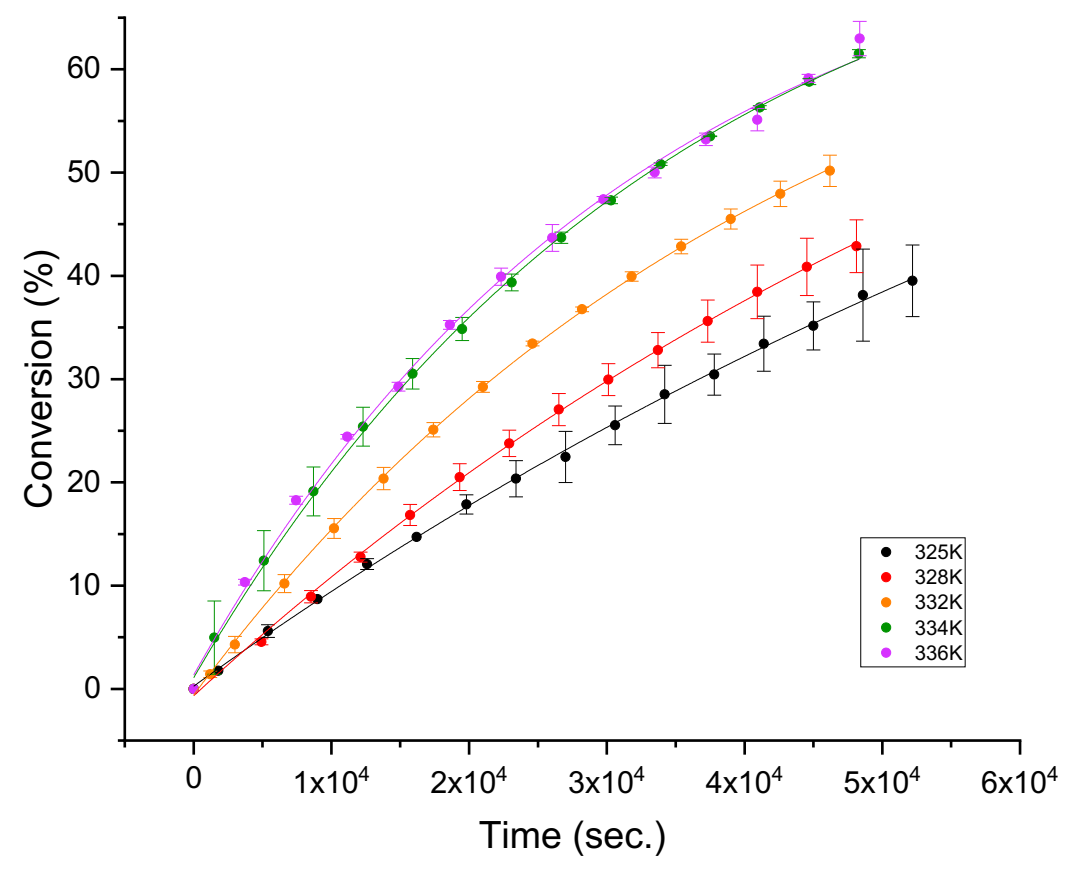

Figure S99: Fitting for the cyclization of guest 3 inside of $\mathbf{2}_{2}$ at five different temperatures with $10 \mathrm{mM} \mathrm{CsCl}$

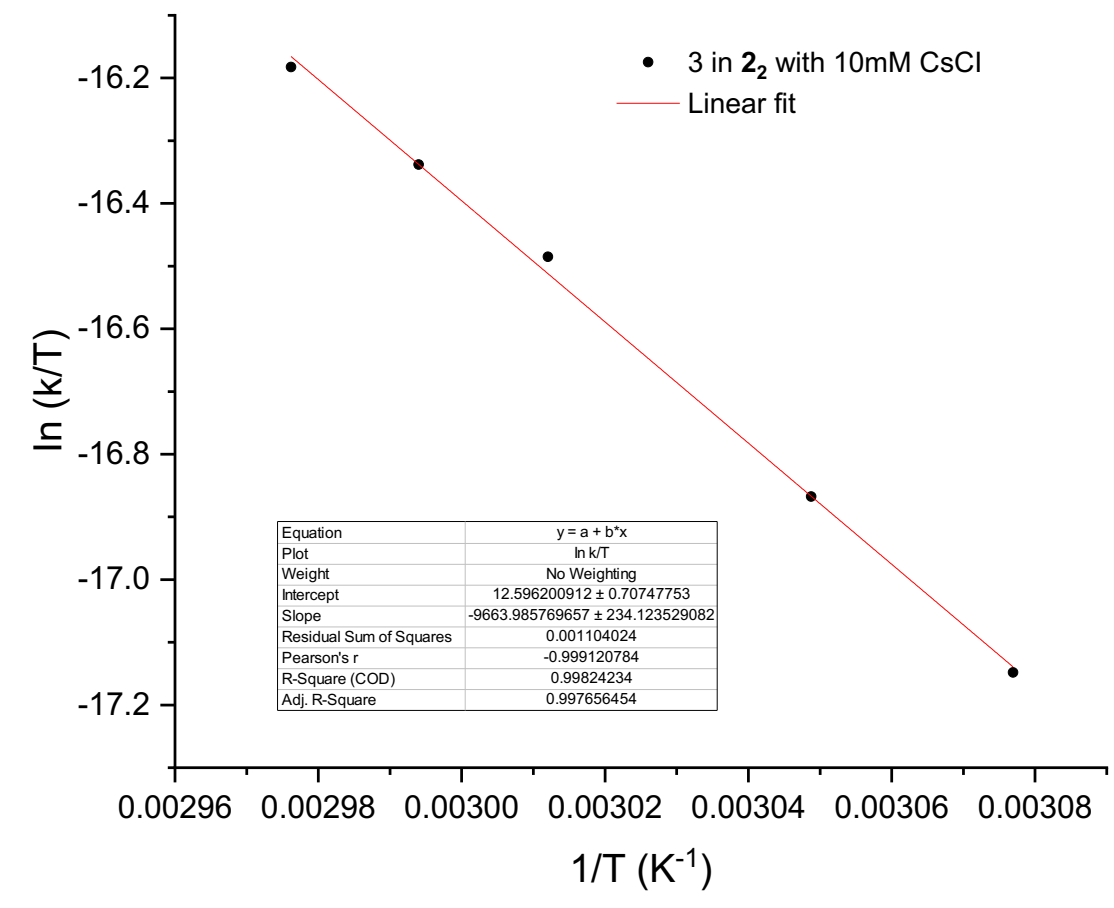

Figure S100: Eyring plot for the cyclization of guest $\mathbf{3}$ in $\mathbf{2}_{\mathbf{2}}$ in presence of $10 \mathrm{mM} \mathrm{CsCl}$ at five different temperatures. 


\section{8) References}

1. Gibb, C. L.; Gibb, B. C., Well-defined, organic nanoenvironments in water: the hydrophobic effect drives a capsular assembly. J. Am. Chem. Soc., 2004, 126 (37), 11408-9.

2. Liu, S.; Whisenhunt-loup, S. E.; Gibb, C. L.; Gibb, B. C., An improved synthesis of 'octaacid' deep-cavity cavitand. Supramol Chem 2011, 23 (6), 480-485.

3. Hillyer, M. B.; Gibb, C. L.; Sokkalingam, P.; Jordan, J. H.; loup, S. E.; Mague, J. T.; Gibb, B. C., Correction to "Synthesis of Water-Soluble Deep-Cavity Cavitands". Org Lett 2016, 18 (24), 6523.

4. Greaves, J.; Munro, K. R.; Davidson, S. C.; Riviere, M.; Wojno, J.; Smith, T. K.; Tomkinson, N. C.; Chamberlain, L. H., Molecular basis of fatty acid selectivity in the zDHHC family of Sacyltransferases revealed by click chemistry. Proc. Natl. Acad. Sci., 2017, 114 (8), E1365E1374.

5. Vigderman, L.; Manna, P.; Zubarev, E. R., Quantitative replacement of cetyl trimethylammonium bromide by cationic thiol ligands on the surface of gold nanorods and their extremely large uptake by cancer cells. Angew. Chem. Int. Ed. Engl., 2012, 51 (3), 636-41.

6. Halby, L.; Champion, C.; Senamaud-Beaufort, C.; Ajjan, S.; Drujon, T.; Rajavelu, A.; Ceccaldi, A.; Jurkowska, R.; Lequin, O.; Nelson, W. G.; Guy, A.; Jeltsch, A.; Guianvarc'h, D.; Ferroud, C.; Arimondo, P. B., Rapid synthesis of new DNMT inhibitors derivatives of procainamide. ChemBioChem 2012, 13 (1), 157-65.

7. Jordan, J. H.; Gibb, C. L. D.; Wishard, A.; Pham, T.; Gibb, B. C., Ion-Hydrocarbon and/or Ion-Ion Interactions: Direct and Reverse Hofmeister Effects in a Synthetic Host. J. Am. Chem. Soc., 2018, 140 (11), 4092-4099. 